Max-Planck-Institut für Psychiatrie

Deutsche Forschungsanstalt für Psychiatrie

\title{
Site-specific overexpression of corticotropin-releasing hormone (CRH) in the mouse brain - modelling central CRH system hyperactivity
}

\begin{abstract}
Ailing Lu
Vollständiger Abdruck der von der Fakultät Wissenschaftszentrum Weihenstephan für Ernährung, Landnutzung und Umwelt der Technischen Universität München zur Erlangung des akademischen Grades eines

Doktors der Naturwissenschaften (Dr. rer. nat.)

genehmigten Dissertation

Vorsitzender: $\quad$ Univ.-Prof. Dr. Alfons Gierl

Prüfer der Dissertation: 1. Univ.-Prof. Dr. Wolfgang Wurst

2. Univ.-Prof. Dr. Kay H. Schneitz

Die Dissertation wurde am 22.03.2005 bei der Technischen Universität München eingereicht und durch die Fakultät Wissenschaftszentrum Weihenstephan für Ernährung, Landnutzung und Umwelt am 19.06.2005 angenommen
\end{abstract}




\section{Table of contents}

Abbreviation list 6

1. Introduction 12

$\begin{array}{ll}\text { 1.1. Corticotropin-releasing hormone (CRH) } & 12\end{array}$

$\begin{array}{ll}\text { 1.2. The CRH family of neuropeptides } & 14\end{array}$

$\begin{array}{ll}\text { 1.3. CRH receptors } & 18\end{array}$

1.4. CRH-binding protein (CRH-BP) 23

1.5. Arginine vassopressin (AVP) 23

1.6. Corticosteroid receptors 24

1.7. CRH gene targeting mice 25

1.8. Conditional mutagenesis in the mouse 28

1.9. Aim of the thesis 30

2. Materials and Methods 31

2.1. Materials 31

2.1.1. Buffers and Solutions 31

2.1.1.1. Buffers for electrophoresis 31

2.1.1.1.1. Buffers for DNA agrose Gel 31

2.1.1.1.2. Buffers for RNA Gel 32

2.1.1.2. Buffers for Southern blot 32

2.1.1.3. Buffers for Mini-Southern blot in 96-Well-Tissue-

Culture-Plates 33

2.1.1.4. Buffers for preparation of genomic DNA from tissues 34

2.1.1.5. Buffers for X-Gal staining of cells and sections 34

2.1.1.6. Buffers for in situ hybridization (ISH) 35

2.1.1.7. Buffers for transfection of embryonic stem (ES) cell 36

2.1.1.8. Buffers for Radioimmunoassay (RIA) 36

2.1.2. Media 37

2.1.2.1. Media for E.coli $\quad 37$ 
2.1.2.2. Media for ES and Feeder cells

2.1.3. Kit systems 38

2.1.4. Primers for cloning and sequencing 38

2.1.5. Probes for Southern blot, Nothern blot and In situ 40

2.1.6. Cell lines 40

2.1.7. Animals 41

2.2. Methods 42

2.2.1. DNA preparation $\quad 42$

2.2.1.1. Preparation of plasmid DNA 42

2.2.1.2. Preparation of genomic DNA 42

2.2.1.2.1. Mouse genomic DNA preparation from tail 42

2.2.1.2.2. Mouse genomic DNA preparation from tissue 42

2.2.2. RNA preparation 43

2.2.3. Restrict digestion of DNA samples 43

2.2.4. DNA Gel Electrophoresis 44

2.2.5. Cloning and Transformation 44

2.2.5.1. Competent cells preparation and transformation 44

2.2.5.2. Cloning 45

2.2.6. Polymerase Chain Reaction (PCR) 45

2.2.7. Southern blot 46

2.2.7.1. Blot gel onto nylon membranes 46

2.2.7.2. Probe labeling 47

2.2.7.3. Hybridization and washing 47

2.2.8. Colony Hybridization 48

2.2.9. Northern blot 48

2.2.10. In situ hybridization $\quad 49$

2.2.10.1. Tissue preparation 49

2.2.10.2. Probe synthesis 49

2.2.10.3. In situ hybridization $\quad 50$

2.2.11. ES and Feeder cells culture $\quad 51$

2.2.11.1. Preparation of EMFI feeder cells plate 51

2.2.11.2. ES cell culture $\quad 52$

2.2.12. Electroporation 52

2.2.13. Screening for positive (homologously recombined) clones 
from Electroporated ES cells

2.2.14. Transient transfection with pCre-Pac plasmid 54

2.2.15. Generation of conditional mutants 54

2.2.16. X-Gal staining of mouse tissues $\quad 55$

2.2.16.1. Tissues preparation 55

2.2.16.2. X-Gal staining 55

2.2.17. Radioimmunoassay (RIA) 56

2.2.17.1. Extraction and Chromatographic Methods 56

2.2.17.2. Preparation of ${ }^{125} \mathrm{I}-\mathrm{CRH}$ tracer 56

2.2.17.3. RIA protocol 56

2.2.18. Endocrine analysis $\quad 57$

2.2.19. Behavioral studies 57

2.2.19.1. Acoustic startle response (ASR) 57

2.2.19.2. Fear conditioning 59

2.2.19.3. Forced swimming test (FST) 60

2.2.19.4. Tail suspension test (TST) 60

3. Results 62

3.1. Generation of mice conditionally overexpressing CRH 62

3.1.1. Generation of targeting construct 62

3.1.2. Screening of Electroporated ES cell 63

3.1.3. In vitro characterization of the overexpression strategy 63

3.1.4. Generation of conditional mutant mice 65

3.2. Analysis of the region-specific overexpression of CRH 67

3.2.1. Analysis of LacZ report gene expression by X-Gal staining 67

3.2.2. Analysis of CRH mRNA expression by in situ hybridization 69

3.2.3. Analysis of CRH protein expression by Radioimmunoassay 72

3.2.4. Analysis of Cre-recombinase mediated excision of the transcriptional terminator sequence by Southern blot 73

3.3. Altered expression of genes related to the CRH system 74

3.3.1. CRH expression in PVN and CeA $\quad 74$

3.3.2. Expression of CRH-R1 75

$\begin{array}{lll}\text { 3.3.3. } & \text { Expression of CRH-R2 } & 77\end{array}$ 
3.3.4. Expression of AVP $\quad 79$

3.3.5. Expression of GR $\quad 80$

3.4. Hypothalamic-Pituitary-Adrenal axis activity 82

3.5. Body weight 82

3.6. Acoustic startle response (ASR) 83

3.6.1. Startle reactivity 83

3.6.2. Habituation 84

3.6.3 The CRH-R1 antagonist (NBI-30775) reversed CRH-induced startle response in COR-Nes but not in COR-Cam mice 84

3.6.4. Reduced prepulse inhibition (PPI) in COR-Nes but not in COR-Cam mice $\quad 86$

3.6.5. CRH-R1 antagonist increased PPI in COR-Nes mice, but not in COR-Cam mice $\quad 88$

3.7. Assessment of conditioned fear in COR-Nes mice 89

3.8. Forced swimming test (FST) in COR-Nes mice 90

3.9. Tail suspension test (TST) in COR-Nes mice 91

4. Discussion 92

4.1. Generation of site-specific CRH overexpressing mice 92

4.2. Alterations in expression of $\mathrm{CRH}$ and $\mathrm{CRH}$ related genes 93

4.2.1. CRH mRNA and protein expression 93

4.2.2. Expression of CRH-R1 and CRH-R2 mRNA 96

4.2.3. Expression of AVP mRNA 100

$\begin{array}{ll}\text { 4.2.4. Expression of GR mRNA } & 100\end{array}$

4. 3. Hyperactivity of HPA axis in CRH overexpressing mice 101

4.4. CRH overexpression decreased body weigh 103

$\begin{array}{lll}\text { 4.5. Acoustic startle response } & 104\end{array}$

4.5.1. Increased startle magnitude in COR mice was dose-dependent 105

4.5.2. The CRH-R1 antagonist (NBI-30775) reversed CRH-induced startle response in COR-Nes but not in COR-Cam mice 107

4.5.3. Impaired prepulse inhibition (PPI) in COR-Nes, but not in COR-Cam mice 108

4.6. Less freezing exhibited by COR-Nes mice in the fear conditioning test 110 
4.7. More activity exhibited by COR-Nes mice in forced swimming test (FST) 112

4.8. Less immobility exhibited by COR-Nes mice in tail suspension test (TST) 113

5. Summary

6. References 


\section{Abbreviation list}

$\mathbf{A}$

A

$\mathrm{ACTH}$

AMY

AP

ARH

AVP

Ambiguus nucleus

Adrenocorticotropic hormone

Amygdala

Anterior pituitary

Arcuate nuclei of the hypothalamus

Arginine vasopressin

\section{B}

BLA Basolateral nucleus of amgdala

BNST

Bed nucleus of the stria terminalis

BSA

Bovine serum albumin

C

$\mathrm{Cb}$

Cerebellum

$\mathrm{CeA}$

Central nucleus of the amygdala

CNS

Central nervous system

CIP

Calf Intestinal Phosphatase

Con

Control

COR

COR-Cam

$\underline{\mathrm{CRH}}$ overexpression from the $\underline{\mathrm{ROSA}} 26$ locus

COR-Nes

COR-CamKII $\alpha$

$\mathrm{CP}$

COR-Nestin

Choroid plexus

$\mathrm{CRH}$

Corticotropin-releasing hormone

CRH-BP

$\mathrm{CRH}$ binding protein

CRH-R1

CRH type I receptor

CRH-R2

CRH type II receptor

CRH-Tg

$\mathrm{CRH}$ transgenic

CS

Conditioned stimulus

Ctx

Cortex 
D

DEPC- $\mathrm{H}_{2} \mathrm{O}$ Diethyl pyrocarbonate-treated $\mathrm{H}_{2} \mathrm{O}$

del Deletion band

DG Dentate gyrus

DMEM Dulbecco's modified eagle medium

DMF Dimethylformamide

DMSO Dimethylsulfoxide

DNA Deoxyribonucleic acid

dNTP Deoxynucleotidetriphosphate

DT Diphteria toxin

DTT Dithiothreitol

DVC Dorsal vestibular column

$\mathbf{E}$

E Epinephrine

E.coli Escherichia coli

EDTA Ethylendiamintetra acetate

EGTA Ethylenglycoltetraacetate

EMFI Embryonic mouse fibroblasts

ES cell Embryonic stem cell

$\mathrm{EtBr} \quad$ Ethidium bromide

$\mathbf{F}$

FCS Fetal calf serum

FST Forced swimming test

G

GI Gastrointestinal

GR Glucocorticoid receptor

H

h Hour

HC Hippocampus

Het Heterozygote 


\begin{tabular}{|c|c|}
\hline Hom & Homozygote \\
\hline HPA axis & Hypothalamic-Pituitary-Adrenal axis \\
\hline \multicolumn{2}{|l|}{$\mathbf{I}$} \\
\hline icv & Intracerebroventricular \\
\hline ISH & In situ hybridization \\
\hline ISI & Inter-stimulus intervals \\
\hline \multicolumn{2}{|l|}{$\mathbf{K}$} \\
\hline $\mathrm{kDa}$ & Kilodalton \\
\hline $\mathrm{Ki}$ & knock in \\
\hline $\mathrm{KO}$ & knock out \\
\hline \multicolumn{2}{|l|}{$\mathbf{L}$} \\
\hline $\mathrm{LC}$ & Locus coeruleus \\
\hline LD & Lateraldorsal nucleus of thalamus \\
\hline LDT & Lateral dorsal tegmentum \\
\hline LHA & Lateral hypothalamus area \\
\hline LIF & Leukemia inhibitory factor \\
\hline LP & Lateral posterior nucleus thalamus \\
\hline LS & Lateral septum \\
\hline LSi & Intermediate lateral septal nucleus \\
\hline LSv & Ventral lateral septal nucleus \\
\hline LV & Lateral ventral nucleus of thalamus \\
\hline \multicolumn{2}{|l|}{$\mathbf{M}$} \\
\hline M & $\mathrm{mol} / 1$ \\
\hline $\mathrm{MeA}$ & Medial amygdaloid nucleus \\
\hline MeAp & Medial nucleus of amygdala posterior part \\
\hline $\min$ & Minute \\
\hline MMC & Mytomycin C \\
\hline MR & Mineralocorticoid receptor \\
\hline MS & Medial septal nucleus \\
\hline $\mathrm{mt}$ & Mutant \\
\hline
\end{tabular}


$\mathbf{N}$

$\mathrm{NaAc}$

Sodium acetate

NE

Norepinephrine

NP40

Nonidet P-40

O

OB

Olfactory bulb

OD

Optical density

OE

Overexpression

$\mathbf{P}$

$\mathrm{pA}$

polyadenylation sequence

PAG

Periaqueductal gray

PBN

Parabranchial nucleus

PCR

Polymerase chain reaction

PFA

Paraformaldehyde

PG

Pontine gray

Pir

Piriform

POMC

Proopiomelanocortin

PPI

Prepulse inhibition

PVN

Paraventricular nucleus

PVT

Paraventricular nucleus thalamus

$\mathbf{R}$

R26

ROSA26

RIA

Radioimmunoassay

$\mathrm{RN}$

Retical nucleus

RT

Reticular nucleus

RNA

Ribonucleic acid

rpm

Rounds per minute 
$\mathbf{S}$

$\mathrm{S}$

Second

SCP

Stresscopin

SDS

Sodium dodecyl sulfate

SON

Supraoptic nucleus

SRP

Stresscopin-related peptide

$\mathrm{Sp}$

Spinal cord

SW

Slow wave

SVG

Sauvagine

T

TAE

Tris-acetate-EDTA

TBE

Tris-borate-EDTA

TE

Tris-EDTA

TEA

Triethanolamine

Thala

Thalamus

tRNA

Transfer RNA

Tris

Tris-(Hydroxylmethyl-) aminomethan

TST

Tail suspension test

$\mathbf{U}$

$\mathrm{u}$

Unit

UCN

Urocortin

UCN2

Urocortin 2

UCN3

Urocortin 3

URO

Urotensin I

US

Unconditioned stimulus

V

V

Voltage

$\mathrm{v} / \mathrm{v}$

Volume per volume

VL

Ventral lateral nucleus of thalamus

$\mathrm{VMH}$

Ventromedial nucleus hypothalamus 
W

WT

Wild type

wt

wild type band

$\mathbf{X}$

X-Gal

5-bromo-4-chloro-3-indolyl- $\beta$-D-galactoside 


\section{Introduction}

\subsection{Corticotropin-releasing hormone (CRH)}

During recent years, a large body of evidence has emerged linking stressful life events with an increased vulnerability for affective and anxiety disorders. Stressful events often precede the onset of depression and stress has also been associated with the severity of the illness (Dunner et al., 1979) (Brown et al., 1987) (Hammen et al., 1992). Stress is a protective mechanism that allows the organism to react to threatening situations. Acute responses to stress are necessary in order to maintain homeostasis in the organism. However, chronic stress or dysregulation of this system can lead to mood and affective disorders, and other diseases. CRH has also been implicated in allostasis, the ability of an organism to maintain stability through change, as a critical component by which organisms actively deal with stress in their environment.

Results from experimental modulation of components of the hypothalamicpituitary-adrenal (HPA) axis have helped to decipher specific roles for each of the receptors and ligands. Stress probably represents one of the main factors that lead to sustained hyperactivity of the HPA system and has been closely related to the etiology of depression. Stressful stimuli activate the HPA axis, which, together with other physiological responses, coordinate the behavioral response of the organism (Herman and Cullinan, 1997). Chronic stress or a chronic change in HPA axis activity can result in pathological consequences, such as psychiatric disorders. Depression and anxiety-related disorders are associated with chronic HPA axis deregulation (Holsboer and Barden, 1996). Treatment of depressed patients with anti-depressants restores HPA axis homeostasis, and this restoration is an important predictor for clinical improvement (Holsboer, 2000) (Holsboer and Barden, 1996).

$\mathrm{CRH}$ plays a pivotal role in the response of an organism to various stressors, coordinating neuroendocrine, autonomic, behavioral, and immunologic responses to stress (Dunn and Berridge, 1990b) (Holsboer, 1999) (Koob and Heinrichs, 1999) (Owens and Nemeroff, 1991) (Koob et al., 1993) (Pich et al., 1993). Rapid activation of CRH and its stimulation of the HPA axis constitute a primary system that promotes adaptive responses. Enhanced $\mathrm{CRH}$ signaling at various sites within the central nervous system (CNS) and activation of the HPA axis lead to enhanced attentive behaviors, suppressed reproductive and feeding behavior as well as physiological 
changes that are aimed at mobilizing energy stores and redirecting oxygen and nutrients to sites of increased demand. Moreover, neuroendocrine studies strongly suggest that hyperactivity of central $\mathrm{CRH}$ circuits, resulting in a characteristic dysregulation of the HPA system, plays a causal role in the development and course of affective and anxiety disorders. The behavioral effects of centrally administered $\mathrm{CRH}$ can be reversed by $\mathrm{CRH}$ receptor antagonists and are independent of activation of the HPA axis. Furthermore, CRH receptor antagonists alone attenuate many of the behavioral consequences of stress, underscoring the role of endogenous $\mathrm{CRH}$ in mediating many stress-induced behaviors (Heinrichs et al., 1995).

For both experimental animals and humans, survival during chronic stress requires not only that increased secretion of corticosteroid hormones has to be maintained in the face of negative feedback control, but also that an additional corticosteroid response can be mounted to an incoming stressor when required. Such requirements dictate adaptive responses at all levels of the HPA axis (Checkley, 1996). However, continued and prolonged stress may disturb the HPA axis to such an extent that the negative feedback mechanisms are disrupted; and the adaptive responses of the HPA axis may then become maladaptive. For experimental animals, the pattern of HPA maladaptation depends both upon the nature of the chronic stressor, and upon the period and mode of stress application. Repeated homotypic stressors such as restraint, foot shock and intraperitoneal injections of hypertonic saline, are associated with consistent elevations of arginine vasopressin (AVP) mRNA expression in the parvocellular paraventricular nucleus (PVN) of the hypothalamus. CRH mRNA expression appears to be elevated only in those stress paradigms that are associated with conserved HPA responses to repeated activation, such as osmotic loading /dehydration or hypertonic saline injection (Aguilera et al., 2001). Some stress paradigms (e.g. adjuvant-induced arthritis) that continuously activate the HPA axis are actually associated with reductions in central $\mathrm{CRH}$ drive, but concomitant increases in AVP drive on the pituitary (Harbuz et al., 1997) (Shanks et al., 1998). The pattern of adrenocorticotrophic hormone (ACTH) release in chronic stress also depends upon the stressor, such that ACTH secretion may be maintained or reduced (Aguilera et al., 2001). 


\subsection{The CRH family of neuropeptides}

$\mathrm{CRH}$ is a 41-amino acid polypeptide derived from a 196-amino acid protein precursor (Vale et al., 1981). The human CRH gene contains two exons separated by one intron in its 5' untranslated region (Shibahara et al., 1983). The rat, ovine and mouse CRH gene have the same organization (Roche et al., 1988), the coding region of the $\mathrm{CRH}$ precursor is in exon 2 , the 24 amino acids in the $\mathrm{N}$-terminal contain a typical signal peptide sequences which is commonly associated with neuropeptides that undergo secretion (Thompson et al., 1987).

$\mathrm{CRH}$ is widely recognized as the major hypophysiotropic hormone in the mammalian stress response. In response to stress, neural input to the hypothalamus signals for increased synthesis of CRH in the PVN of the hypothalamus, which is then transported axonally to the median eminence and released into the portal circulation. $\mathrm{CRH}$ acts on pituitary corticotropes to stimulate proopiomelanocortin (POMC) synthesis and $\mathrm{ACTH}$ release. ACTH then induces the adrenal cortex to secrete glucocorticoids. Glucocorticoids mediate a variety of physiological and metabolic responses that are important for the survival of the organism, including negative feedback at multiple levels of the HPA axis to return the system to homeostasis (Arborelius et al., 1999) (Figure 1).

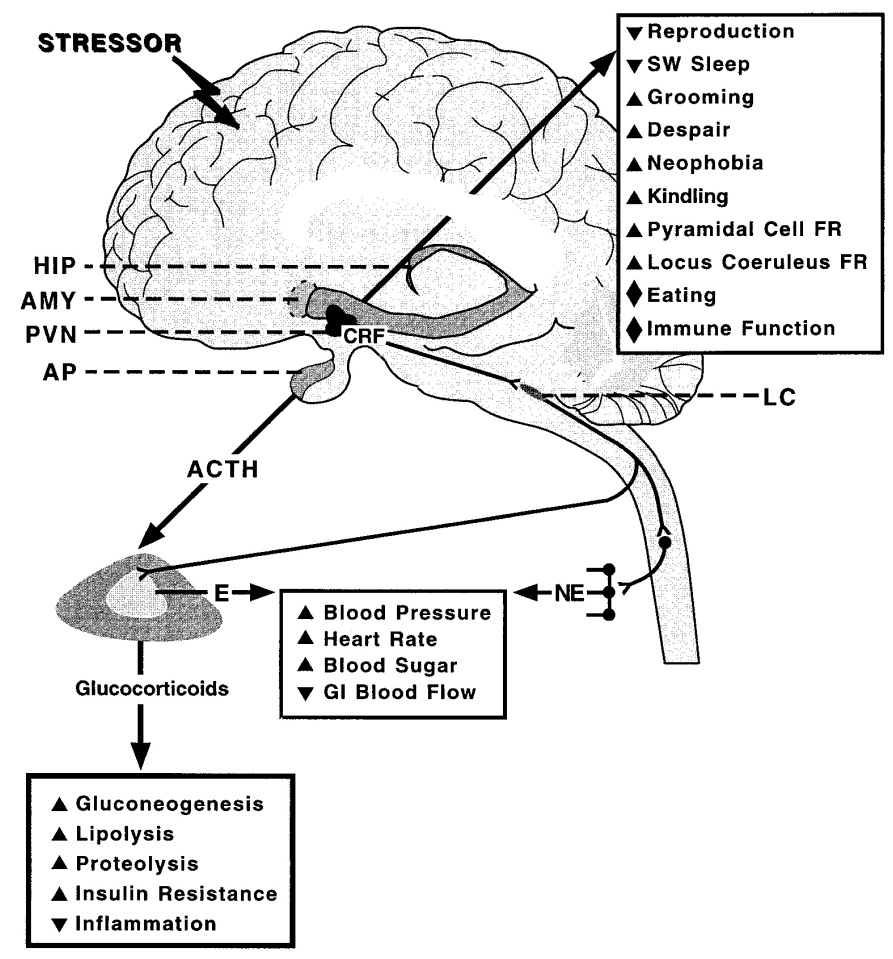

Figure 1. Schematic representation of the endocrine, behavioral, autonomic, and immunologic responses to stress mediated by central CRH neurons. $\boldsymbol{\Delta}$, increase; $\boldsymbol{\nabla}$, decrease; \, both increase and decrease. Abbreviations: AMY, amygdala; $\mathrm{AP}$, anterior pituitary; E, epinephrine; HIP, hippocampus; LC, locus coeruleus; NE, norepinephrine; PVN, paraventricular nucleus; GI, gastrointestinal; FR, firing rate; $\mathrm{SW}$, slow wave (picture adapted from (Arborelius et al., 1999)). 
Histochemical studies indicate that $\mathrm{CRH}$ is distributed heterogeneously throughout the CNS and in peripheral tissues (Cummings et al., 1983) (Imaki et al., 1991) (Mezey and Palkovits, 1991) (Vamvakopoulos et al., 1990) (Figure 2). CRH has been found in the amygdala, bed nucleus of the stria terminalis (BNST), septum, Barrington's nucleus in the pons, cerebellum, cerebral cortex, and spinal cord in the brain. At these sites, $\mathrm{CRH}$ is thought to act as a neurotransmitter or neuromodulator, mediating a wide variety of responses including increased anxiety-like behavior, decreased food intake, enhanced learning, increased arousal, altered blood pressure, diminished sexual behavior and altered locomotor activity (Dunn and Berridge, 1990a) (Owens and Nemeroff, 1991). CRH was also found to express strongly in PVN of the hypothalamus in the brain. The hypothalamic $\mathrm{CRH}$ system is important for modulating endocrine and metabolic responses to stress while the amygdala, in concert with other extra-hypothalamic limbic regions has been important in manifesting the behavioral responses to stress (Davis et al., 1997b). In peripheral tissues, CRH is produced in the adrenal medulla, ovary, testis, heart, lung, liver, stomach, duodenum, pancreas, T-lymphocytes and placenta (Muglia et al., 1994) (Suda et al., 1984) (Herman et al., 1996).

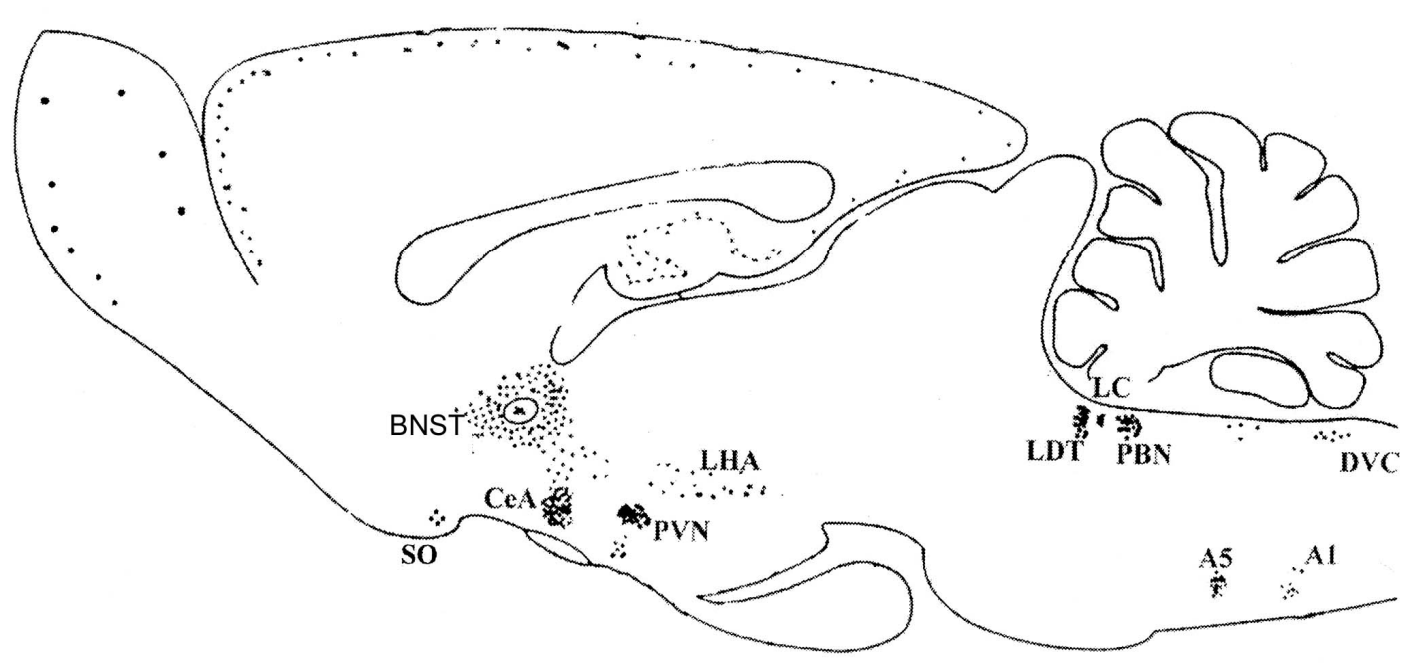

Figure 2. The distribution of CRH-immunoreactive cells in the rodent brain (picture adapted from (Smagin et al., 2001), data from (Behan et al., 1996) (Kozicz et al., 1998) (Yamamoto et al., 1998)). Abbreviations: A, nucleus ambiguus; BNST, bed nucleus of the stria terminalis; CeA, central nucleus of amygdala; DVC, dorsal vestibular column; LC, locus coerulus; LDT, lateral dorsal tegmental; LHA, lateral hypothalamus area; PBN, parabranchial nucleus; PVN, paraventricular nucleus; SO, supraoptic nucleus. 
Taken together, these results suggest that CRH not only controls the endocrine stress response, but also integrates the autonomic, behavioral, and immunologic responses to stress. Moreover, aberrant regulation of $\mathrm{CRH}$ expression and activity contributes to a number of psychiatric disorders including depression, anxiety disorders, and anorexia. Investigation on the expression and regulation of CRH activity is critical to our understanding of the pathophysiology of these clinical disorders (Salas et al., 1997).

CRH was first isolated and characterized from ovine hypothalamus in 1981 by Vale and colleagues (Vale et al., 1981). There is a high degree of homology between rat, mouse and human CRH genes (Herman et al., 1992) (Seasholtz et al., 1988) (Vamvakopoulos et al., 1990). Other CRH-like peptides were soon discovered in the urophyses of teleost fish (Catostomus commersoni) (Lederis et al., 1982) (Ichikawa et al., 1982) and skin of the tree frog (Phyllomedusa sauvegei) (Montecucchi and Henschen, 1981) (Broccardo et al., 1981). These peptides are known as urotensin I and sauvagine respectively, and exhibit ACTH releasing activity from pituitary with equal efficacy to human or rat CRH. However, it was until 1995 that a new CRH-like peptide was isolated and characterized in mammals by Vaughan and colleagues (Vaughan et al., 1995). This 40 amino acid amidated peptide, known as urocortin (UCN), shows $45 \%$ amino acid identity to human CRH (Vaughan et al., 1995) and is a potent agonist for both receptors. In situ hybridization (ISH) and immunocytochemistry studies demonstrate a limited expression profile for UCN in the brain (i.e. Edinger Westphal, lateral septum, lateral superior olive, supraoptic nucleus of the hypothalamus, brainstem motor nuclei), with numerous sites of peripheral expression (Bittencourt et al., 1999) (Vaughan et al., 1995). In contrast to CRH, levels of UCNimmunoactivity are not high in the median eminence, suggesting that UCN is not an important endocrine factor in the regulation of ACTH or beta-endorphin release (Turnbull and Rivier, 1996). While intracerebroventricular (icv) administration of UCN has been shown to decrease food and water intake (Jones et al., 1998) (Spina et al., 1996), increase anxiogenic behavior (Jones et al., 1998) (Moreau et al., 1997), stimulate ACTH release (Vaughan et al., 1995), decrease mean arterial blood pressure (Vaughan et al., 1995), and inhibit injury-induced edema (Turnbull et al., 1996). The nucleotide sequence of the $\mathrm{CRH}$ gene is highly conserved throughout all vertebrates, including teleost fish, toad, chicken, golden hamster, rat, mouse, cow, sheep, pig, dog and humans. Recently, two new members of the CRH neuropeptide family have been 
cloned: stresscopin-related peptide (SRP)/urocortin II (UCN2) and stresscopin (SCP)/ urocortin III (UCN3) (Hsu and Hsueh, 2001) (Lewis et al., 2001) (Reyes et al., 2001). SRP/UCN2 shows moderate to low similarity with human/rat CRH (34\%), human urocortin (43\%), SCP/UCN3 (37-40\%), urotensin I (34\%), and sauvagine $(<25 \%)$. However, SCP/UCN3 is more distant from other members of the CRH family (18-32 $\%$ identity) (Figure 3). SRP/UCN2 mRNA is highly expressed in the paraventricular, supraoptic and arcuate nuclei of the hypothalamus (ARH), the locus coeruleus, and motor nuclei of the brain stem and spinal cord. In the periphery, SRP/UCN2 mRNA is detected in the heart, adrenal gland and peripheral blood cells (Reyes et al., 2001) (Hsu and Hsueh, 2001). The posterior part of the BNST, the lateral septum (LS) and the medial amygdaloid nucleus (MeA) are important brain sites that express $\mathrm{SCP} / \mathrm{UCN} 3 \mathrm{mRNA}$; high levels of SCP/UCN3 mRNA expression have been detected in the gastrointestinal tract, muscle, adrenal gland and skin. Their terminal fields innervate hypothalamic and brain stem areas matching CRH type 2 receptor (CRH-R2) distribution (Li et al., 2002). Because of their selectivity for the CRH-R2, UCN2 and UCN3 have been described as 'stress-coping' peptides (Hsu and Hsueh, 2001). Both peptides are capable of reducing anxiety, blood pressure and arousal. The ability of UCN2 to increase exploration on the elevated plus maze (Valdez et al., 2002) strongly suggests a role for the CRH-R2 in mediating anxiolytic effects, which suggest that $\mathrm{CRH}$ and UCN are two anti-parallel stress systems that function as organizers of the sympathetic and parasympathetic response respectively.

\begin{tabular}{lccc} 
Peptide & \multicolumn{1}{c}{ Sequence } & $\begin{array}{c}\text { Length } \\
\text { Identity } \\
(\%)\end{array}$ \\
hCRF & SEEPPISLDLTFHLLREVLEMARAEQLAQQAHSNRKLMEII & 41 & 100 \\
OCRF & SQEPPISLDLTFHLLREVLEMTKADQLABQAHSNRKLLDIA & 41 & 83 \\
URO & NDDPPISIDLTFHLLRNMIEMARIENEREQAGLNRKYLDEV & 41 & 54 \\
hUCN & DNPSLSIDLTFHLLRTLLELARTQSQRERAEQNRIIFDSV & 40 & 43 \\
SVG & ZGPPISIDLSLELLRKMIEIEKQEKEKQQAANNRLLLDTI & 40 & 48 \\
hSRP & IVLSLDVPIGLLQILLEQARARAAREQATTNARILARV & 38 & 34 \\
mUCNII & VILSLDVPIGLLRILLEQARYKAARNQAANAQILAHV & 38 & 34 \\
hSCP & FTLSLDVPTNIMNLLFNIAKAKNLRAQAAANAHLMAQI & 38 & 32 \\
mUCNIII & FTLSLDVPTNIMNILFNIDKAKNLRAKAAANAQLMAQI & 38 & 26 \\
\cline { 2 - 2 } & & \multicolumn{3}{c}{ TRENDSin Pharmacological Sciences }
\end{tabular}

Figure 3. Alignment of members of the CRH family of neuropeptides. The amino acids that are homologous between the CRH peptides were boxed. Abbreviations: h, human; m, mouse; o, ovine; SVG, sauvagine; URO, urotensin I (picture adapted from (Dautzenberg and Hauger, 2002)). 


\subsection{CRH receptors}

Since CRH was first characterized, a growing family of ligands and receptors have been indentified. The mammalian family members include CRH, UCN, UCN2, and UCN3, along with two receptors - the CRH type 1 receptor (CRH-R1) and the CRH type 2 receptor (CRH-R2), and a CRH binding protein (CRH-BP). In addition to HPA axis, CRH acting upon receptors at hypothalamic and extra-hypothalamic sites mediates behavioral and autonomic responses to stress (Holmes et al., 1987) (Vale et al., 1983a). Excessive or deficient production of CRH can result in psychiatric disorders, alterations of growth, reproductive and immune systems. It is hypothesized that $\mathrm{CRH}$ exerts its pathophysiological effects by acting upon receptors in the limbic system and autonomic areas of the brain, and also by causing inappropriate control of glucocorticoid secretion.

The two classes of CRH receptors were identified in 1993 (Chen et al., 1993) (Perrin et al., 1993) (Perrin et al., 1995) (Kishimoto et al., 1995) (Lovenberg et al., 1995) (Stenzel et al., 1995). They are the products of distinct genes which all contain seven trans-membrane helical domains and they show $70 \%$ amino acid identity, but differ considerably in their pharmacology and tissue distribution. Several CRH-R1 and CRH-R2 splice variants have been described. The CRH-R1 gene expresses multiple subtypes (Ross et al., 1994) (Grammatopoulos et al., 1999) (Pisarchik and Slominski, 2001), which are produced by differential exon splicing. Similar exon rearrangements have been described for the calcitonin and parathyroid hormone/parathyroid hormone-related peptide receptors. Each CRH-R1 variant has a defect in its expression, binding or signalling characteristics. The CRH-R1 $\alpha$ is a 415 amino acid protein, containing seven hydrophobic $\alpha$-helices that are predicted to span the plasma membrane. CRH-R1 $\alpha$ is widespread both within the CNS and periphery (Chen et al., 1993). The human CRH-R1 $\beta$ (hCRH-R1 $\beta$ ) carries a 29 amino acid insertion in its first intracellular loop (Chang et al., 1993) and only weakly couples to the stimulatory $\mathrm{G}$ protein (Xiong et al., 1995). The hCRH-R1 $\gamma$, in which exon 3 of the hCRH-R1 gene (Xiong et al., 1995) has been deleted by exon-skipping, is lacking 40 amino acids in its first intracellular loop domain (Ross et al., 1994). This variant is a low-affinity receptor. The hCRH-R $1 \delta$ is lacking 14 amino acids in the C-terminal part of the seventh trans-membrane helices due to the deletion of exon 13 (Grammatopoulos et al., 1999). In addition, a CRH-R1 variant from sheep (oCRH- 
R1var) has been described (Myers et al., 1998). This receptor differs from the normal oCRH-R1 in the C-terminal part of the seventh trans-membrane helices and the fourth intracellular loop. Both hCRH-R1 $\delta$ and oCRH-R1var bind CRH with high affinity but are unable to stimulate the accumulation of intracellular cyclic AMP. Finally, a CRHR1 mutant was cloned from the rat (Chen et al., 1993), the receptor is a truncated 224 amino acid receptor protein lacking all sequences $\mathrm{C}$-terminal to the third transmembrane helices. No data on the pharmacology of this receptor is available yet. The CRH-R1 splice variants seem to be expressed at low levels and may not be of physiological relevance. While CRH-R2 gene expresses three known subtypes $2 \alpha, 2 \beta$ and $2 \gamma$ and one truncation mutant (Liaw et al., 1996) (Valdenaire et al., 1997) (Kostich et al., 1998) that differ in their N-termini due to alternative splicing. The splice variants have a common 377 amino acid C-terminal part, whereas the extreme N-termini, which are encoded by one or two exons (Dautzenberg and Hauger, 2002), differ substantially from one another. The CRH $2 \alpha$ receptor, a 411-413 amino acid protein, has been isolated from mammalian and amphibian species (Dautzenberg et al., 1997) (Liaw et al., 1996) (Liaw et al., 1996) (Palchaudhuri et al., 1999). In contrast, CRH $2 \beta$ receptors, which are 430-438 amino acids in size, have only been reported in mammals (Kishimoto et al., 1995) (Lovenberg et al., 1995) (Palchaudhuri et al., 1999) (Valdenaire et al., 1997). Finally, the 397 amino acid CRH $2 \gamma$ receptor is exclusively found in humans (Kostich et al., 1998) (Palchaudhuri et al., 1999). In addition to the functional splice variants, a truncated $\mathrm{CRH} 2 \alpha$ mutant (CRH 2avar) has been identified in the rat (Miyata et al., 1999). This receptor is lacking all sequences Cterminal to the third transmembrane helices. CRH 2avar binds CRH but not sauvagine or urocortin, and is unable to stimulate cAMP production. The physiological role of this receptor variant needs to be determined. Because of its existence in mammalian and amphibian species and its higher degree of sequence conservation between the species (Palchaudhuri et al., 1999), it is suggestive that the CRH $2 \alpha$ receptor arose very early during evolution. The $\mathrm{CRH} 2 \beta$ receptor, which is conserved to a lower extent, has developed in mammalian species only and thus probably arose later in evolution than the $\mathrm{CRH} 2 \alpha$ receptor. Finally, the $\mathrm{CRH} 2 \gamma$ receptor because of its restriction to humans has probably occurred very late during evolution.

The CRH-R1 is expressed in anterior pituitary corticotropes and the intermediate lobe of the pituitary, and is thus thought to be the primary mediator of $\mathrm{CRH}$-induced 
ACTH release. The many CNS sites of CRH-R1 expression include the neocortex, olfactory and hippocampal cortices, cerebellum, septum, amygdala, and brainstem sensory relay structures (Potter et al., 1994). The CRH-R2, exhibits an mRNA expression profile which is distinct from CRH-R1. CRH-R $2 \beta$ in rodents is found largely in the periphery (i.e. heart skeletal muscle, intestine, lung, kidney, and epididymis, but also choroid plexus (CP) and cerebral arterioles). In the rat, CRH-R $2 \alpha$ is expressed primarily in the CNS, including olfactory bulb, lateral septum, medial amygdala, dorsal and median raphe, and ventromedial and medial preoptic nuclei of the hypothalamus (Van Pett et al., 2000) (Chalmers et al., 1995). However, in primate species, CRH-R2 is more widely distributed and occurs in higher densities in cortical regions. None of the forms of CRH-R2 are expressed in the pituitary, suggesting that CRH-R1 is the key receptor for CRH in the pituitary (Chalmers et al., 1995). The different distribution is complementary to that of CRH-R1 and has been suggested to underline a putative function dissociation between the $\mathrm{CRH}$ receptor subtypes.

More recently, in the diploid catfish species, a third CRH receptor (CRH-R3), encoding a 428-amino-acid protein, has been identified (Arai et al., 2001). This novel $\mathrm{CRH}$ receptor is structurally closer to catfish CRH-R1 (85\%) than CRH-R2 (80\%), and binds CRH with a 5-fold higher affinity than urotensin I and sauvagine. CRH-R3 in the catfish is expressed in the pituitary gland, urophysis and brain. This multiplicity of receptor subtypes and ligands provides for diversity of receptor expression and signaling.

In addition to the distinct anatomic profiles of CRH-R1 and CRH-R2, the receptors also differ in their pharmacological properties. CRH-R1 has high affinity for UCN and $\mathrm{CRH}$, binding both peptides with similar affinity, while not showing any affinity for UCN2 or UCN3 (Vaughan et al., 1995). In contrast, CRH-R2 has a significantly higher affinity for UCN, UCN2 and UCN3 than for CRH (Vaughan et al., 1995). The higher affinity of CRH-R2 for UCN coupled with anatomic studies that identified several potential sites of UCN/CRH-R2 interactions suggested that UCN is the endogenous mammalian ligand for CRH-R2 (Vaughan et al., 1995). However, CRH-R1 also has a very high affinity for UCN, suggesting that UCN could also mediate effects through CRH-R1 at sites of UCN/CRH-R1 co-localization (Bittencourt et al., 1999) (Vaughan et al., 1995). Therefore, some of the functions originally attributed to CRH may in fact be mediated, at least in part, by UCN or other CRH-like ligands. 
The specific tissue distribution and pharmacological properties of these receptors suggests that distinct CRH pathways exist, thus providing separate routes to direct adaptive changes. CRH-R1 deficiency in mice leads to a decrease in CRH and UCN signaling, resulting in a significantly impaired HPA axis and decreased anxiety-like behavior (Smith et al., 1998) (Timpl et al., 1998). CRH-R1 deficient mice showed increased exploration of the open arms on an elevated plus maze and they spent more time in the brightly lit compartment of a light-dark transition box than did wild-type (WT) control mice. This pattern of behavior has been suggested to reflect a reduced level of anxiety in CRH-R1 knock out (KO) mice (Contarino et al., 1999) (Smith et al., 1998) (Timpl et al., 1998). One study found that AVP mRNA and protein levels in the PVN were elevated in the CRH-R1 deficient mice, thus suggesting that in the absence of CRH-R1, AVP V1a receptors maintained a compensatory activation of basal HPA axis hormone levels (Muller et al., 2000). Other studies examining these mice, however, have detected no increases in AVP protein or mRNA expression in the PVN in the absence of CRH-R1 (Smith et al., 1998) (Bale et al., 2002). CRH mRNA and protein levels were elevated in the absence of CRH-R1, which was partially due to decreased endogenous corticosterone negative feedback, as glucocorticoid replacement diminished the increased CRH expression in these mice (Smith et al., 1998) (Bale et al., 2002). This observation also suggests an additional regulatory mechanism for CRH expression that might involve CRH-R2. CRH-R1 KO mice had normal baseline levels of plasma $\mathrm{ACTH}$, probably due to a maintenance of ACTH levels by AVP through AVP receptors (Turnbull et al., 1999). Taken together, these results support the notion that CRH-R1 plays an important role in the expression of stress-like behavioral responses and that blockade of this receptor may lead to reduced baseline anxiety-like states.

The conditional CRH-R1 (exon 9-13) KO mice (Crhrl ${ }^{\text {loxp/loxp }}$ Camk2 $\alpha$-cre) was generated in 2003 (Muller et al., 2003), in which CRH-R1 function is inactivated postnatal in anterior forebrain and limbic brain structures, but not in the pituitary. Crhrl ${ }^{\text {loxp/loxp }}$ Camk2 $\alpha$-cre mutants showed reduced anxiety, and the normal basal activity of their HPA system. Moreover, conditional mutants were hypersensitive to stress, corticotropin and corticosterone levels remained significantly elevated after stress. All those results suggested that limbic CRH-R1 modulates anxiety-related behavior and that this effect is independent of HPA system function. 
Lack of CRH-R2 also resulted in reduced CRH and UCN signaling in the CNS and periphery. CRH-R2 deficient mice exhibited impaired cardiovascular function and altered feeding after food deprivation or UCN administration (Bale et al., 2000) (Coste et al., 2000) (Kishimoto et al., 2000). Compared to WT mice, none of CRH-R2 KO mice showed any alteration in baseline locomotor activity levels, but exhibited significantly reduced grooming behavior in a novel open-field suggesting that $\mathrm{CRH}-$ $\mathrm{R} 2$ is involved in adaptations to stress and supporting a role for this receptor in maintaining allostasis. An increase in stress-induced ACTH and corticosterone levels was observed in the mutant mice (Bale et al., 2002) (Coste et al., 2000), and basal levels of these hormones did not appear to be affected by the gene deletion. Interestingly, no differences were found in basal CRH mRNA or protein levels in the PVN in CRH-R2 KO mice (Bale et al., 2000) (Coste et al., 2000). However, Vale and colleagues have found increased expression levels of AVP in the PVN, which may be augmenting the $\mathrm{CRH}$ response in these mice and thus resulting in the increased sensitivity and hormone levels detected (Bale et al., 2002).

The response to stress in mice deficient for both $\mathrm{CRH}$ receptors (CRH-R1/2 KO) has also been examined. In the absence of either known receptor, mice displayed remarkably little HPA axis response to a restraint stress (Bale et al., 2002) (Preil et al., 2001). ACTH and corticosterone levels following restraint stress were significantly lower in the CRH-R1/2 KO mice compared to CRH-R1 KO mice suggesting a possible role of CRH-R2 in mediation of HPA-axis sensitivity (Bale et al., 2002).

The response to stress involves initiation, maintenance and recovery processes, both CRH and CRH-R1 are critical to initiate HPA activation in response to stress (Smith et al., 1998) (Timpl et al., 1998). It is possible that CRH-R2 also modifies the stress response following initial activation of the HPA axis.

The development of possible therapeutically relevant $\mathrm{CRH}$ receptor antagonists has become a current focus in drug discovery for treatment of stress-related disorders, such as depression and anxiety. Several small-molecular CRH-R1 antagonists have been produced and studied in recent years. CRH-R1 antagonists NBI-27914 (Chen et al., 1996) and NBI-30775 (formerly R-121919) (Oshima et al., 2003) have shown promising results in treatment of stress-related behaviors in rodents. Chronic treatment of mice with NBI-30775 caused complex changes in hippocampal serotonergic neurotransmission that may reveal molecular mechanisms of CRH-R1 involvement in the development of depression. 


\subsection{CRH-binding protein (CRH-BP)}

The CRH-BP is a $37-\mathrm{kDa}$ secreted glycoprotein that binds human $\mathrm{CRH}$ with an equal or greater affinity than the CRH receptor, and is expressed in rodent and primate brain and pituitary (Potter et al., 1991) (Potter et al., 1992) (Potter et al., 1994) (Chen et al., 1993) (Cortright et al., 1995). In humans, CRH-BP was found in plasma, amniotic fluid, placenta, pituitary and brain, where it inactivates $\mathrm{CRH}$ and has been proposed to prevent inappropriate pituitary-adrenal stimulation during pregnancy (Potter et al., 1991). In contrast, CRH-BP was not found in rodent plasma, rat and mouse CRH-BP have been detected only in the brain and pituitary.

The association of $\mathrm{CRH}$ with its binding protein forms a dimer complex and is thought to modulate the endocrine activity of CRH (Lowry et al., 1996). Recombinant CRH-BP has been shown to block CRH-induced adrenal ACTH secretion from rat anterior pituitary cells (Potter et al., 1991). CRH-BP has also been detected in brain regions not associated with $\mathrm{CRH}$ activity, suggesting that it may also have $\mathrm{CRH}-$ independent actions.

\subsection{Arginine vassopressin (AVP)}

CRH neurons are the principal regulators of the HPA axis and are present in the parvocellular subdivisions of the PVN. The decapeptide AVP is primarily a neurohypophysial hormone and is coexpressed in some of these CRH neurons. AVP is released into the portal circulation with $\mathrm{CRH}$ in response to stress and potentiates CRH-induced ACTH secretion. Thus, AVP and CRH are both endogenous releasing peptides for ACTH with AVP acting as a second 'releasing factor' for ACTH along with CRH. However, most vasopressinergic neurones are present in the magnocellular subdivisions of the PVN and the supraoptic nucleus. In certain conditions, increases in vasopressin of magnocellular origin could facilitate pituitary ACTH secretion (Holmes et al., 1986) (Irvine et al., 1989). However, prolonged activation of the magnocellular vasopressinergic system during chronic osmotic stimulation decreases rather than increases pituitary ACTH responsiveness (Dohanics et al., 1990) (Chowdrey et al., 1991).

Acute stress stimulates release of $\mathrm{CRH}$ and AVP from the median eminence into the pituitary portal circulation and increases expression of both peptides in parvocellular neurons of the PVN (Plotsky et al., 1991) (Plotsky, 1991). In addition, 
in vivo and in vitro studies have shown that the rate of release of immunoreactive AVP from median eminence terminals increases in response to repeated or chronic stress (de Goeij et al., 1991) (Aguilera et al., 1993). Even a transient activation of hypothalamic $\mathrm{CRH}$ neurons by a single stressor can cause long lasting increases in AVP coexpression, irrespective of the nature of the stressor, which in most cases is not accompanied by changes of CRH (Schmidt et al., 1997). Basal levels of CRH and AVP expression are under feedback inhibition by glucocorticoids, and AVP transcription is highly sensitive to glucocorticoid inhibition.

\subsection{Corticosteroid receptors}

Glucocorticoids (corticosterone in rodents, cortisol in primates) are synthesized in the adrenal cortex and secreted from the gland into the circulation, which allows them to act on many different cell types throughout the body (Bartlett and Miller, 1956) (Tronche et al., 1998). Two closely related corticosteroid receptors have been identified so far, the type I mineralocorticoid receptor (MR) and the type II glucocorticoid receptor (GR) (Arriza et al., 1987) (Hollenberg et al., 1985).

In general, GR has a much broader expression pattern than does MR, the GR is found throughout the brain, with high density in the limbic system (hippocampus, septum) and in the parvocellular neurons of the PVN, and is also found in relatively high concentrations in the ascending monoaminergic neurons of the brain stem, prefrontal cortex, nuleaus accumbens, bed nucleus of the stria terminals, and central nucleus of the amygdala. During stress, corticosterone levels may increase about 100fold and GRs get occupied by corticosterone. Their main function in brain is to suppress stress-induced hyperactivity of the HPA axis at the level of the PVN, anterior pituitary, but also at the hippocampal level (Joels and De Kloet, 1992). Thus, it has been suggested that the adaptive function of the HPA axis is critically dependent on glucocorticoid feedback mechanisms to dampen the stressor-induced activation of the HPA axis and to shut off further glucocorticoid secretion (Jacobson and Sapolsky, 1991). The MR is found only in the brain and in epithelial cells of the kidney, the colon, and exocrine glands (Kretz et al., 2001) (Reul et al., 2000). Moreover, MR and GR appeare to be co-localized in abundance in limbic neurons including hippocampal CA1 and dentate gyrus (DG) (van Steensel et al., 1996). Colocalization occurres also in the nuclei of amygdala and medial prefrontal cortex areas 
that have an important function in emotion and cognition (Helm et al., 2002). In the hippocampus, the glucocorticoid concentration determines which receptor is activated. Low concentrations are believed to activate only MR, and higher concentrations are believed to activate both MR and GR (Reul and de Kloet, 1985). Pharmacological and antisense-RNA studies confirmed the hypothesis that MR in the hippocampus inhibits basal HPA axis activity by influencing $\mathrm{CRH}$ and AVP secretion from the PVN, whereas hippocampal GR acts the opposite (Dittmar et al., 1998) (Ratka et al., 1989). GR exerts inhibitory action in the PVN and the pituitary, which prevents an overreaction of the HPA axis under stress conditions and during the diurnal peak.

In behavior, central MR activation stimulates autonomic outflow (Van den Berg et al., 1994) (van den Buuse et al., 2002), in the spatial learning tests MR affects interpretation of environmental information and selection of the appropriate behavioral response to deal with the stressor. Dysregulation of GR function has been associated with human depression and anxiety disorder. Blockade of brain GRs impairs the storage of new information (Oitzl and de Kloet, 1992) (Sandi et al., 1997). Likewise, mutant mice with a point mutation in GR, which obliterates binding to DNA, were unable to store learned information (Oitzl et al., 2001). Transgenic mice with down-regulated GR (knock down) showed also cognitive defects and elevated plasma ACTH and corticosterone concentrations in response to stress. GR overexpression in the forebrain resulted in increased anxiety- and depressant-like behavior. No changes in basal plasma ACTH and corticosterone levels in GR overexpression mice were detected either in the morning nor in the evening. Moreover, GR overexpressing mice showed no differences from WT mice in corticosterone levels immediately and $10 \mathrm{~min}$ after the elevated plus maze test, a mild stressor. The cellular data in various limbic regions suggest that MR prevents disturbance of homeostasis, while GR promotes its recovery.

Glucocorticoid levels undergo a diurnal rhythm reaching peak levels before the onset of the active phase of the organism (in the morning for humans and in the evening for rodents).

\subsection{CRH gene targeting mice}

Gene targeting in mouse embryonic stem cells and mice has been used widely to study in vivo functions of genes during delevopment and in adult life. The efforts to 
identify and characterize genetic/environment interactions in the regulation of stress have followed two general directions in rodent studies: the evaluation of stress-related behaviors in animals that have gained by classic transgenesis or lost one particular gene function by knock out or antisense approaches.

CRH knock out (KO) mice were generated in 1995 by Muglia and colleagues (Muglia et al., 1995). In terms of behavioral effects, CRH KO mice appeared to be nearly indistinguishable from genetically unaltered WT control mice. Baseline locomotor, exploratory, stereotypic, startle, and operant learning behaviors were unaffected by CRH gene deletion (Dunn and Swiergiel, 1999) (Weninger et al., 1999). Interestingly, deletion of the $\mathrm{CRH}$ gene seemed to alter certain endocrine measures, normal levels of ACTH were found in the pituitary and plasma, but the circadian pattern for this hormone was disrupted in CRH knockouts (Muglia et al., 1997) (Muglia et al., 2000). Stress-induced activation of the HPA axis was preserved in mice without the $\mathrm{CRH}$ gene, albeit the level of activation was significantly decreased (Jacobson et al., 2000). It is possible that this relative sparing of HPA axis function is related to increases in PVN AVP mRNA that were seen in CRH KO mice (Muglia et al., 2000).

To gain more insight into the relationship between central CRH hyperactivity and neuroendocrine, automonic, physiological, and behavioral changes associated with chronic stress, two CRH-overexpressing mouse lines have been developed. The first one was generated in 1992 by Stenzel-Poore and colleagues (Stenzel-Poore et al., 1992). In these mice, a metallothionine (MT) promoter, which drives wide-spread gene expression throughout the brain and the peripheral organs, was used; gene overexpression was thus achieved not only in brain regions where $\mathrm{CRH}$ is endogenously found, but also in other CNS regions and in peripheral organs (testis, heart, and lung) where CRH is not endogenously found. These mice have been found not only to display the behavioral effects associated with acute CRH administration, but also to show marked long-term alterations in endocrine and immune function that are associated with disease states involving hypercortisolemia. Thus, over-production of CRH in the CNS clearly led to elevated ACTH release and increased circulating glucocorticoid levels. Compared to WT mice, basal ACTH levels were elevated 3fold and corticosterone levels were increased 10-fold. The high circulating corticosterone levels of $\mathrm{CRH}$ transgenic (CRH-Tg) mice resulted in a striking, physical phenotype that resembles Cushing's syndrome: thin skin, hair loss, brittle 
bones, truncal obesity and a characteristic buffalo hump (Stenzel-Poore et al., 1992). CRH-Tg mice reverted to a normal phenotype upon adrenalectomy and subsequently survived for months without corticosterone replacement. These mice also showed a number of physiologic and behavioral features that parallel those seen in stress, and thus are particularly well suited to explore the consequences of altered $\mathrm{CRH}$ system activation as occurs during chronic stress. In addition, overexpression of the CRH gene also resulted in a marked decrease in immune functioning, as evidenced by overall reductions in cell numbers and tissue weight in immune system organs such as the spleen and thymus gland and a failure to mount immunoglobulin antibody responses to immune challenge (Bremner et al., 1997). Behaviorally, CRH-Tg mice exhibited a profile that was consistent with increased levels of stress, such as reduced baseline and stress-induced exploration of a novel environment, and decreased activity and time spent in the open arms of an elevated plus maze (Stenzel-Poore et al., 1994). These effects were potently blocked by administration of the CRH receptor antagonist $\alpha$-helical CRH. CRH-Tg mice also showed a profound decrease in sexual behaviors and significant deficits in learning (Heinrichs et al., 1996) (Heinrichs et al., 1997).

The second CRH overexpressing mouse line (CRH-OE2122) was generated in 2002 by Olivier and colleagues (Dirks et al., 2002). In CRH-OE2122 mice, CRH was expressed under the control of the Thy-1 promotor, which drives constitutive transgene expression in neurons in postnatal and adult brain (Morris and Grosveld, 1989) (Vidal et al., 1990) (Moechars et al., 1996) (Luthi et al., 1997) (Wiessner et al., 1999) resulting in central CRH overexpression only. Increased amounts of CRH peptide and CRH mRNA were observed throughout the CNS in transgenic mice. CRH immunoreactivity, especially in the PVN and CeA, was increased significantly compared with WT mice, increased amounts of CRH were also present in the BNST. These changes in hypothalamic CRH content were accompanied by increased plasma corticosterone levels (4.4-fold) and adrenal gland hypertrophy, whereas basal plasma ACTH concentrations were not increased significantly in CRH-overexpressing mice (Groenink et al., 2002). This could suggest that the adrenal cortex of the CRHOE2122 mice was hyper-responsive to ACTH. Moreover, CRH-OE12122 mice clearly exhibited significant changes including increased body temperature and heart rate as well as food and water intake. However, the CRH-OE2122 mice had no Cushing-like phenotype despite elevated plasma corticosterone levels. Only after 6 
months did increase fat deposition and hair loss become apparent. In CRH-OE2122 mice, chronic CRH hyperactivity was associated with reductions in startle reactivity, disturbed habituation of the acoustic startle response, and impaired prepulse inhibition. The latter two abnormalities are also observed in schizophrenia patients.

\subsection{Conditional mutagenesis in the mouse}

The ability to modify the mouse genome by random integration of transgenes or at predetermined sites by homologous recombination in embryonic stem (ES) cells has greatly advanced our understanding of mammalian gene function in health and disease (Jaenisch, 1988) (Capecchi, 1989). These techniques allow us to introduce a permanent genetic alterations into the mouse germ line, but not to manipulate the genome in a spatio-temporally controlled manner in vivo and therefore there are some of the problems inherent to these technologies, such as embryonic lethality, possible compensatory effects during development, and difficulties in interpreting phenotypes caused by interactions of multiple tissues carrying the mutation. In case of random integration, it is difficult to know how many copies and where the transgene is integrated in the genome.

To circumvent these limitations of conventional gene targeting, conditional mutagenesis has become an important tool for investigating the function of a gene in a specific tissue/cell at a defined period of time (Metzger and Feil, 1999) (Nagy, 2000) (Hadjantonakis et al., 1999). Gain-of-function as well as loss-of-function can be engineered with the Cre-loxP system. The system allows for the inactivation or overproduction of a selected gene in a spatially and temporally controlled manner $(\mathrm{Gu}$ et al., 1994). There are two components in the system which permit an evaluation of gene function within genetically modified animals in a tissue-specific manner: one is the site-specific recombinase, such as Cre recombinase, which is a $38-\mathrm{kDa}$ bacteriophage $\mathrm{P} 1$ protein, binds to the 34-bp DNA sequences loxP target sequences and catalyzes the recombination between the two loxP sites in the same orientation without the need for any cofactors (Abremski et al., 1983). A "floxed" allele, a gene in which two loxP sites in the same orientation introduced by homologous recombination in ES cells (Thomas and Capecchi, 1987) flank one or more important exons of the gene of interest, which permits subsequent recombination and gene disruption coincident with expression of the appropriate recombinase. 
Recombination occurs only in cells expressing Cre recombinase. Expression of a site-specific/cell-type-restricted or inducible recombinase is achieved either through a tissue or cell-restricted transgene or by inserting the recombinase cDNA into a genetic locus with a known tissue expression profile. For example, in transgenic CamKII $\alpha$-Cre mice (Minichiello et al., 1999), the Cre recombinase expression was driven by the calcium /calmodulin-dependent kinase II (CamKIIa) promoter. In this mouse line, the pattern of Cre recombinase expression matches the expression of the endogenous CamKII gene. At or after P20, Cre recombination is specifically observed in the forebrain including pyramidal neurons of the hippocampus (strong staining in CA1) and anterior forebrain neocortex, striatum, and amygdala. To another Cre-expressing transgenic mouse line, Cre recombinase expression is driven by the rat nestin (Nes) promoter and enhancer. In these mice, Cre recombinase is expressed in neuronal and glia cells from embryonic day 7.75 (Tronche et al., 1999) (Dahlstrand et al., 1995).

In such experimental outlines, it is necessary to monitor if Cre activity at desired time points or if the recombination takes place in the desired region, this can be achieved by crossing Cre transgenic mice to a Cre recombinase dependent reporter mouse line. For example the ROSA26 (R26) reporter mouse line, which has been generated using the previously trapped ROSA26 locus (Friedrich and Soriano, 1991). It is known that the proviral ROSA26 allele transcribes the $\beta$ geo gene as early as the morula/blastocyst stage (Mao et al., 1999). This reporter line has been used to monitor Cre expression in transgenic mice since it was first shown to be successful in the Soriano laboratory (Soriano, 1999). In this line, the native ROSA26 gene drives expression of the LacZ enzyme upon Cre recombination. The resulting transgenic mice consequently express LacZ only in the cells that express Cre recombinase (Soriano, 1999). The recombination efficiency will depend on the level of Cre expression and thus might vary between different mouse strains.

Tissue- or cell-specific gene disruption or overproduction is often used to circumvent embryonic or fetal lethality associated with complete somatic disruption, thus permitting an examination of gene function in the tissue of interest or at later developmental stages. However, one significant limitation of these present approaches is the liability to control the timing of Cre-mediated recombination, because gene disruption closely parallels the earliest expression profile of the chosen promoter. As a result, some groups developed inducible Cre mouse line mice, for example, Mantamadiotis and colleagues (Casanova et al., 2002) generated tamoxifen inducible 
CamKIIa ERiCreER transgenic mice. They were able to induce the Cre recombinase expression by intraperitoneal injection or oral admistration of tamoxifen at the time they liked.

\subsection{Aim of the thesis}

The neuropeptide $\mathrm{CRH}$ functions as a key mediator of the responses to stress (Vale et al., 1981). In addition to its neuroendocrine effects, CRH acts as a neuromodulator in stress-associated limbic regions to propagate and integrate stressinduced behaviors, including anxiety-like behavior, arousal and motor function (Dunn and Berridge, 1990a) (Steckler and Holsboer, 1999). Chronic CRH hyperactivity is implicated in human stress-related and affective disorders, including major depression. To examine the effects of chronic CRH excess, two CRH transgenic mice were generated previously (Stenzel-Poore et al., 1992) (Dirks et al., 2002a). Due to their wide-spread expression pattern - whole body or entire CNS respectively, CRH overexpressing mice showed elevated ACTH and glucocorticoids levels resulting in symptoms of Cushing-like syndrome (Stenzel-Poore et al., 1992) (Groenink et al., 2002). Therefore, it can not be excluded that part of the CRH effects e.g. on anxietyrelated behavior observed in these mice may be mediated via its chronic activation of the HPA-system. In order to circumvent these problems, we utilized the Cre/LoxP system - a highly flexible, reliable and reproducible system to generate a mouse

model of central CRH hyperactivity that allows the in depth analysis of effects of $\mathrm{CRH}$ overexpression in different brain regions. 


\section{Materials and Methods}

\subsection{Materials}

\subsubsection{Buffers and Solutions}

Buffers and solutions were prepared using Milipore Q-destilled water. Chemicals were purchased from Sigma, Roth, Merck unless indicated otherwise.

\subsubsection{Buffers for electrophoresis}

\subsection{Buffers for DNA agrose Gel}

$$
\begin{aligned}
0.5 \text { M EDTA: } & 181.6 \mathrm{~g} \quad \text { EDTA-Na.2 } \mathrm{H}_{2} \mathrm{O} \\
& 800 \mathrm{ml} \quad \text { aqua dest } \mathrm{H}_{2} \mathrm{O} \\
\rightarrow & \text { adjust } \mathrm{pH} \text { to } 8.0 \text { with } 1 \mathrm{M} \mathrm{NaOH} \\
\rightarrow & \text { adjust volume to } 1 \text { liter with aqua dest } \mathrm{H}_{2} \mathrm{O}
\end{aligned}
$$

$2 \mathrm{M}$ Tris/HCl: $242.2 \mathrm{~g} \quad$ Tris

$$
800 \mathrm{ml} \text { aqua dest } \mathrm{H}_{2} \mathrm{O}
$$

$\rightarrow$ adjust $\mathrm{pH}$ to 7.5 with $\mathrm{HCl}$

$\rightarrow$ adjust volume to 1 liter with aqua dest $\mathrm{H}_{2} \mathrm{O}$

TAE buffer: $4.84 \mathrm{~g} \quad$ Tris

$1.142 \mathrm{ml} \quad$ Acetate acid

$20 \mathrm{ml} \quad 0.5 \mathrm{M}$ EDTA, $\mathrm{pH} 8.0$

$800 \mathrm{ml}$ aqua dest $\mathrm{H}_{2} \mathrm{O}$

$\rightarrow$ adjust $\mathrm{pH}$ to 8.3 with acetate acid

$\rightarrow$ adjust volume to 1 liter with aqua dest $\mathrm{H}_{2} \mathrm{O}$

TBE buffer: $10.8 \mathrm{~g} \quad$ Tris

$5.5 \mathrm{~g} \quad$ Boric acid

$4.0 \mathrm{ml} \quad 0.5 \mathrm{M}$ EDTA, $\mathrm{pH} 8.0$

$800 \mathrm{ml} \quad$ aqua dest $\mathrm{H}_{2} \mathrm{O}$

$\rightarrow$ adjust $\mathrm{pH}$ to 8.3 with acetate acid

$\rightarrow$ adjust volume to 1 liter with aqua dest $\mathrm{H}_{2} \mathrm{O}$ 
Loading buffer:

$6 \mathrm{x}$ Loading buffer: $1 \mathrm{~g} \quad$ Orange $\mathrm{G}$

(Orange) $\quad 10 \mathrm{ml} \quad 2 \mathrm{M}$ Tris/HCl, $\mathrm{pH} 7.5$

$150 \mathrm{ml} \quad$ Glycerol

$\rightarrow$ adjust volume to 1 liter with aqua dest $\mathrm{H}_{2} \mathrm{O}$

$6 \mathrm{x}$ Loading buffer: $\quad 0.25 \mathrm{~g} \quad$ Bromophenol Blue

(Blue) $\quad 600 \mathrm{ml} \quad$ Glycerol

$10 \mathrm{ml} \quad 2 \mathrm{M}$ Tris/HCl, $\mathrm{pH} 7.5$

$\rightarrow$ adjust volume to 1 liter with aqua dest $\mathrm{H}_{2} \mathrm{O}$

\subsection{Buffers for RNA Gel}

$10 \mathrm{x}$ running buffer: $\quad 41.94 \mathrm{~g} \quad$ MOPS

$4.1025 \mathrm{~g} \quad$ NaAceticum

$20 \mathrm{ml} \quad 0.5 \mathrm{M}$ EDTA, $\mathrm{pH} 8.0$

$800 \mathrm{ml} \quad$ DEPC- $\mathrm{H}_{2} \mathrm{O}$

$\rightarrow$ adjust $\mathrm{pH}$ to 7.4 with $2 \mathrm{~N} \mathrm{NaOH}$

$\rightarrow$ adjust volume to 1 liter with DEPC- $\mathrm{H}_{2} \mathrm{O}$

Loading buffer: $\quad 0.0025 \mathrm{~g} \quad$ Bromphenoblue

$4 \mathrm{ml} \quad$ Formamid

$2 \mathrm{ml} \quad$ Formaldehyd

$2 \mathrm{ml} \quad 10 \mathrm{x}$ running Buffer

$\rightarrow$ adjust volume to $10 \mathrm{ml}$ with DEPC- $\mathrm{H}_{2} \mathrm{O}$

\subsubsection{Buffers for Southern blot}

Denaturation buffer: $100 \mathrm{ml} \quad 5 \mathrm{M} \mathrm{NaOH}$

$300 \mathrm{ml} \quad 5 \mathrm{M} \mathrm{NaCl}$

$600 \mathrm{ml} \quad \mathrm{H}_{2} \mathrm{O}$

Neutralization buffer: $250 \mathrm{ml} \quad 2 \mathrm{M}$ Tris/HCl, $\mathrm{pH} 7.5$

$300 \mathrm{ml} \quad 5 \mathrm{M} \mathrm{NaCl}$

$10 \mathrm{ml} \quad 0.5 \mathrm{M}$ EDTA, $\mathrm{pH} 8.0$

$440 \mathrm{ml} \quad \mathrm{H}_{2} \mathrm{O}$ 
Transfer buffer:

$20 \times \mathrm{SSC}$

$175.3 \mathrm{~g} \quad \mathrm{NaCl}$

$88.2 \mathrm{~g} \quad \mathrm{Na}$-citrate. $2 \mathrm{H}_{2} \mathrm{O}$

$800 \mathrm{ml}$ aqua dest $\mathrm{H}_{2} \mathrm{O}$

$\rightarrow$ adjust $\mathrm{pH}$ to 7.4 with $1 \mathrm{M} \mathrm{HCl}$

$\rightarrow$ adjust volume to 1 liter with aqua dest $\mathrm{H}_{2} \mathrm{O}$

Washing buffer:

$2 \times$ SSC, $0.1 \%$ SDS: $100 \mathrm{ml} \quad 20 \times \mathrm{SSC}$

$10 \mathrm{ml} \quad 10 \% \mathrm{SDS}$

$\rightarrow$ adjust volume to 1 liter with aqua dest $\mathrm{H}_{2} \mathrm{O}$

$0.2 \times \mathrm{SSC}, 0.1 \% \mathrm{SDS}: 10 \mathrm{ml} \quad 20 \times \mathrm{SSC}$

$10 \mathrm{ml} \quad 10 \% \mathrm{SDS}$

$\rightarrow$ adjust volume to 1 liter with aqua dest $\mathrm{H}_{2} \mathrm{O}$

\subsubsection{Buffers for Mini-Southern blot in 96-Well-Tissue-Culture-Plates}

Lysis buffer: $\quad 5 \mathrm{ml} \quad 1 \mathrm{M}$ Tris $\mathrm{HCl}, \mathrm{pH} 8.0$

$10 \mathrm{ml} \quad 0.5 \mathrm{M}$ EDTA, $\mathrm{pH} 8.0$

$1 \mathrm{ml} \quad 5 \mathrm{M} \mathrm{NaCl}$

$12.5 \mathrm{ml} \quad 20 \%$ Sarcosyl

$\rightarrow$ adjust volume to $500 \mathrm{ml}$ with aqua dest $\mathrm{H}_{2} \mathrm{O}$

$\rightarrow$ add $0.6 \mathrm{ml} / 12 \mathrm{ml}$ (20 mg/ml stock) Proteinase $\mathrm{K}$ to lysis solution prior to use

Precipitation buffer: $0.15 \mathrm{ml}$ of $5 \mathrm{M} \mathrm{NaCl}$ to $10 \mathrm{ml}$ cold $100 \%$ Ethanol

Restriction Digest Mix: $\quad 23.5 \mu \mathrm{l} \quad \mathrm{H}_{2} \mathrm{O}$

$$
\begin{array}{ll}
3.0 \mu \mathrm{l} & \text { Restriction buffer } \\
1.2 \mu \mathrm{l} & \text { Spermidine }(0.1 \mathrm{M}) \\
0.3 \mu \mathrm{l} & \text { RNase }(10 \mathrm{mg} / \mathrm{ml})
\end{array}
$$

mix well, add $2 \mu 1$ Enzyme (EcoRV or ApaI, $40 \mathrm{u} / \mu \mathrm{l}$ ) to each well, final volume is 30 $\mu 1$ 


\subsubsection{Buffers for preparation of genomic DNA from tissues}

SDS/Proteinase K buffer: $\quad 0.44 \mathrm{~g} \quad \mathrm{NaCl}$

$\begin{array}{ll}1 \mathrm{ml} & 1 \mathrm{M} \text { Tris/HCl, } \mathrm{pH} 8.0 \\ 5 \mathrm{ml} & 0.5 \mathrm{M} \text { EDTA, } \mathrm{pH} 8.0 \\ 10 \mathrm{ml} & 10 \% \mathrm{SDS}\end{array}$

$\rightarrow$ adjust volume to $100 \mathrm{ml}$ with aqua dest $\mathrm{H}_{2} \mathrm{O}$ and store at room temperature (RT)

$\rightarrow$ add $0.4 \mathrm{mg} / \mathrm{ml}$ proteinase $\mathrm{K}$ just prior to use

\subsubsection{Buffers for $X-$ Gal staining of cells and sections}

10 x PBS: $\quad 80 \mathrm{~g} \quad \mathrm{NaCl}$

$2 \mathrm{~g} \quad \mathrm{KCl}$

$26.28 \mathrm{~g} \quad \mathrm{Na}_{2} \mathrm{HPO}_{4} \cdot 12 \mathrm{H}_{2} \mathrm{O}$

$2.4 \mathrm{~g} \quad \mathrm{KH}_{2} \mathrm{PO}_{4}$

$800 \mathrm{ml} \quad$ aqua dest $\mathrm{H}_{2} \mathrm{O}$

$\rightarrow$ adjust $\mathrm{pH}$ to 7.4 with $1 \mathrm{M} \mathrm{HCl}$

$\rightarrow$ adjust volume to 1 liter with aqua dest $\mathrm{H}_{2} \mathrm{O}$

$20 \%$ PFA: $20 \mathrm{~g} \quad$ PFA

$\rightarrow$ adjust volume to $100 \mathrm{ml}$ with $1 \mathrm{x}$ PBS, incubate at $65^{\circ} \mathrm{C}$ overnight

$20 \%$ sucrose: $20 \mathrm{~g} \quad$ sucrose

$\rightarrow$ adjust volume to $100 \mathrm{ml}$ with $1 \mathrm{x}$ PBS (containing $0.005 \mathrm{M}$ EGTA, $0.001 \mathrm{M} \mathrm{MgCl}_{2)}$

LacZ-Fix buffer: $\quad 20 \mathrm{ml} \quad 20 \%$ PFA / PBS, pH 7.4

$0.5 \mathrm{ml} \quad 1 \mathrm{M} \mathrm{EGTA}$

$0.1 \mathrm{ml} \quad 1 \mathrm{M} \mathrm{MgCl}_{2}$

$\rightarrow$ adjust volume to $100 \mathrm{ml}$ with $1 \mathrm{x}$ PBS

LacZ-Wash buffer: $\quad 0.2 \mathrm{ml} \quad 1 \mathrm{M} \mathrm{MgCl}_{2}$

$0.2 \mathrm{ml} \quad 5 \%$ Deoxycholate

$0.2 \mathrm{ml} \quad 10 \% \mathrm{NP} 40$

$\rightarrow$ adjust volume to $100 \mathrm{ml}$ with $1 \times$ PBS 


$$
\begin{array}{lll}
\text { LacZ-Stain buffer: } & 2 \mathrm{ml} & 4 \% \mathrm{X} \text {-Gal (in DEMF) } \\
\text { (prepare fresh) } & 10 \mathrm{ml} & 0.05 \mathrm{M} \text { potassium-ferrocyanide } \\
& 10 \mathrm{ml} & 0.05 \mathrm{M} \text { potassium-ferricyanide } \\
& \rightarrow \text { adjust volume to } 100 \mathrm{ml} \text { with LacZ-Wash buffer }
\end{array}
$$

\subsubsection{Buffers for in situ hybridization (ISH)}

Hybridization-mix: $50 \mathrm{ml}$ formamide, $1 \mathrm{ml} 2 \mathrm{M}$ Tris/HCl, $\mathrm{pH} 8.0,1.775 \mathrm{~g} \mathrm{NaCl}$, $1 \mathrm{ml} \mathrm{0.5} \mathrm{M} \mathrm{EDTA,} \mathrm{pH} \mathrm{8.0,} 10 \mathrm{~g}$ dextransulphate, $0.02 \mathrm{~g}$ Ficoll 400, $0.02 \mathrm{~g}$ PVP40, $0.02 \mathrm{~g}$ BSA, $5 \mathrm{ml} 10 \mathrm{mg} / \mathrm{ml}$ tRNA, $1 \mathrm{ml} 10 \mathrm{mg} / \mathrm{ml}$ carrier DNA, $4 \mathrm{ml} 5 \mathrm{M}$ DTT.

This buffer can not be autoclaved and thus should be handled with care. Use DEPC-treated buffers. Store hybridization mix as 1 to $5 \mathrm{ml}$ aliquots at $-80{ }^{\circ} \mathrm{C}$. It can be kept for at least one year.

\section{M DTT/DEPC: $\quad 7.715$ g DTT $+4 \mathrm{ml} \mathrm{DEPC-H_{2 } \mathrm { O }}$}

$\rightarrow$ shake the FALCON tube until the powder is nearly solved $\rightarrow$ adjust volume to $10 \mathrm{ml}$ with DEPC- $\mathrm{H}_{2} \mathrm{O}$

$10 \mathrm{x}$ TEA/DEPC-stock solution: $84 \mathrm{ml}$ TEA (1 M triethanolamine (Sigma T1377))

$$
300 \mathrm{ml} \text { DEPC- } \mathrm{H}_{2} \mathrm{O}
$$

$\rightarrow$ adjust $\mathrm{pH}$ to 8.0 with $32 \% \mathrm{HCl}$

$\rightarrow$ adjust volume to $500 \mathrm{ml}$ with DEPC- $\mathrm{H}_{2} \mathrm{O}$, autoclave once

\begin{tabular}{|c|c|c|}
\hline \multirow[t]{3}{*}{5 x NTE stock solution: } & $146.1 \mathrm{~g}$ & $\mathrm{NaCl}$ \\
\hline & $50 \mathrm{ml}$ & $1 \mathrm{M}$ Tris/HCl, $\mathrm{pH} 8.0$ \\
\hline & $50 \mathrm{ml}$ & 0.5 M EDTA, pH 8.0 \\
\hline
\end{tabular}

10 x Proteinase K buffer/DEPC: $\quad 500 \mathrm{ml} \quad 1 \mathrm{M}$ Tris/HCl, $\mathrm{pH} 7.5$

$$
100 \mathrm{ml} \quad 0.5 \mathrm{M} \text { EDTA, } \mathrm{pH} 8.0
$$

$\rightarrow$ adjust volume to 1 liter with DEPC- $\mathrm{H}_{2} \mathrm{O}$, autoclave once

$\begin{array}{lll}\text { Hybridization Chamber Fluid: } & 250 \mathrm{ml} & \text { formamide } \\ & 50 \mathrm{ml} & 20 \times \mathrm{SSC} \\ & 200 \mathrm{ml} & \text { aqua dest } \mathrm{H}_{2} \mathrm{O}\end{array}$




\subsubsection{Buffers for transfection of embryonic stem (ES) cell}

2 x BBS: $\quad 1.1 \mathrm{~g} \quad$ BES

$1.6 \mathrm{~g} \quad \mathrm{NaCl}$

$0.02 \mathrm{~g} \quad \mathrm{Na}_{2} \mathrm{HPO}_{4}$

$\rightarrow$ adjust $\mathrm{pH}$ to 6.95 with $5 \mathrm{~N} \mathrm{NaOH}$

$\rightarrow$ adjust volume to $100 \mathrm{ml}$ with aqua dest $\mathrm{H}_{2} \mathrm{O}$, pass through 0.22 $\mu \mathrm{M}$ filter, store $1 \mathrm{ml}$ aliquots at $-20{ }^{\circ} \mathrm{C}$.

$2 \mathrm{M} \mathrm{CaCl}_{2:} \quad 24.8 \mathrm{~g} \quad \mathrm{CaCl}_{2}$

$\rightarrow$ adjust volume to $100 \mathrm{ml}$ with aqua dest $\mathrm{H}_{2} \mathrm{O}$, pass through 0.22 $\mu \mathrm{M}$ filter, store $1 \mathrm{ml}$ aliquots at $-20{ }^{\circ} \mathrm{C}$.

$10 \mathrm{mM}$ Tris: $\quad 0.121 \mathrm{~g} \quad$ Tris

$80 \mathrm{ml} \quad$ aqua dest $\mathrm{H}_{2} \mathrm{O}$

$\rightarrow$ adjust $\mathrm{pH}$ to 7.6 with $1 \mathrm{M} \mathrm{HCl}$

$\rightarrow$ adjust volume to $100 \mathrm{ml}$ with aqua dest $\mathrm{H}_{2} \mathrm{O}$, pass through $0.22 \mu \mathrm{M}$ filter, store $1 \mathrm{ml}$ aliquots at $-20{ }^{\circ} \mathrm{C}$.

\subsubsection{Buffers for Radioimmunoassay (RIA)}

Lysis Buffer: $26.7 \mathrm{~g} \quad \mathrm{NaH}_{2} \mathrm{PO}_{4}$ (Merck 6346)

$0.2 \mathrm{~g} \quad \mathrm{NaN}_{3}$

$2.0 \mathrm{~g} \quad$ Calfalbumin (Roth 8076)

$1.86 \mathrm{~g} \quad$ EDTA (Triplex III) (Merck 8418)

$1 \mathrm{ml} \quad$ TritonX100 (Sigma X-100)

$400.000 \quad$ KIE trasylol (Bayer)

$800 \mathrm{ml} \quad$ aqua dest $\mathrm{H}_{2} \mathrm{O}$

$\rightarrow$ adjust $\mathrm{pH}$ to 7.5 with $5 \mathrm{~N} \mathrm{NaOH}$

$\rightarrow$ adjust volume to 1 liter with aqua dest $\mathrm{H}_{2} \mathrm{O}$

TEAF Buffer: $1 \%$ formic acid with triethylamine, $\mathrm{pH} 3.0$ 


\subsubsection{Media}

\subsubsection{Media for $E . c o l i$}

LB-medium:

$10 \mathrm{~g}$

Bacto-Trypton

$5 \mathrm{~g} \quad$ Bacto Yeast-extract

$10 \mathrm{~g}$

$\mathrm{NaCl}$

$\rightarrow$ adjust volume to 1 liter with aqua dest $\mathrm{H}_{2} \mathrm{O}$, autoclave once

TY broth medium: $\quad 20 \mathrm{mg} \quad$ Bacto-Trypton

$5 \mathrm{~g} \quad$ Bacto Yeast-extract

$6 \mathrm{~g} \quad \mathrm{NaCl}$

$800 \mathrm{ml}$ aqua dest $\mathrm{H}_{2} \mathrm{O}$

$\rightarrow$ adjust $\mathrm{pH}$ to 7.0 with $\mathrm{NaOH}$

$\rightarrow$ adjust volume to 1 liter with aqua dest $\mathrm{H}_{2} \mathrm{O}$, autoclave once

TFB1:

$2.94 \mathrm{~g} \quad$ postassium acetate

$4.75 \mathrm{~g} \quad$ manganese chloride

$7.4 \mathrm{~g} \quad$ potassium chloride

$\rightarrow$ adjust $\mathrm{pH}$ to 5.8 with $0.2 \mathrm{M}$ acetic acide

$\rightarrow$ adjust volume to 1 liter with aqua dest $\mathrm{H}_{2} \mathrm{O}$, filtrate to sterilize

TFB2:

$4.194 \mathrm{~g} \quad$ sodium-MOPS

$8.325 \mathrm{~g} \quad$ calcium chloride

$0.74 \mathrm{~g} \quad$ potassium chloride

$200 \mathrm{ml} \quad$ Glycerol

$\rightarrow$ adjust volume to 1 liter with aqua dest $\mathrm{H}_{2} \mathrm{O}$, filtrate to sterilize

\subsubsection{Media for ES and Feeder cells}

Growth Medium for ES cells:

$500 \mathrm{ml}$ Dulbeccos' Modified Eagles Medium, high glucose, + Na-Pyruvate

$75 \mathrm{ml}$ Gibco-ES Fetal Calf Serum (FCS) (inactivated for $30 \mathrm{~min}$ at $56{ }^{\circ} \mathrm{C}$ )

$1 \mathrm{ml} \quad \beta$-Mercaptoethanol $500 \times\left(\right.$ Gibco) (aliquots $-20^{\circ} \mathrm{C}$ )

$5 \mathrm{ml} \quad$ Glutamine (aliquots at $-20^{\circ} \mathrm{C}$ )

$90 \mu \mathrm{l} \quad$ Leucocyte Inhibitor Factor (LIF) from Gibco for TBV2 cells 
Wash Medium:

contains already all supplements, but only $10 \%$ FCS and no LIF

Growth Medium for feeder cells:

$500 \mathrm{ml}$ DMEM high glucose

$57 \mathrm{ml} \quad$ FCS from PAA

$5.7 \mathrm{ml} \quad$ Glutamine

$5.7 \mathrm{ml} \quad$ non-essential Amino Acids

2 x Freezing Medium for ES and feeder cells:

$\begin{array}{ll}5 \mathrm{ml} & \text { FCS } \\ 3 \mathrm{ml} & \text { DMEM complete } \\ 2 \mathrm{ml} & \text { DMSO }\end{array}$

\subsubsection{Kit systems}

QIAquick Gel extraction kit (250) (QIAgen)

QIApre spin midiprep kit (250) (QIAgen)

QIAfilter Plasmid Maxi kit (25) (QIAgen)

QIAprep spin Midiprep kit (250) (QIAgen)

RNeasy Clean up kit (QIAgen)

pCRII-TOPO cloning kit (Invitrogen)

Radioimmune assay kits (ICN Biomedicals)

Quick Ligation kit (NEB)

Wizard® Genomic DNA Purification Kit (Promega)

Megaprime DNA labeling system (Amersham Bioscience) 


\subsubsection{Primers for cloning and sequencing}

Oligonucleotides were purchased from MWG (Ebersberg, Germany) and applied as primers for the following cloning PCR or Sequencing reactions.

Primers for cloning into pCR II-TOPO vector

\begin{tabular}{|c|c|c|}
\hline Primer name & Sequence (5-prime to 3-prime) & insert $[\mathrm{bps}]$ \\
\hline Notch-5 & TTAATTAACTCGACGGTATCG & \multirow{2}{*}{$282 \mathrm{bp}$} \\
\hline Notch-3 & TTCGGCCGGCAGCTTGGACTT & \\
\hline CRH-5 & TATAAGCGGCCGCCATGCGGCTGCGGCTGCT & \multirow{2}{*}{$620 \mathrm{bp}$} \\
\hline CRH-3 & TTAATTAATTGTGTGCTAAATGCAGAATC & \\
\hline ROSA26-5 F & TTCCTGCTACCAGG & \multirow[b]{2}{*}{$584 \mathrm{bp}$} \\
\hline ROSA26-5 R & ATAAGTGTGGGGCGGTGG & \\
\hline ROSA26-3 F & GTTGAGCCACTGAGAATGG & \multirow{2}{*}{$610 \mathrm{bp}$} \\
\hline ROSA26-3 R & ACAAACACTTCTACATGTCAG & \\
\hline
\end{tabular}

\section{Primers for genotyping}

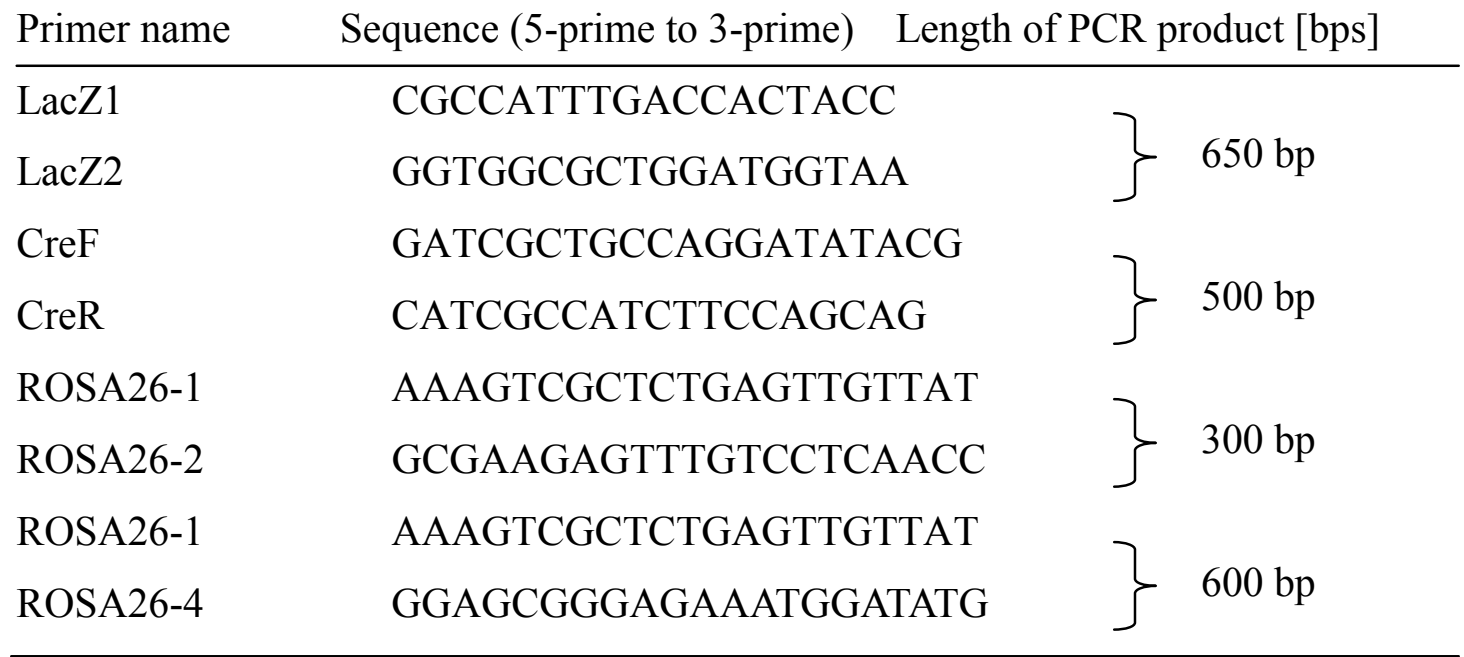

\section{Primers for sequencing}

\begin{tabular}{ll} 
Primer name & Sequence (5-prime to 3-prime) \\
\hline Rs-Con3 & GGAATGCAAGGTCTGTTGAA \\
Rs-Con4 & ATCAAGCTGATCCGGAACC \\
\hline
\end{tabular}




\subsubsection{Probes for Southern blot, Nothern blot and In situ}

Probes for Southern blot

Probe Restriction enzyme to isolate probe from plasmid Length of probe [bps]

\begin{tabular}{lll}
\hline ROSA26-5 & XhoI & $180 \mathrm{bp}$ \\
ROSA26-3 & EcoRI & $700 \mathrm{bp}$ \\
Cre & XbaI/MluI & $1500 \mathrm{bp}$ \\
\hline
\end{tabular}

Probes for Nothern blot

Probe Restriction enzyme to isolate probe from plasmid Length of probe [bps]

\begin{tabular}{lll}
\hline $\mathrm{CRH}$ & EcoRI & $700 \mathrm{bp}$ \\
$\mathrm{LacZ}$ & EcoRI & $800 \mathrm{bp}$ \\
\hline
\end{tabular}

Probes for in situ

Probe Orientation Restriction enzyme for linearization Vector RNA polymerase

\begin{tabular}{lllll}
\hline CRH & Antisense & SpeI & pCRII-TOPO & T7 \\
CRH & Sense & EcoRV & pCRII-TOPO & Sp6 \\
AVP & Antisense & HindIII & pCRII-TOPO & T7 \\
AVP & Sense & XhoI & pCRII-TOPO & Sp6 \\
CRH-R1 & Antisense & XbaI & pCRII-TOPO & T7 \\
CRH-R1 & Sense & XhoI & pCRII-TOPO & Sp6 \\
CRH-R2 & Antisense & XbaI & pCRII-TOPO & SP6 \\
CRH-R2 & Sense & BamHI & pCRII-TOPO & T7 \\
MR & Antisense & XhoI & pCRII-TOPO & SP6 \\
MR & Sense & BamHI & pCRII-TOPO & T7 \\
GR & Antisense & NotI & pCRII-TOPO & SP6 \\
GR & Sense & HindIII & pCRII-TOPO & T7 \\
\hline
\end{tabular}

\subsubsection{Cell lines}

Neomycin resistant embryonic mouse fibroblasts (EMFI) feeder cell (provided by S. Bourier, IDG/GSF).

TBV2 (129 SvP) ES cell (provided by S. Bourier, IDG/GSF). 


\subsubsection{Animals}

All animals were housed with a $12 \mathrm{~h} / 12 \mathrm{~h}$ light-dark cycle and allowed to access food and water ad libitum. CamKII $\alpha$-Cre mouse line and Nestin-Cre mouse line were obtained from R. Kuehn of IDG/GSF and R. Klein of MPI of Neurobiology, Martinstried (Tronche et al., 1999) respectively. 


\subsection{Methods}

\subsubsection{DNA preparation}

\subsubsection{Preparation of plasmid DNA}

E.coli cells containing plasmid DNA were usually grown, if not differently specified, in autoclave sterilized LB-medium with a selective specific antibiotic, ampicillin $(100 \mu \mathrm{g} / \mathrm{ml})$ or kanamycin $(30 \mu \mathrm{g} / \mathrm{ml})$, for overnight at $37^{\circ} \mathrm{C}$. Mini- $(5 \mathrm{ml}$ culture), medium- (25 ml culture) and large- (100 ml culture) scale preparations of plasmid DNA were carried out by means of the respectively Plasmid Mini-, Midi- and Plasmid Maxi-Kit from QIAgen, according to the provided enclosed protocol. Elution from the column was performed with water.

To elute large DNA fragments $(>15 \mathrm{~kb})$ from the QIAgen column, pre-warmed $\left(70{ }^{\circ} \mathrm{C}\right) \mathrm{QE}$ buffer was applied.

\subsubsection{Preparation of genomic DNA}

\subsubsection{Mouse genomic DNA preparation from tail}

$1-1.5 \mathrm{~cm}$ of mouse tail tips from at least 3 -week old mice were cut. They were used directly or were frozen at $-20^{\circ} \mathrm{C}$ until used. DNA was prepared with the Wizard Genomic DNA Purification kit from Promega according to the enclosed protocol (see 2.1.3).

\subsubsection{Mouse genomic DNA preparation from tissue}

Tissue was dissected, chopped into pieces and placed it in $1 \mathrm{ml}$ of SDS/proteinase $\mathrm{K}$ buffer (see 2.1.1.4.) per $100 \mathrm{mg}$ of tissue. The mixture was pipetted up and down several times. Lysed tissue was shaked for 30-45 min gently at $50{ }^{\circ} \mathrm{C}$ and pipetted up and down from time to time, then $25 \mu \mathrm{g} / \mathrm{ml}$ RNAase was added for 15-20 min at 37 ${ }^{\circ} \mathrm{C} .1 \mathrm{vol}$ of phenol /chloroform $(1: 1, \mathrm{v} / \mathrm{v})$ was added to the clear lysate, vortexed for 1 min and centrifuged for $5 \mathrm{~min}$ at $8,000 \mathrm{~g}$. The supernatant was transfered to a new tube and this step was repeated once more. The step once was repeated with chloroform/isoamylalcohol $(24: 1, \mathrm{v} / \mathrm{v})$ alone. The supernatant was transfered to a new tube. $0.1 \mathrm{vol}$ of $3 \mathrm{M}$ sodium acetate and $2.5 \mathrm{vol}$ of pre-cooled pure ethanol were added to the aqueous phase, mixed gently but thoroughly and centrifuged at 8,000 $\mathrm{g}$ for 15 $\min$ at $4{ }^{\circ} \mathrm{C}$. The supernatant was removed carefully and washed the pellet with $75 \%$ Ethanol, centrifuged again for $2 \mathrm{~min}$, aspirated off the ethanol and repeated this step 
four times. The pellet was dried in air and resuspended the pellet thoroughly in TE buffer. To facilitate solubilization, DNA was shaken gently at $65^{\circ} \mathrm{C}$ for several hours.

\subsubsection{RNA preparation}

Total RNA was isolated from ES cells using TRIZOL (Chomczynski and Sacchi, 1987). In brief, cells were lysed directly in a culture dish by adding $3 \mathrm{ml}$ of TRIZOL reagent to a $10 \mathrm{~cm}$ diameter dish, and the cell lysate was passed several times through a pipette. The homogenized samples were incubated for $5 \mathrm{~min}$ at room temperature to permit the complete dissociation of nucleoprotein complexes. $0.2 \mathrm{ml}$ of chloroform per $1 \mathrm{ml}$ TRIZOL Reagent was added. Sample tubes were capped securely. Tubes were shaked vigorously by hand for $15 \mathrm{~s}$ and were incubated at room temperature for 2-3 min. Then samples were centrifuged at 4,000 rpm for $25 \mathrm{~min}$ at $4{ }^{\circ} \mathrm{C}$. Following centrifugation, the mixture was separated into a lower red phenol-chloroform phase, an interphase, and a colorless upper aqueous phase. RNA remained exclusively in the aqueous phase. The aqueous phase was transfered to a fresh tube, $0.5 \mathrm{ml}$ of isopropanol per $1 \mathrm{ml}$ of TRIZOL Reagent used for the initial homogenization to precipation RNA was added. Samples were incubated at room temperature for $10 \mathrm{~min}$ and centrifuged at $4,000 \mathrm{rpm}$ for $10 \mathrm{~min}$ at $4{ }^{\circ} \mathrm{C}$. The RNA precipitate formed a gellike pellet on the side and bottom of the tube. The supernate was removed, the RNA pellet was washed once with $75 \%$ Ethanol, adding at least $1 \mathrm{ml}$ of $75 \%$ Ethanol per 1 $\mathrm{ml}$ of TRIZOL Reagent used for the initial homogenization. The samples were mixed by vortexing and centrifuged at $4,000 \mathrm{rpm}$ for $5 \mathrm{~min}$ at $4{ }^{\circ} \mathrm{C}$. The RNA pellet was left in air for 20-30 min, then dissolved in RNase-free water by passing the solution a few times through a pipette tips, and incubated for $10 \mathrm{~min}$ at $60^{\circ} \mathrm{C}$.

\subsubsection{Restrict digestion of DNA samples}

Restriction digestion of DNA was performed for screening of plasmid clones and related orientation analysis, for Southern blot analysis of genomic DNA, and for isolation and preparation of DNA fragments in cloning procedures. Restriction enzymes from the following suppliers were used, Gibco BRL, Roche, New England Biolabs (NEB). Enzyme units to use were empirically determined for each reaction and working buffers were chosen in accordance to the information provided by the 
suppliers. Incubations took place, if not differently specified, for a minimum time of 30 min up to overnight at $37^{\circ} \mathrm{C}$ or at temperature recommended by the supplier.

\subsubsection{DNA Gel Electrophoresis}

Conventional gel electrophoresis for separation of DNA molecules in the range of $100 \mathrm{bp}-20 \mathrm{~kb}$ was usually performed on $1 \%$ agarose gels (Ultra Pure Agarose, Invitrogen BRL) in $1 \mathrm{x}$ TAE or $1 \mathrm{x}$ TBE buffer (see 2.1.1.1.1.). The agarose percentage was adjusted between $0.8 \%$ and $2 \%$ according to the desired separation range for specific purposes as described in the single cases. For separation of DNA molecules between $80 \mathrm{bp}$ and $200 \mathrm{bp}, 1.5-2 \%$ agarose gels were performed. The Gel run was performed with variable time and voltage conditions according to the separation range and agarose percentage using an electrophoresis power supply (Pharmacia Biotech). For size comparison, a DNA molecular weight marker was loaded on the gel next to the samples (SmartLadder, Eurogentec, or 100 bp Ladder, Gibco BRL). DNA was stained with the intercalating fluorescent reagent ethidium bromide (EtBr), which was added in the gel before solidification at the concentration of $0.5 \mu \mathrm{g} / \mathrm{ml}$. Stained DNA was visualized on a UV-transilluminator at a wavelength of $254 \mathrm{~nm}$ and photographed with a gel documentation apparatus.

\subsubsection{Cloning and Transformation}

\subsubsection{Competent cells preparation and transformation}

Chemically competent E.coli cells (DH5 $\alpha$ ) were prepared as following. One single colony from an LB-Agar plate was inoculated into $2 \mathrm{ml} \mathrm{LB}$ and grew overnight at $37{ }^{\circ} \mathrm{C}$. On the next day, $500 \mu \mathrm{l}$ of starter culture was transferred into $100 \mathrm{ml} \mathrm{LB}$ medium and shaked at $37{ }^{\circ} \mathrm{C}$ until cell density reached an optical density (OD600) between 0.4 and 0.6. Growth was stopped by placing the culture on ice for $15 \mathrm{~min}$. The cells were subsequently centrifuged at $2,500 \mathrm{rpm}$ for $5 \mathrm{~min}$ at $4{ }^{\circ} \mathrm{C}$ and the pellet was resuspended in $25 \mathrm{ml}$ TFB1 (see 2.1.2.1.), left on ice for $1 \mathrm{~h}$, cells were spun down at 2,000 rpm for $5 \mathrm{~min}$ at $4{ }^{\circ} \mathrm{C}$, then were resuspended in $4 \mathrm{ml} \mathrm{TFB} 2$ (see 2.1.2.1.) and left on ice for $1 \mathrm{~h}$ before use. Finally, cells were split in $100 \mu 1$ aliquots, snap frozen in liquid nitrogen and stored at $-80{ }^{\circ} \mathrm{C}$. For transformation, $100 \mu 1$ cell aliquots were thawed on ice and incubated for $30 \mathrm{~min}$ on ice with up to $10 \mu 1$ of a 20 $\mu 1$ ligation mix or 1 to $10 \mathrm{ng}$ of plasmid DNA for retransformation. 
For uptake of plasmid DNA, the cells were heat-shocked at $42{ }^{\circ} \mathrm{C}$ for $45 \mathrm{~s}$ and subsequently put on ice for $5 \mathrm{~min}, 950 \mu \mathrm{SOC}$ medium was added and cells were incubated shaking at $37^{\circ} \mathrm{C}$ for $30 \mathrm{~min}-1$ h. $100 \mu \mathrm{l}$ of cells were plated on LB plates of supplemented with $15 \%$ agar and the appropriate antibiotic for selection. Plates were then incubated overnight at $37^{\circ} \mathrm{C}$, if not differently required. Single colonies were picked and inoculated in LB medium with appropriate antibiotic and grown overnight at $37{ }^{\circ} \mathrm{C}$ for DNA mini-prep analysis (see 2.1.3.).

In the case of utilizing pCRII-TOPO TA cloning (Invitrogen), blue-white selection of the colonies was possible. For this purpose, LB-Agar plates were previously added with $40 \mu \mathrm{l}$ of $40 \mathrm{mg} / \mathrm{ml} \mathrm{X-Gal} \mathrm{in} \mathrm{dimethylformamide} \mathrm{(DEMF)}$ solution. White colonies after $37{ }^{\circ} \mathrm{C}$ overnight incubation were picked for screening. Bacterial clones were stored as glycerol stocks at $-80{ }^{\circ} \mathrm{C}(250 \mu 1$ volume bacterial culture $+750 \mu 1$ volume autoclaved $80 \%$ glycerol). Blue-white selection is also possible for other vectors, for example, pBluescript II KS(+) and pBluescript II KS(-).

\subsubsection{Cloning}

PCR products with A-overhangs, obtained from amplification with Taq DNA polymerase, were cloned into the pCRII-TOPO vectors (Invitrogen) according to the provided protocol. Cloning of DNA fragments obtained from restriction digestion was accomplished into linearized plasmid vectors with compatible ends. If vector ends were compatible to each other, appropriate 5 '-end dephosphorylation was executed by incubation with 1 unit of Alkaline Phosphatase (Calf Intestinal Phosphatase (CIP) (NEB)) for $1 \mathrm{~h}$ at $37{ }^{\circ} \mathrm{C}$, with subsequent purification by means of the QIAquick Gel Extraction Kit (QIAgen) (see 2.1.3.) according to the provided protocol. Ligations were performed in a molecular ratio of insert and vector 6:1 using the quick ligation Kit (NEB).

\subsubsection{Polymerase Chain Reaction (PCR)}

This technique for DNA amplification has several different applications: e.g. production of DNA fragments for subcloning, checking of correctness of clone constructs, probe synthesis, gene expression analysis and genotyping of mice. According to the specific purpose, PCR amplifications are realized from various types of template: genomic DNA, first strand cDNA and cloned DNA, like plasmids. 
Moreover, different types of DNA polymerases were chosen. In general, when no subcloning of the PCR product was required, a normal Taq polymerase was employed from Roche. In general, if not differently specified, PCR reaction mixes were set up as following:

$$
\begin{array}{ll}
10 \mu \mathrm{l} & 10 \mathrm{x} \text { PCR buffer, } \\
2 \mu \mathrm{l} & 10 \mathrm{mM} \mathrm{dNTP}, \\
2 \mu \mathrm{l} & 10 \mathrm{pmol} / \mu \mathrm{l} \text { each primer } \\
50 \mathrm{ng} & \text { template DNA } \\
0.5 \mu \mathrm{l} & 5 \mathrm{u} / \mu \mathrm{l} \text { of Taq polymerase (Roche) } \\
\mathrm{x} \mu \mathrm{l} & \mathrm{H}_{2} \mathrm{O} \\
\hline 100 \mu \mathrm{l} & \text { total volume }
\end{array}
$$

\section{PCR reaction were performed with the following standard program}

PCR-cycling:

\begin{tabular}{lll} 
1. & $95{ }^{\circ} \mathrm{C}$ & $5 \mathrm{~min}$ \\
\hline 2. & $95{ }^{\circ} \mathrm{C}$ & $30 \mathrm{sec}$ \\
3. & $57{ }^{\circ} \mathrm{C}$ & $30 \mathrm{sec}$ \\
4. & $72{ }^{\circ} \mathrm{C}$ & $1 \mathrm{~min} / \mathrm{kb}$ \\
\hline \multicolumn{2}{l}{ Repeated steps 2 to 4 for 30 to 35 times } \\
5. & $72{ }^{\circ} \mathrm{C}$ & 7 min \\
6. & $4{ }^{\circ} \mathrm{C}$ & forever
\end{tabular}

If the PCR product was cloned, the proofreading (Pfu) DNA polymerase was used (Gibco, BRL), mixed with Taq polymerase (3:7).

\subsubsection{Southern blot}

\subsubsection{Blotting of gels onto nylon membranes}

This method was used for transferring DNA from agarose gel onto nylon membranes for subsequent hybridization with specific probes. Electrophoresis was executed at low voltage overnight ( $40 \mathrm{v}$ for 19-24 h) to ensure a better separation of the bands. DNA was denatured by bathing the gel $2 \times 15$ min in denaturation buffer (not longer) (see 2.1.1.2.), which was bathed for $2 \times 15 \mathrm{~min}$ in neutralization buffer (see 2.1.1.2.), equilibrated for at least $10 \mathrm{~min}$ in $20 \mathrm{x}$ SSC (see 2.1.1.2.). Finally the right-up corner of the gel was cut and the nylon membrane was marked with necessary information with a pencil and also the right-up corner of the membrane was 
cut. The nylon membrane (Hybond N+, Amersham) and Whatman $3 \mathrm{MM}$ filter paper were prewetted in fresh $20 \mathrm{x}$ SSC (see 2.1.1.2.). The gel (facing down) was blotted onto Whatman $3 \mathrm{MM}$ filter paper, then the nylon membrane was put onto the Gel with alignment of the corners of Gel and membrane, then $2 \times$ Whatman 3 MM paper were put onto the nylon membrane. Any air bubbles between the gel, the membrane and Whatman $3 \mathrm{MM}$ filter paper were removed. The gel was blotted as depicted in figure 4 for overnight (12-16 h, not more than $24 \mathrm{~h}$ ), and immobilized by UV cross-linking (UV Stratalinker ${ }^{\circledR} 2400$; Stratagene).

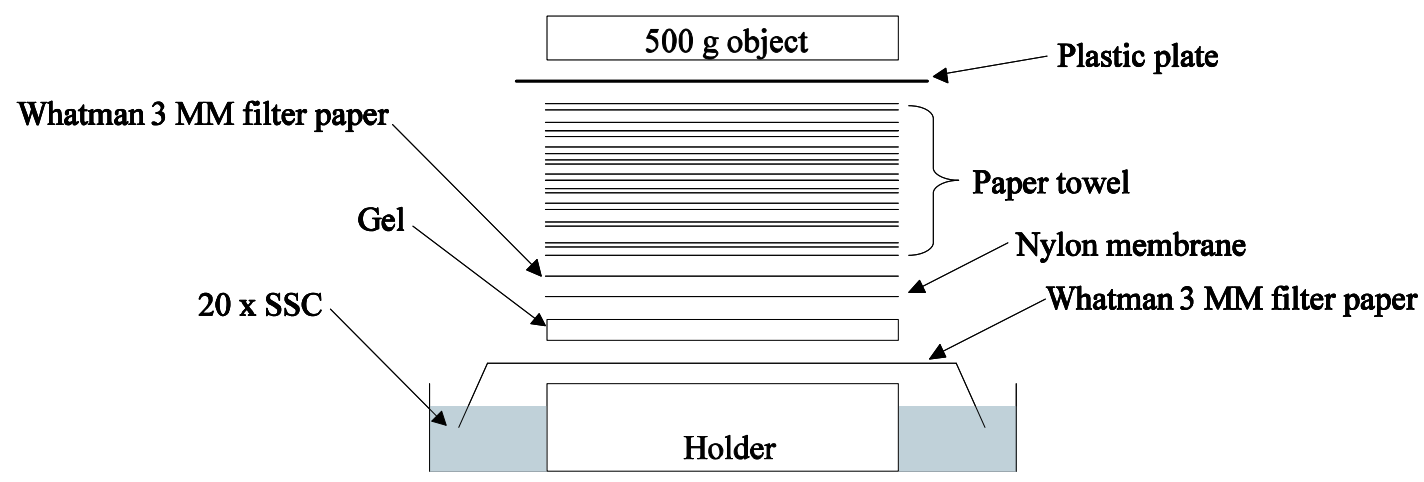

Figure 4 . Transfering DNA from agrose gel to Nylon membrane.

\subsubsection{Probe labeling}

25-50 ng of DNA probe were labeled with $50 \mu \mathrm{Ci} \alpha-{ }^{32} \mathrm{P}-\mathrm{dCTP}$ (Amersham) by means of the Megaprime DNA Labeling Kit (Amersham) (see 2.1.3.) according to the manufacture's instructions. The labeled probe was purified from free nucleotides through MicroSpin S-300 HR Columns (Pharmacia). The efficiency of labeling was checked by liquid scintillation counting of Ersicount 400 .

\subsubsection{Hybridization and washing}

Prehybridization was carried out at $65{ }^{\circ} \mathrm{C}$ for $30 \mathrm{~min}$ in rapid-hyb buffer (Amersham). Radiolabeled linearized DNA probes were denatured for $5 \mathrm{~min}$ at $95^{\circ} \mathrm{C}$. Hybridization was carried out for 2-3 h at $65{ }^{\circ} \mathrm{C}$ in rapid-hyb buffer (Amersham). Blots were washed once in $2 \times \mathrm{SSC}, 0.1 \%$ SDS for $20 \mathrm{~min}$, in $0.2 \times \mathrm{SSC}, 0.1 \% \mathrm{SDS}$ for $2 \times 15 \mathrm{~min}$ at $65^{\circ} \mathrm{C}$. Blots were exposed to a x-ray Kodak Biomax film with intensifying screens for $1-2$ days at $-80{ }^{\circ} \mathrm{C}$. If the membrane was to be reused for hybridization with a different probe, the old probe was removed by bringing the 
membrane to boil in $0.1 \%$ SDS for $10 \mathrm{~min}$ and let it cool down to room temperature. After rinsing with $2 \times \mathrm{SSC}$, the membrane was ready to be used again.

\subsubsection{Colony Hybridization}

Hybond $\mathrm{N}+$ (Amersham) membranes were laid for 1 min onto agar plates with E.coli colonies for transfer. In the meanwhile they were marked with reference ink dots. Subsequently the membranes were laid twice facing up on denaturalization buffer (see 2.1.1.2.) for $10 \mathrm{~min}$ and similarly twice on neutralization buffer (see 2.1.1.2.) for $10 \mathrm{~min}$, once on $2 \mathrm{x} \mathrm{SSC}$ for $5 \mathrm{~min}$ (the excessive solution was each time drained with Whatman paper to avoid washing off the colonies). Then they were let dry, immobilized by UV cross-linking (UV Stratalinker® 2400; Stratagene) and used for hybridization.

The following procedure was the same as for Southern blot (see 2.2.7.), but exposure time to the $\mathrm{x}$-ray Kodak Biomax film was for only 30 min to $2 \mathrm{~h}$.

\subsubsection{Northern blot}

Formaldehyde denaturing gels were prepared with a 0.8-1.0\% agarose concentration. Agarose was dissolved in $1 \times$ MOPS buffer and cooled down to about $50{ }^{\circ} \mathrm{C}$ before addition of formaldehyde to a final concentration of 2.2 M. 5-10 $\mu$ g RNA samples were diluted in $22 \mu 1$ RNA loading buffer (see 2.1.1.1.2.) and heated up to 65 ${ }^{\circ} \mathrm{C}$ for $15 \mathrm{~min}$ in order to release RNA secondary structures. After running $4-6 \mathrm{~h}$ at 60-80 $\mathrm{V}$ in $1 \mathrm{x}$ MOPS buffer, the gel was photographed, equilibrated in $20 \mathrm{x}$ SSC for $15 \mathrm{~min}$ and blotted overnight (12-16 h, not more than $24 \mathrm{~h}$ ) onto nylon membranes (Hybond N+, Amersham) as described for Southern blot (Figure 4). The RNA was immobilized by UV cross-linking (UV Stratalinker® 2400; Stratagene).

Hybridization and washing was carried out as described above for Southern blotting (see 2.2.7.), but hybridization time was at least $4 \mathrm{~h}$ or overnight. 


\subsubsection{In situ hybridization}

\subsubsection{Tissue preparation}

All animal experiments were conducted in accordance with the guide for the care and use of laboratory animals of the government of Bavaria, Germany. 3-5 months old mice were anesthetized with Isoluran and brains were transcardially perfused with $4 \%$ PFA.

To prepare cryosections, the brains were shock frozen on dry ice directly after removal, and used directly or stored at $-80{ }^{\circ} \mathrm{C}$ prior to sectioning. Frozen brains were mounted on Tissue Tek (Polysciences, PA, USA), and $20 \mu \mathrm{M}$-thick consecutive sections were cut from brain regions of interest on a cryostat (Microtrome HM 560, Microm). Sections were mounted onto frozen SuperFrost/plus slides (Fisher Scientific), dried on a $37{ }^{\circ} \mathrm{C}$ warming plate and stored at $-20{ }^{\circ} \mathrm{C}$ until used (for longer storage, sections were frozen into $-80{ }^{\circ} \mathrm{C}$ ).

To prepare paraffin sections, the brains were post-fixed in $4 \%$ PFA for $4-5 \mathrm{~h}$, then dehydrated by immersing the brain into series of Ethanol: $2 \times 1 \mathrm{~h}$ in $70 \%$ Ethanol, $2 \times 1 \mathrm{~h}$ in $90 \%$ Ethanol, $2 \times 1.5 \mathrm{~h}$ in $95 \%$ Ethanol, $2 \times 1.5 \mathrm{~h}$ in $100 \%$ Ethanol, 2-3 x $1.5 \mathrm{~h}$ in Xylol until the brains were clear. Then the brain was embedded with paraffin. Paraffin embedded brains were cut into $8 \mu \mathrm{m}$-thick sections on a microtome. Sections were mounted onto frozen SuperFrost/plus slides (Fisher Scientific), dried on a $37{ }^{\circ} \mathrm{C}$ warming plate and then the slides were put in $37{ }^{\circ} \mathrm{C}$ incubator overnight. Sections were stored at $4{ }^{\circ} \mathrm{C}$ until used.

\subsubsection{Probe synthesis}

Radioactive $\left.{ }^{35} \mathrm{~S}\right)$ labeled riboprobes were used. The majority of probes were generated from DNA as templates cloned into pCRII-TOPO vector with the T3, T7 or Sp6 promotor. The identity of all clones used for ISH was checked by sequencing. Linearized template DNA was precipitated by $1 / 10$ vol $3 \mathrm{M} \mathrm{NaAc}$ and 2 vol $100 \%$ Ethanol and resuspended in DEPC- $\mathrm{H}_{2} \mathrm{O}$ at a concentration of $1 \mu \mathrm{g} / \mu \mathrm{l}$. The template DNA was stored at $-20{ }^{\circ} \mathrm{C}$ until used. For ${ }^{35} \mathrm{~S}$-labeled riboprobes, in vitro transcription was carried out for $3 \mathrm{~h}$ at $37{ }^{\circ} \mathrm{C}$ in a total volume of $42 \mu \mathrm{lmix}$ as following: 


\begin{tabular}{ll}
$\mathrm{x} \mu \mathrm{l}$ & linearized plasmid DNA template $(1.5 \mu \mathrm{g}$ DNA) \\
$\mathrm{y} \mu \mathrm{l}$ & DEPC- $\mathrm{H}_{2} \mathrm{O}$ \\
\hline $30 \mu \mathrm{l}$ & total volume \\
$3 \mu \mathrm{l}$ & $10 \mathrm{x}$ transcriptions buffer \\
$3 \mu \mathrm{l}$ & $\mathrm{NTP}-\mathrm{mix}(\mathrm{rATP} / \mathrm{rCTP} / \mathrm{rGTP} 10 \mathrm{mM}$ each $)$ \\
$1 \mu \mathrm{l}$ & $0.5 \mathrm{M}$ DTT \\
$1 \mu \mathrm{l}$ & RNasin $(40 \mathrm{u} / \mu 1$; Promega $)$ \\
$3 \mu \mathrm{l}$ & ${ }^{35}$ S-thio-rUTP (Amersham) \\
$1 \mu \mathrm{l}$ & T7, T3 or SP6 RNA polymerase $(20 \mathrm{u} / \mu \mathrm{l})$ \\
\hline $42 \mu \mathrm{l}$ & total volume
\end{tabular}

Reactions were treated with 20 units of RNase free DNaseI (Roche Molecular Diagnostics) for $15 \mathrm{~min}$ at $37{ }^{\circ} \mathrm{C}$, and labeled probes were purified by column exchange (Nucleotide removal kit, QIAgen). Suitable restriction enzymes (NEB, Roche) were used for linearization and the corresponding RNA polymerases T3, T7 or Sp6 (Roche Molecular Diagnostics) were used in order to get labeled antisense and sense riboprobes, respectively, of the cloned insert. In ISH experiments, sense controls did not give any detectable signals (data not shown), and antisense probes gave distribution patterns identical to those already published in rat or mouse.

\subsubsection{In situ hybridization}

For paraffin sections, slides were dewaxed in Rotihistol for $2 \times 15$ min, rinsed in $100 \%$ Ethanol for $2 \times 5 \mathrm{~min}$, in $70 \%$ Ethanol for $5 \mathrm{~min}$, in $\mathrm{DEPC}-\mathrm{H}_{2} \mathrm{O}$ for $3 \mathrm{~min}$, in PBS/DEPC for $3 \mathrm{~min}$. The slides were postfixed in $4 \% \mathrm{PFA} / \mathrm{PBS}$ (on ice) for $20 \mathrm{~min}$, and rinsed in PBS/DEPC for $2 \times 5 \mathrm{~min}$, followed by proteinase $\mathrm{K}$ treatment in proteinase-K buffer $(20 \mu \mathrm{g} / \mathrm{ml})$ for $7 \mathrm{~min}$. Slides were rinsed in PBS/DEPC again for $5 \mathrm{~min}$, and fixed in $4 \% \mathrm{PFA} / \mathrm{PBS}$ for $20 \mathrm{~min}$.

For cryosections, slides were warmed up for at least $30 \mathrm{~min}$ at room temperature, fixed in ice-cold $4 \%$ PFA/PBS for $10 \mathrm{~min}$, washed them for $3 \times 5 \mathrm{~min}$ in $1 \mathrm{x}$ PBS.

Both kinds of slides were incubated for $10 \mathrm{~min}$ in $0.1 \mathrm{M}$ triethanolamine- $\mathrm{HCl}(\mathrm{pH}$ 8.0 ) to which $0.6 \mathrm{ml}$ of acetic anhydride was added dropwise. Slides were rinsed in 2 x SSC for 2 x 5 min, dehydrated in graded series of Ethanol: in $60 \%, 75 \%, 95 \%$ and $100 \%$ Ethanol for $1 \mathrm{~min}$ respectively, delipidized in chloroform for $1 \mathrm{~min}$, rinsed in $100 \%$ and $95 \%$ Ethanol for 1 min respectively again, and air-dried. Hybridization 
was carried out overnight $(12-16 \mathrm{~h})$ at $57^{\circ} \mathrm{C}$ in $90-100 \mu$ l of hybridization buffer (see 2.1.1.6.) containing the respective ${ }^{35} \mathrm{~S}$-labeled riboprobe $(35,000-70,000$ c.p.m./ $\mu \mathrm{l})$. After incubation in a humid chamber, slides were rinsed 4 x 5 min in 4 x SSC at room temperature, incubated for $20 \mathrm{~min}$ at $37^{\circ} \mathrm{C}$ in $20 \mu \mathrm{l} / \mathrm{ml}$ of RNaseA in NTE buffer (see 2.1.1.6.), rinsed at room temperature in decreasing concentrations of SSC $(2 \times 5 \mathrm{~min}$ in $2 \mathrm{x} \mathrm{SSC}, 10 \mathrm{~min}$ in $1 \mathrm{x} \mathrm{SSC}, 10 \mathrm{~min}$ in $0.5 \mathrm{x} \mathrm{SSC}$ ) containing $1 \mathrm{mM}$ DTT, washed for $2 \times 30 \mathrm{~min}$ at high stringency in $0.1 \times \mathrm{SSC} / 1 \mathrm{mM}$ DTT at $64{ }^{\circ} \mathrm{C}, 2 \times 10 \mathrm{~min}$ at room temperature in $0.1 \times \mathrm{SSC}$. At this point, ${ }^{35} \mathrm{~S}$-labeled slides were dehydrated in graded ethanol series: $30 \%, 50 \%, 70 \%, 95 \%$ and $2 \times 100 \%$ Ethanol in $300 \mathrm{mM}$ $\mathrm{NH}_{4} \mathrm{OAC}$ for $1 \mathrm{~min}$ respectively, air-dried and exposed to x-ray Kodak Biomax film (Kodak, Germany). On the next day, slides were dipped in photographic emulsion (NTB-2 from Kodak, diluted 1:1 in distilled water). After exposure for 4-5 weeks at 4 ${ }^{\circ} \mathrm{C}$, slides were developed for 3 min (D-19, Kodak) in developing solution, fixed for 6 min in fixing solution (Kodak fixer), rinsed for $25 \mathrm{~min}$ in tap water and air-dried. Slides were mounted in histofluid (Marienfeld, Lauda-Königshofen).

Semi-quantitative analysis of mRNA levels was performed blind to genotype using NIH Image (http://rsb.info.nih.gov/nih-image/. At least three serial tissue sections per animal and region were analyzed. In the case of CRH-R1, CRH-R2 and GR mRNA, CA1, CA3 and DG were analyzed.

\subsubsection{ES and Feeder cells culture}

\subsubsection{Preparation of EMFI feeder cells plate}

A frozen vial of EMFI cells was thawed quickly at $37{ }^{\circ} \mathrm{C} .10 \mathrm{ml}$ DMEM complete was added and centrifuged at 1,200 rpm for $5 \mathrm{~min}$. The cell pellet was resuspended gently in $10 \mathrm{ml}$ DMEM complete and cells were split onto $3 \mathrm{x} 15 \mathrm{~cm}$ plates each containing a total of $25 \mathrm{ml}$ DMEM complete. The cells were incubated at $37{ }^{\circ} \mathrm{C}, 5 \% \mathrm{CO}_{2}$ for 3 days. Medium was removed from the plates and $15 \mathrm{ml}$ DMEM complete containing $150 \mu \mathrm{l}$ Mitomycin C (MMC) $(1 \mathrm{mg} / \mathrm{ml})$ was added, plates were swirled to ensure an even distribution of the medium, the cells were incubated at 37 ${ }^{\circ} \mathrm{C}, 5 \% \mathrm{CO}_{2}$ for $2.5 \mathrm{~h}$ (not longer). The monolayer was washed twice with about 10 $\mathrm{ml}$ PBS and $7.5 \mathrm{ml}$ trypsin/ EDTA was added to each plate, plates were incubated for about $5 \mathrm{~min}$ at $37^{\circ} \mathrm{C}$ until the cells came off the plate, cell suspension was pipetted up and down for 3 times to break any cell aggregates, the cell solution was transfered to 
complete medium in a FALCON tubes, containing at least the same amount medium as Trypsin volume. The cells were centrifuged and the pellet was resuspended in DMEM complete, $7.5 \mathrm{ml}$ per $15 \mathrm{~cm}$ diameter plate, a cell suspension of $2.0 \times 10^{5}$ cells/ml was made. The cells were plated immediately on new dishes, containing DMEM complete, the best concentration was $1.0 \times 10^{4}$ cells $/ \mathrm{cm}^{2}$ for TBV2 cells. The feeder cells were allowed to attach overnight for best results or used at least $3 \mathrm{~h}$ later. The medium was changed to ES cell medium before adding ES cells. $1.5 \mathrm{x}$ concentrated cell suspension was used for the Multi-well plates.

\subsubsection{ES cell culture}

The TBV2 ES cells were applied for electroporation of the targeting vector and functional analysis. One vial frozen ES cells was thawed and transfered to a FALCON tube containing $10 \mathrm{ml}$ ES cell medium without LIF for washing, cells suspension was centrifuged at 1,200 rpm for $5 \mathrm{~min}$, cells pellet was resuspended in $5 \mathrm{ml}$ ES cell medium containing LIF and plated onto one $6 \mathrm{~cm}$ dish with EMFI cells, medium was changed next day. The cells was washed with PBS on the third day and $1.5 \mathrm{ml}$ Trypsin/EDTA was added for $10 \mathrm{~min}$ until the cells began to get detached $\left(37^{\circ} \mathrm{C}, 5 \%\right.$ $\mathrm{CO}_{2}$ ). The cells were gently pipetted up and down to get a single cell suspension, 10 $\mathrm{ml}$ of ES cell medium without LIF was added and the cells was centrifuged for $5 \mathrm{~min}$ at 1,200 rpm, supernatant was aspirated and cells were resuspended in ES cell medium with LIF. About $2 \times 10^{6}$ cells per $10 \mathrm{~cm}$ diameter dish were plated to a fresh $10-\mathrm{cm}$ diameter feeder plate or on gelatinized plates with $0.1 \%$ gelatin containing 9 ml ES cell medium (dilution 1:3) for freezing or further electroporation respectively.

\subsubsection{Electroporation}

ES cells were counted and prepared according to the calculation of $1 \times 10^{8}$ cells /electroporation/500 $\mu$ l cold PBS. $120 \mu 1$ of the linearized targeted ROSA26 construct DNA $(120 \mu \mathrm{g})$ was added to cell suspension, not more than $900 \mu$ totally (Vector linearization: digested with SwaI, concentration: $1 \mu \mathrm{g} / \mu \mathrm{l})$. Cell suspension was transfered to the electroporation cuvette (BioRad cuvette). The cuvette was transfered into the cuvette holder with electrodes facing the output leads and electric pulse was delivered on $0.8 \mathrm{kV}, 3 \mu \mathrm{F}$ for the Bio Rad gene pulser about $0.1 \mathrm{msec}$ (push both red pulse buttons). Cuvette was removed from the cuvette holder and left on ice for 10 to 
$20 \mathrm{~min}$. The cell suspension was transfered from one cuvette very carefully into $12 \mathrm{ml}$ ES cell medium containing LIF and distributed onto $12 \mathrm{x}$ gelatinized with $0.1 \%$ gelatin 10-cm diameter plates containing already $9 \mathrm{ml}$ medium with LIF. Medium was changed the next day (supplemented with LIF). Two days after electroporation, the drugs for selection (G418 $200 \mu \mathrm{g}$ (inactive)/ml) (in addition to LIF) was added, one plate was prepared for control that would receive only G418 for selection. After about 6-8 days of selection, drug resistant colonies $\left(\mathrm{G} 418^{\mathrm{r}}\right)$ appeared and were ready for analysis. Colonies were picked into 96-well feeder cell coated plates and then resistant colonies were passaged until onto $2 \mathrm{x}$ gelatinized and $2 \mathrm{x}$ feeder cell coated 96-well plates, freezed $2 \times$ feeder cell coated 96 -well plates in $-80^{\circ} \mathrm{C}$.

\subsubsection{Screening for positive (homologously recombined) clones from Electroporated ES cells}

When the cells were ready for DNA extraction procedure, the cell plates were rinsed twice with PBS and $50 \mu$ lysis buffer per well was added (see 2.1.1.3.), the plates were incubated overnight at $50{ }^{\circ} \mathrm{C}$ in a humid atmosphere. The next day, the plates were spun down for $2 \mathrm{~min}$ at 2,500 rpm, then $100 \mu \mathrm{l}$ per well of a mixture of $\mathrm{NaCl}$ and ethanol $(150 \mu \mathrm{l}$ of $5 \mathrm{M} \mathrm{NaCl}$ to $10 \mathrm{ml}$ of cold absolute Ethanol) was added for precipitating DNA using a multichannel pipettor. The 96-well plate was being shaked for $30 \mathrm{~min}$ at room temperature, spun down again. The plate was inverted carefully to discard the solution, the nucleic acids was remained attached to the plate. The excess liquid was blotted on paper towels. The nucleic acids was rinsed 3 times by dripping $150 \mu \mathrm{l}$ of $75 \%$ Ethanol per well using the multichannel pipettor. The cell plates were spun down and the alcohol was discarded carefully by inverting of the plate each time. After the final washing, the plates were inverted and allowed to dry on the bench. The DNA was ready to be cut with restriction enzymes. $30 \mu \mathrm{l}$ of restriction digest mix was added per well with a multichannel pipettor, the contents of the well was mixed using the pipette tip and the reaction was incubated at $37{ }^{\circ} \mathrm{C}$ for overnight in a humid atmosphere. Gel electrophoresis loading buffer was added to the samples and proceeded to conventional electrophoresis. DNA was transfered to Nylon membranes as described for Southern blot (Figure 4), immobilized by UV crosslinking (UV Stratalinker® 2400; Stratagene) and did Southern blot. 


\subsubsection{Transient transfection with pCre-Pac plasmid}

The functionality of the strategy was tested in ES cells. In order to remove the transcriptional terminator sequence, targeted ES cell clones were transfected transiently with a Cre-recombinase expression plasmid - pCre-Pac plasmid (Taniguchi et al., 1998). Transfected clones were analyzed for LacZ reporter gene expression by X-Gal staining (see 2.2.17.). Cells were seeded the day before transfection onto $10-\mathrm{cm}$ feeder cell dishes with $2 \times 10^{5}$ cells/dish. DNA mixture was prepared as following, distributed carefully and incubated it for $30 \mathrm{~min}$ at room temperature. DNA mixture was mixed under sterile conditions:

\begin{tabular}{ll}
$20 \mu \mathrm{g}$ & DNA \\
$\mathrm{x} \mu \mathrm{l}$ & $10 \mathrm{mM}$ Tris, $\mathrm{pH} 7.6$ \\
$\mathrm{y} \mu \mathrm{l}$ & $\mathrm{H}_{2} \mathrm{O}$ \\
\hline $450 \mu \mathrm{l}$ & total volume \\
$50 \mu \mathrm{l}$ & $\mathrm{CaCl}_{2}(2.5 \mathrm{M})$ \\
$500 \mu \mathrm{l}$ & $2 \times \mathrm{BBS}$ \\
\hline $1000 \mu \mathrm{l}$ & total volume
\end{tabular}

This DNA mixture was added drop-wise to the cells. The dish was tilt to ensure homogenous distribution of the precipitates and cultured on. In the following morning, cells were washed with PBS and medium was exchanged, from the third day, transfected clones were positively selected in puromycin $(2 \mu \mathrm{g} / \mathrm{ml})$ supplemented medium for 3-4 days. In the course of selection, specifically transfected cells were able to grow and formed dense islands. These clonal cell aggregates were picked in 96-well feeder cell coated plate and then the clones were passaged until onto 1 x 96well plate coated with feeder cell and 1 x 96-well plate gelatinized with $0.1 \%$ gelatin. 96-well feeder cell coated plate was frozen into $-80^{\circ} \mathrm{C}$, the gelatinized plate was used for X-Gal staining (see 2.2.17.).

\subsubsection{Generation of conditional mutants}

Mutant ES cells were used to generate chimeric mice by blastocyst injection. Chimeras were bred with $\mathrm{C} 57 \mathrm{BL} / 6 \mathrm{~J}$ mice to obtain F1 offspring, and germ-line transmission of the mutant allele was determined by Southern blot analysis using the ROSA26 3' external probe after ApaI digestion. For the conditional overexpression of $\mathrm{CRH}$ in the brain, we used transgenic mice carrying the gene encoding Cre 
recombinase under the control of the CamKIIa promoter (Minichiello et al., 1999) or under the control of the rat Nestin (Nes) promoter and enhancer (Tronche et al., 1999).

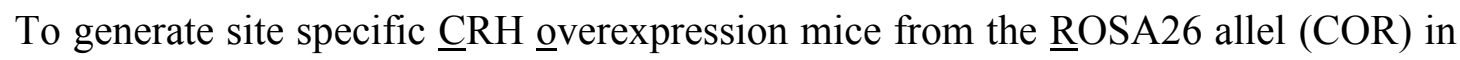
the brain, we crossed mice harboring only one $\mathrm{R} 26^{\text {neoCRH }}$ allele with transgenic CamKII $\alpha$-Cre or Nestin-Cre mice to obtain COR-CamKII $\alpha$ Cre (COR-Cam Cre) and COR-Nestin Cre (COR-Nes Cre) mouse lines respectively. Mice used for this study were kept on a mixed 129/Svp x C57BL/6J background. Genotyping was performed by PCR with ROSA26 specific primers, LacZ primers and Cre primers, and/or by Southern blot analysis of EcoRV- or ApaI-digested tail DNA using external probes and a Cre recombinase-specific probe.

\subsubsection{X-Gal staining of mouse tissues}

\subsubsection{Tissues preparation}

3-5 months old mice were anesthetized with Isofluran and perfused via intracardial perfusion using the LacZ-Fix buffer (see 2.1.1.5.). The brains were removed and incubated in $20 \%$ cryoprotection sucrose for overnight.

Brains were frozen on dry ice for at least $15 \mathrm{~min}$ and mounted one brain on Tissue Tek (Polysciences, PA, USA), 100- $\mu \mathrm{M}$ thick consecutive sections were cut from brain regions of interest on a cryostat (Microtrome HM 560, Microm). Sections were put into $1 \mathrm{x}$ PBS, which were used directly or were stored at $4{ }^{\circ} \mathrm{C}$ for at most two weeks until used.

\subsubsection{X-Gal staining}

Sections (or cell culture dishes) were immersed for $5 \mathrm{~min}$ in LacZ-Wash buffer (see 2.1.1.5.), and were then put in LacZ-Stain buffer (see 2.1.1.5.) at $37^{\circ} \mathrm{C}$ for up to $12 \mathrm{~h}$ (staining was checked from time to time), subsequently sections were washed in $1 \mathrm{x}$ PBS for $6 \times 10 \mathrm{~min}$, fixed at least for $1 \mathrm{~h}$ in $4 \%$ PFA/PBS (here storage possible at $4{ }^{\circ} \mathrm{C}$ ). Sections were dehydrated through series of Ethanol: $70 \%, 80 \%, 95 \%$ and 2 $\mathrm{x} 100 \%$ Ethanol for $30 \mathrm{~min}$ respectively, then the sections were transferred into BABB for about 20 min. Pictures were then taken directly. 


\subsubsection{Radioimmunoassay (RIA)}

\subsubsection{Extraction and Chromatographic Methods}

Half brains and different brain regions were extracted with Sep-Pak C18 (Waters) by modification of Vale and colleagues (Vale et al., 1983b). For this reason cartridges were preconditioned with $6 \mathrm{ml}$ TEAF ( $1 \%$ formic acid with triethylamine, $\mathrm{pH} 3.0) /$ acetonitrile (4/6, v/v) and $6 \mathrm{ml}$ TEAF alone. Briefly, $2 \mathrm{ml}$ lysis buffer (see 2.1.1.8.) was added for each sample, the samples were homogenated and then freezed at $-80{ }^{\circ} \mathrm{C}$ for overnight. Next day, $1 \mathrm{ml} \mathrm{C18}$ Pulver $(300 \mathrm{mg} / \mathrm{ml})$ was added into new tube and then centrifuged for $5 \mathrm{~min}$ at 4,000 rpm, the supernatant was discarded and $3 \mathrm{ml}$ TEAF (see 2.1.1.8.) was added, the supernatant was vortexed shortly and centrifuged in the same way as the above. The supernatant was discarded, $2 \mathrm{ml}$ TEAF and $1 \mathrm{ml}$ sample supernatant was added, the tubes were shaked it for $10 \mathrm{~min}$, centrifuged again. Supernatant was discarded again, and this step was repeated with $2 \mathrm{ml}$ TEAF for washing, then $3 \mathrm{ml}$ TEAF/propanol $(1: 1, \mathrm{v} / \mathrm{v})$ was added, tubes were shaked for 10 min and then centrifuged again, supernatant was taken to new tubes, stored in $-80{ }^{\circ} \mathrm{C}$ for overnight.

Next day, the TEAF/propanol solution was evaporated and extracted samples were suspended in assay buffer and measured by using a buffer standard curve.

\subsubsection{Preparation of ${ }^{125} \mathrm{I}-\mathrm{CRH}$ tracer}

Rat $\mathrm{CRH}(\mathrm{rCRH})$ was labeled with $350 \mu \mathrm{Ci}{ }^{125} \mathrm{I}$ within $3 \mathrm{~s}$ using $3 \mu \mathrm{g}$ chloramines $\mathrm{T}$ resulting in a specific activity of the probe ranging from 40 to 70 $\mu \mathrm{Ci} / \mu \mathrm{g}$. The iodine was separated from the labeled peptide by Sephadex G 10 column chromatography with $0.1 \mathrm{~g} / \mathrm{dl} \mathrm{BSA}$ in $0.1 \mathrm{~N}$ acetic acid.

Further purification was achieved by Sephadex G50 rechromagraphy $(60 \times 1 \mathrm{~cm})$ which resulted in 2 peaks. The second peak was used as tracer in the radioimmunoassay. ${ }^{125}$ I-Histidine-labeled CRH was used only for chromatographic studies and to follow extraction procedure. Since the ${ }^{125}$ I-tyrosine tracer had no longer stability and was therefore more suitable for radioimmunoassay.

\subsubsection{RIA protocol}

The incubation volume consisted of $0.1 \mathrm{ml}$ antibody in $0.05 \mathrm{M} \mathrm{PO}_{4}$ buffer $(\mathrm{pH} 7.4)$ with $5 \mathrm{mM}$ EDTA, $400 \mathrm{kIU} / \mathrm{ml}$ Trasylol, $2 \mathrm{~g} / \mathrm{dl}$ BSA. For direct measurement, CRH- 
free serum was used for a standard curve (dose range 40-2,500 pg/ml), which was obtained by adsorption on Sep-Pak C18 cartilages. Preincubation was performed over 2 days. After 1 day of tracer incubation, bound/free separation was performed by the double antibody-PEG method. For direct measurement EDTA-plasma specimens with trasylol were used.

\subsubsection{Endocrine analysis}

Two weeks before the experiments, 3-7 months old animals were separated and housed singly to avoid uncontrolled stress reactions. All experiments and data analyses were performed only with male animals. To determine the basal hormone plasma levels, mice ( $n=10-12$ per genotype) were left undisturbed throughout the night before the experiment. Blood sampling was collected in the early morning (07:00-09:00 am) by collecting trunk blood from rapidly decapitated animals, with the time from first handling of the animal to completion of bleeding not exceeding 1 min. Blood was collected in ice-cooled Eppendorf cups containing Potassium-EDTA.

Plasma was separated by centrifugation $\left(10,000 \mathrm{~g}\right.$ for $15 \mathrm{~min}$ at $\left.4{ }^{\circ} \mathrm{C}\right)$. Supernatants were stored at $-20{ }^{\circ} \mathrm{C}$ until assayed. Plasma corticosterone and ACTH concentrations were measured in duplicate by commercially available Radioimmunoassay kits (ICN Biomedicals).

\subsubsection{Behavioral studies}

\subsubsection{Acoustic startle response (ASR)}

Animals: 6-8 weeks old male animals were housed singly in a temperaturecontrolled $\left(21-22{ }^{\circ} \mathrm{C}\right)$ room under a $12 \mathrm{~h}$ light/dark cycle (light on at 6:00 am). All testing occurred from 10:00 am to 1:00 pm and was conducted in accordance with the principles of laboratory animal care.

Apparatus: Startle chambers (SR-LAB; San Diego Instruments, San Diego, CA) consisted of nonrestrictive $5 \mathrm{~cm}$ in diameter Plexiglas cylinders resting on a Plexiglas platform in a ventilated chamber. High-frequency speakers mounted $33 \mathrm{~cm}$ above the cylinders produced all acoustic stimuli, which were controlled by SR-LAB software. Piezoelectric accelerometers mounted under the cylinders transduced movements of the animal, which were digitized and stored by an interface and computer assembly. Beginning at startling stimulus onset, 65 consecutive 1 msec readings were recorded 
to obtain the peak amplitude of the animals' startle response. A dynamic calibration system was used to ensure comparable sensitivities across chambers. Sound levels were measured as described previously using the A weighting scale in units of decibels sound pressure level (Dulawa and Geyer, 2000). The house light remained on throughout all testing sessions.

Peptide infusions: The selective CRH-R1 antagonist NBI-30775 (also known as R-121919) was diluted in $5 \%$ cremophor-sterile water and $2 \mathrm{mg} / \mathrm{kg}$ and $20 \mathrm{mg} / \mathrm{kg}$ dose were administered (icv) using a free-hand method in lightly anesthetized mice as described previously (Pelleymounter et al., 2002) (Risbrough et al., 2003).

Acoustic startle: For all acoustic startle sessions, the intertrial interval between stimulus presentations averaged $15 \mathrm{sec}$ (range of 7-23 sec). A $65 \mathrm{~dB}$ background was presented continuously throughout the session. After placement into the startle chambers, a 5 min acclimation period preceded testing. Then 80 startle stimuli of varying intensities were presented, with the duration of $40 \mathrm{msec}$ and variable interstimulus intervals (ISI) of 20-30 sec. The following stimulus intensities were used: 65, $80,90,100,110,120 \mathrm{~dB}$ noise.

Habituation: After an 5 min acclimation period, 100 startle stimuli of $110 \mathrm{~dB}$ noise were presented (duration $40 \mathrm{msec}$ ), with an interval of 15 seconds.

Prepulse inhibition: Two different procedures were used, one examined the effects of prepulse with varying intensities on PPI, and the other was designed to study the effects of different intervals between the onset of the prepulse and that of the startle stimulus on PPI. In the first procedure, the first block tested acoustic startle response only and included three different acoustic stimulus intensities: 90, 105 and $120 \mathrm{~dB}$. After a $5 \mathrm{~min}$ acclimation period, startle stimuli $(120 \mathrm{~dB}, 40 \mathrm{msec})$ were preceded by noise prepulse ( $20 \mathrm{msec}$ ) of 2, 4, 8 and $16 \mathrm{~dB}$ above background, with the inter-stimulus interval $(100 \mathrm{msec})$ from onset of the prepulse to onset of the pulse. In the second procedure, after a $5 \mathrm{~min}$ acclimatization, prepulses (120 dB noise, 20 msec) preceded the startle stimuli (110 dB noise, $40 \mathrm{msec}$ ), with intervals (onset-onset) varying from 0 to $1080 \mathrm{msec}(0,20,70,120,360$ and $1080 \mathrm{msec})$. The trial with no interval between prepulse and startle stimulus was considered as a stimulus-alone trial.

Four to ten days before drug testing, mice were tested briefly to measure baseline acoustic startle response and PPI. The mice were then assigned to drug groups (i.e. counterbalanced) so that all drug groups averaged similar startle response levels and PPI performance before drug testing. Startle pulses were $40 \mathrm{msec}$ in duration, 
prepulses were $20 \mathrm{msec}$ in duration, and prepulses preceded the pulse by $100 \mathrm{msec}$ (onset-onset).

Data analysis: In all experiments, the average startle magnitude over the record window (i.e., $65 \mathrm{msec}$ ) was used for all data analysis. Either a two-way ANOVA as the between-subject factor, or prepulse-pulse intensity as within-subject factor, was used. Post hoc analysis followed significant main or interaction effects as appropriate. Unless specified otherwise, PPI data presented were collapsed across prepulse intensities, and startle reactivity data were shown at the $120 \mathrm{~dB}$ startle intensity.

\subsubsection{Fear conditioning}

Experiments were approved by the Committee on Animal Health and Care of the local governmental body of Bavaria.

Animals: All animals ( $\mathrm{n}=10-12$ mice per genotype) were housed singly under standard laboratory conditions and were maintained on an inversed $12 \mathrm{~h}$ light-dark cycle (lights off between 8:00 am and 8:00 pm) with food and water ad libitum. Mice were separated at least 2 weeks before starting the experiments.

Fear conditioning: animals were placed into conditioning chambers (ENV-307A; MED Associates, St. Albans, VT, USA) that was equipped with a shock floor and placed into a sound-attenuated isolation cubicle. Context- and tone-dependent fear conditioning were performed as described previously (Kamprath and Wotjak, 2004). Briefly, training consisted of exposure of the mice to a conditioning context ( $3 \mathrm{~min}$ ) followed by a 20-s tone (sine wave, $9 \mathrm{kHz}, 80 \mathrm{~dB}$ ) that co-terminated with a 2-s electric foot shock $(0.70 \mathrm{~mA})$. Animals were returned to their home cages $60 \mathrm{~s}$ after shock application. The test for contextual memory was performed $24 \mathrm{~h}$ later by reexposing the mice to the conditioning chamber for $3 \mathrm{~min}$ without tone presentation. Two hours later, mice were placed in a novel context (Plexiglas cylinder) for $7 \mathrm{~min}$ with a re-exposure to the tone for $3 \mathrm{~min}$ starting $3 \mathrm{~min}$ after insertion into the context. The test of tone-dependent freezing was repeated 5 and 20 days later. All sessions were videotaped. Freezing behavior (characterized as immobility except for respiratory movements) was analyzed off-line by trained observers that were blind to the genotype (Kamprath and Wotjak, 2004). The duration of freezing, which served as a measure of fear-related memory, was normalized to the respective observation periods. 
Data analysis: data were analyzed by a one-way ANOVA using Graphpad software. Significance between groups was further analyzed using one of the following post hoc tests (Tukey, Bonferroni, Newman Keul). $\mathrm{P}<0.05$ was considered as statistically significant.

\subsubsection{Forced swimming test (FST)}

Experiments were approved by the Committee on Animal Health and Care of the local governmental body of Bavaria.

All animals ( $\mathrm{n}=10-12$ mice per genotype) were housed singly under standard laboratory conditions and were maintained on an inversed $12 \mathrm{~h}$ light-dark cycle (lights off between 8:00 am and 8:00 pm) with food and water ad libitum. All experiment testing sessions were conducted between 1:00 pm and 7:00 pm and were performed with the experimenter unaware of the animals' genotype.

To facilitate adaptation to novel surroundings, 2-3 months old male mice were transported to the testing room at least $12 \mathrm{~h}$ before testing. Briefly, swim sessions were conducted by placing mice in glass cylinders (16 $\mathrm{cm}$ in diameter, $30 \mathrm{~cm} \mathrm{high})$ containing $24-26{ }^{\circ} \mathrm{C}$ or $32{ }^{\circ} \mathrm{C}$ warm water at a depth of $15 \mathrm{~cm}$. A 6-min test duration was used, and the water was changed between subjects. All test sessions were recorded by a video camera and the behavior was scored by a trained observer who was blinded to genotype. Immobility was defined as the state in which mice were judged to be making only the movements necessary to keep their heads above water. Struggling was defined as any vertical movement in which mice were breaking the water surface with their front paws.

Data (from forced swimming test and tail suspension test) were analyzed by oneway ANOVA using Graphpad software (Graphpad Software Inc). Significance between groups was further analyzed using one of the following post hoc tests (Tukey, Bonferroni, Newman Keul). $\mathrm{P}<0.05$ was considered as statistically significant.

\subsubsection{Tail suspension test (TST)}

Experiments were approved by the Committee on Animal Health and Care of the local governmental body of Bavaria.

All animals ( $\mathrm{n}=10-12$ mice per genotype) were housed singly under standard laboratory conditions and were maintained on an inversed $12 \mathrm{~h}$ light-dark cycle (lights 
off between 8:00 am and 8:00 pm) with food and water ad libitum. All experiment testing sessions were conducted between 1:00 pm and 7:00 pm and were performed with the experimenter unaware of the animals' genotype.

The TST for antidepressant activity was conducted in a slightly modified version of the one previously described (Holmes et al., 2002) (Cryan and Mombereau, 2004). All mice were adapted to novel surroundings as described for the FST. Mice were securely fastened with medical adhesive tape by the tip $(1.0-1.5 \mathrm{~cm})$ of the tail to a round metallic bar and suspended $30 \mathrm{~cm}$ above the ground. The presence or absence of immobility, defined as the absence of limb movement, was scored over a 6-min test session by a highly experienced observer who was blinded to genotype. 


\section{Results}

\subsection{Generation of mice conditionally overexpressing CRH}

\subsubsection{Generation of targeting construct}

To investigate potential effects of site-specific $\mathrm{CRH}$ overexpression in the brain, we utilized the properties of the retrovial-trapped ROSA26 (R26) locus (Figure 5A). The ROSA26 locus has proven as a useful tool to achieve ubiquitous expression during development and in the adult (Zambrowicz et al., 1997). We introduced a single copy of the murine $\mathrm{CRH}(\mathrm{mCRH}) \mathrm{cDNA}(0.6 \mathrm{~kb}$ fragment) into the ROSA26 locus (Soriano, 1999) (Figure 5B) generating a R26 knock in (Ki) allele (R26 $6^{\text {neoCRH }}$ ) (Figure 5C).

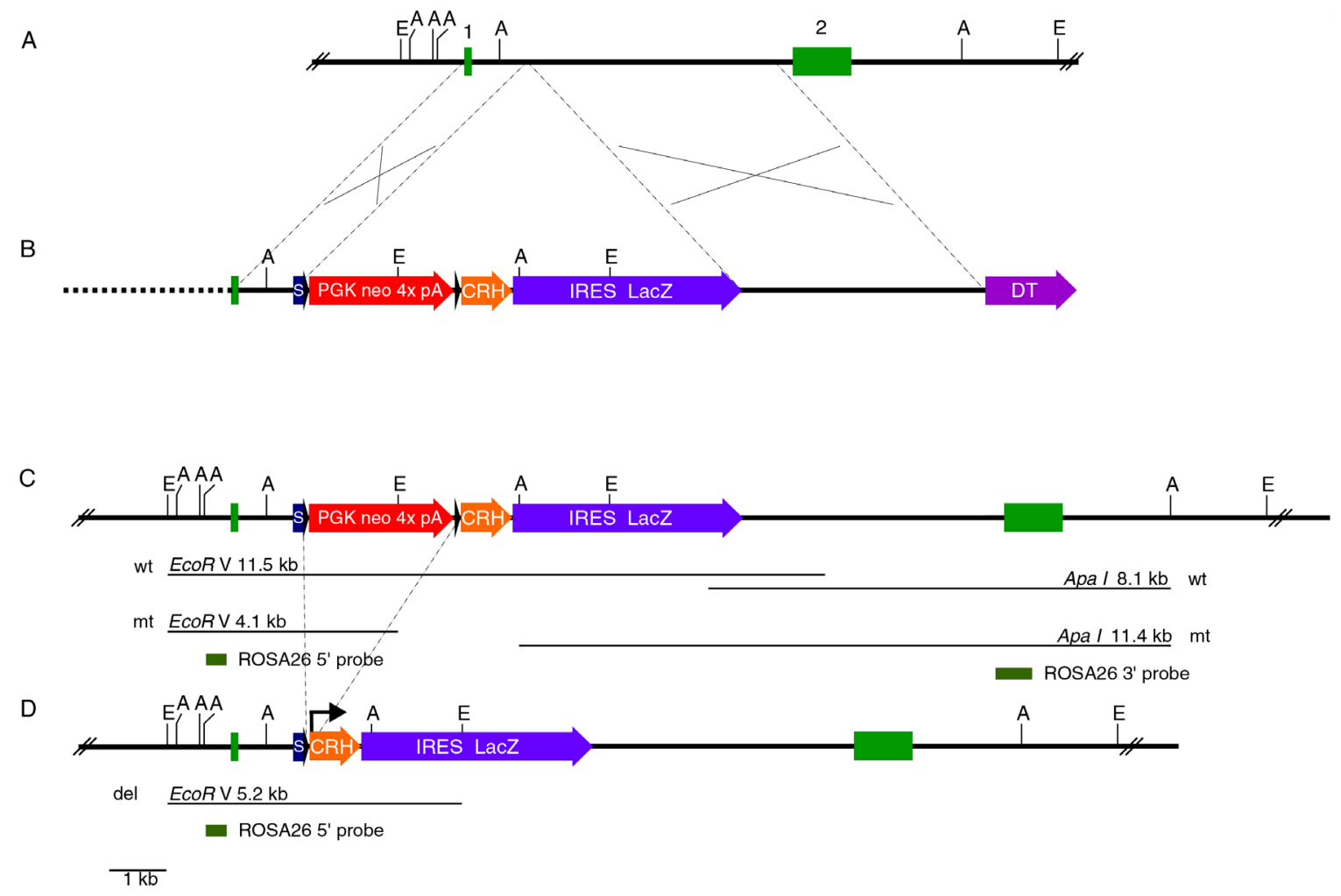

Figure 5. Strategy for CRH knock-in by homologous recombination in ES cells. (A) Genomic structure and partial restriction map of the wild type ROSA26 locus. Exons were numbered. A, ApaI; E, EcoRV. (B) Targeting vector with about $5 \mathrm{~kb}$ homology arm to the ROSA26 gene locus. DT, diphteria toxin. (C) ROSA26 gene locus after homologous recombination in ES cells $\left(\mathrm{R} 26^{\mathrm{neoCRH}}\right)$. Informative restriction digests and external probes were indicated below. (D) Removal of transcriptional terminator cassette after Cre-recombination (del, deletion fragment following Cre mediated recombination; mt, mutant fragment; wt, wild-type fragment). 


\subsubsection{Screening of Electroporated ES cell}

The ROSA26 targeting vector (Figure 5B) carries a 5-kb genomic fragment subcloned in a plasmid vector along with a diphtheria toxin (DT) expression cassette for negative selection, a splice acceptor sequence (SA), and a neomycin expression cassette flanked by two loxP sites. A triple polyadenylation sequence (pA) (Maxwell et al., 1989) was added to the 3' end of the neomycin expression cassette to prevent transcriptional read-through. A IRES-LacZ gene was inserted at a unique XbaI site approximately 300 -bp 5' of the original gene-trap integration site. The mCRH cDNA was inserted in front of the IRES-LacZ gene by a unique PacI site. This targeted construct was linearized with SwaI and electroporated into TBV2 ES cells. Following G418 selection, G418 resistant $\left(\mathrm{G} 418^{\mathrm{r}}\right)$ clones were analysed for homologious recombination by Southern blot. 2 of $298 \mathrm{G} 418^{\mathrm{r}}$ colonies were found to have correctly undergone homologous recombination and were further verified by Southern blot analysis with external ROSA26 5' and 3' probes (Figure 6A and B).
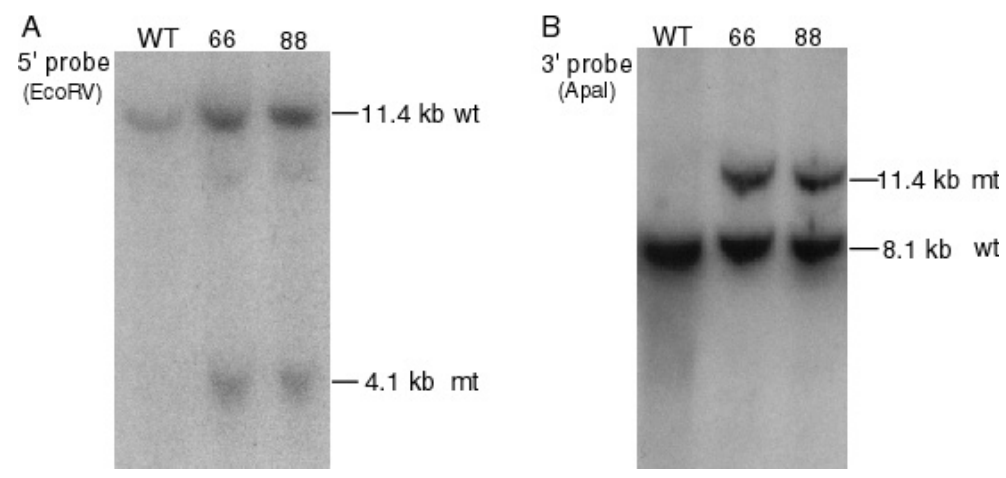

Figure 6. Southern blot analysis of wild-type (WT) and targeted ES cell clones. (A) Southern blot analysis of WT and targeted ES cell clones with ROSA26 5' external probe hybridized to $E c o R V$-digested tail genomic DNA. The targeted allele was indicated by the presence of an additional mutant $4.1 \mathrm{~kb}$ fragment. (B) ROSA26 3' external probe was hybridized to ApaIdigested DNA from the same WT and targeted ES cell clones confirming homologous recombination, a additional mutant fragment was detected at $11.4 \mathrm{~kb}$ (WT, wild-type cells; 66 , 88 , targeted cells; mt, mutant fragment; wt, wild-type fragment).

\subsubsection{In vitro characterization of the overexpression strategy}

In parallel with the generation of mCRH knock-in mice, the functionality of the strategy was tested in ES cells. In order to remove the transcriptional terminator sequence (Figure 5D), we transfected targeted ES cell clones transiently with the Crerecombinase expression plasmid pCre-Pac (Taniguchi et al., 1998). Transfected 
clones were analysed for LacZ reporter gene expression by X-Gal staining (Figure 7A), and excision of the termination sequence was analysed by Southern blot with ROSA26 5' probe (Figure 7B). Finally, the expression of $\mathrm{CRH}$ and LacZ was analysed by Northern blot using CRH-, LacZ- and Neo-probe, simultaneously with a $\beta$-actin control probe (Figure 7C and D).

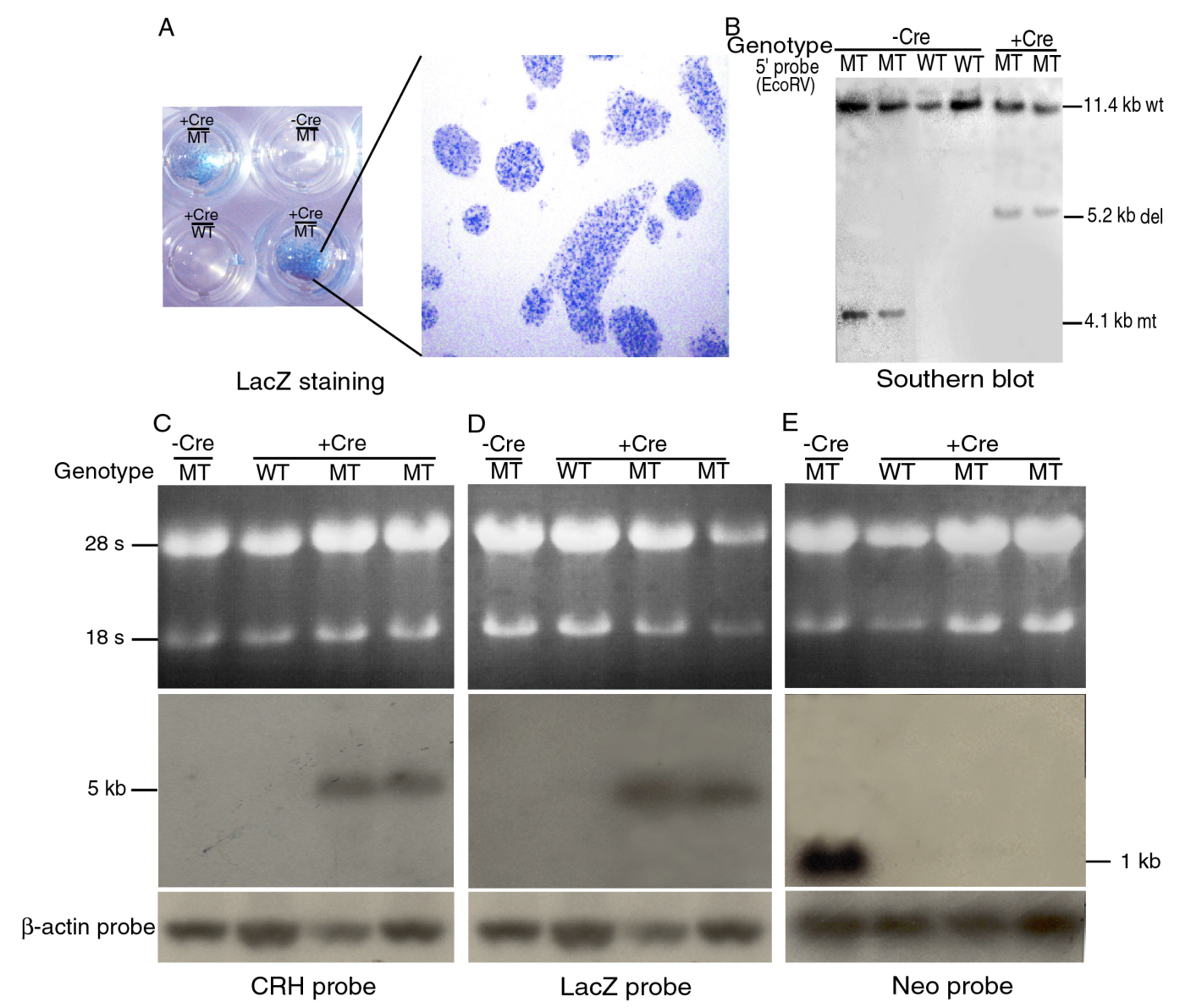

Figure 7. Functional analysis of the mCRH knock-in strategy in targeted ES cell clones. (A) X-Gal staining of targeted ES cell clones transiently transfected with Cre-recombinase expression plasmid pCre-Pac. (B) Southern blot analysis of targeted ES cell clones following transient Cre transfection. Removal of the transcriptional terminator sequence was indicated by the presence of a $5.2 \mathrm{~kb}$ fragment. (C, D and E) Northern blot analysis of targeted ES cell clones following Cre-mediated recombination. The removal of the terminator sequence and transcription of a CRH-IRES- LacZ fusion transcript was indicated by the presence of a $5 \mathrm{~kb}$ fragment detected by CRH- and LacZ-probe respectively. The Neomycin cassette was present in targeted ES cells without Cre-mediated recombination, which was indicated by the presence of a $1 \mathrm{~kb}$ transcript by Neomycin probe. The blots were hybridized simultaneously with a $\beta$-actin specific probe for comparison of loaded RNA amount for CRH-, LacZ- and Neo-probes (WT, wild-type cells; MT, mutant cells; del, deletion fragment following Cre mediated recombination; $\mathrm{mt}$, mutant fragment; wt, wild-type fragment). 


\subsubsection{Generation of conditional mutant mice}

Targeted ES cell clones were used to produce chimeric mice and germline transmission of the modified ROSA26 allele was confirmed in offspring from male chimeras bred to wild-type $\mathrm{C} 57 \mathrm{BL} / 6 \mathrm{~J}$ mice. The obtained $R 26^{+/ \text {neoCRH }}$ mice were intercrossed with each other to obtain homozygous $\left(R 26^{\text {neoCRH/neoCRH }}\right) \mathrm{COR}$ mice (ㅁH overexpression from the ROSA26 locus) (Figure 8). As previously reported (Soriano, 1999), these mice were indistinguishable from wild-type littermates in terms of development, fertility, endocrine parameters and behavior (data not shown).

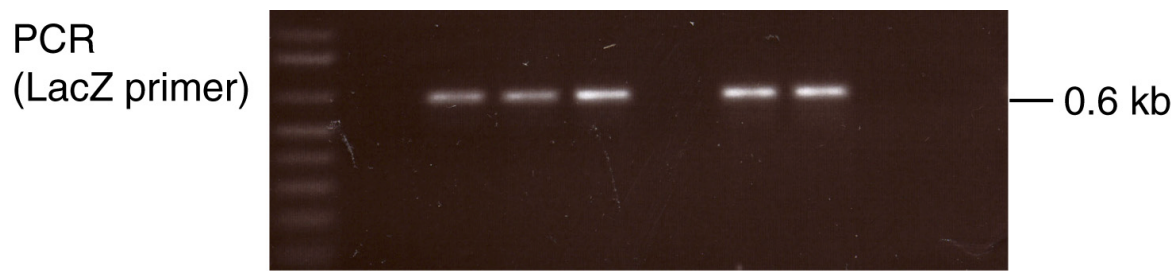

Southern blot (3' probe)

Figure 8. Generation of COR mouse line. PCR analysis of tail DNA by LacZ primers and Southern blot analysis of ApaI-digested tail DNA by ROSA26 3' external probe from F2 offspring mice (wt, wild-type fragment; mt, mutant fragment).

The $\mathrm{R} 26^{\text {neoCRH }}$ allele is sensitive to Cre recombinase, which catalyses sitespecific recombination between two loxP sites, removing the transcriptional terminator sequence and thus activating CRH expression. Therefore, the COR mouse line was crossed either to transgenic CamKII $\alpha$-Cre mice (Minichiello et al., 1999), or to transgenic Nestin-Cre mice (Tronche et al., 1999) to obtain COR-Cam mice (Figure 9A) or COR-Nes mice (Figure 9B). 

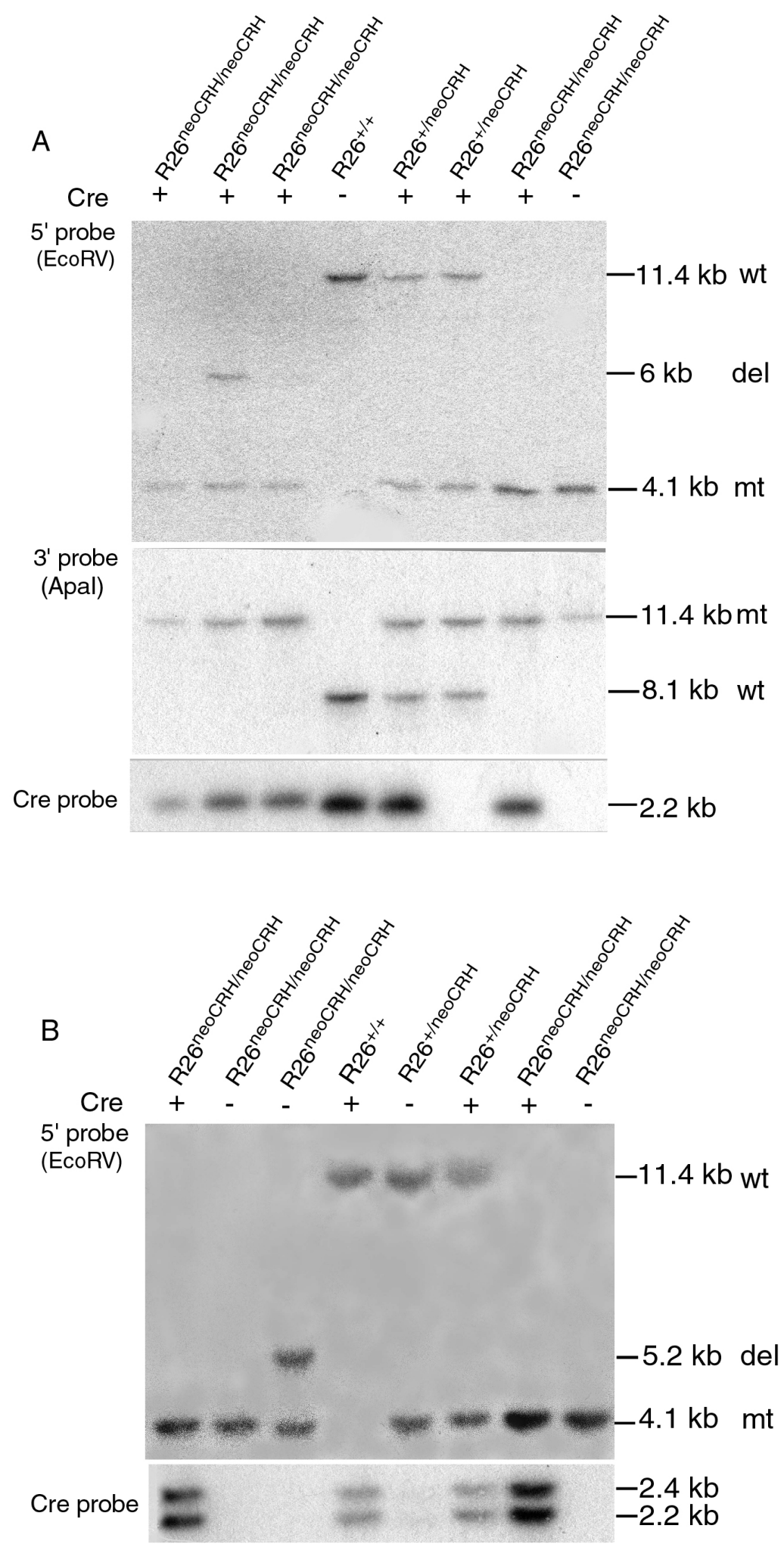

Figure 9. Generation of COR-Cam and COR-Nes mouse lines. Southern blot analysis of $E c o R V$ - or ApaI-digested tail DNA of COR-Cam (A) and COR-Nes mice (B) with ROSA26 5' or ROSA26 3' external probe, hybridized simultaneously with a Cre recombinase-specific probe (del, deletion fragment caused by occasional/transient Cre activity in the genomes; $\mathrm{mt}$, mutant fragment; wt, wild-type fragment). 


\subsection{Analysis of the region-specific overexpression of CRH}

\subsubsection{Analysis of LacZ report gene expression by X-Gal staining}

To assess the regional pattern of Cre activity in vivo, saggital and coronal sections of mouse brains from control $\left(\mathrm{R} 26^{\mathrm{neoCRH} / \mathrm{neoCRH}}\right)$, heterozygous $\left(\mathrm{R} 26^{+/ \text {neocRH }}\right.$ $\mathrm{Cre}$ ) and homozygous ( $\left.\mathrm{R} 26{ }^{\mathrm{neoCRH} / \mathrm{neo} C \mathrm{CRH}} \mathrm{Cre}\right)$ mice of both conditional mouse lines (COR-Cam and COR-Nes) were analysed for $\mathrm{Cre}$ recombination by X-Gal staining. No Cre recombination and LacZ reporter gene expression to be observed in control mice (data not shown). Homozygous COR-Cam mice (Figure 10A and C) showed stronger LacZ gene expression than heterozygous COR-Cam mice (Figure 10B), in which Cre recombination and $\mathrm{LacZ}$ reporter gene expression was specifically observed in the anterior forebrain, including the olfactory bulb (OB), hippocampus (HC) (strong staining in CA1), neocortex (Ctx), striatum (Str), the central nucleus of amygdala (CeA) and lateral hypothalamus area (LHA) (Figure 10A and C), indicating CamKII $\alpha$-driven $\mathrm{Cre}$ expression in these selected brain regions. In heterozygous COR-Nes mice, Cre recombination and LacZ reporter gene expression was also specifically observed in the olfactory bulb, hippocampus, neocortex and the central nucleus of amygdala, but additional strong staining was detected in the cerebellum $(\mathrm{Cb})$, brainstem and spinal cord (Sp) (Figure 10E). Cre recombination and LacZ reporter gene expression was observed in all most the entire brain in homozygous COR-Nes mice (Figure 10D and F). No Cre recombination was observed in the pituitary and adrenal gland of both CRH overexpressing mouse lines (data not shown). 

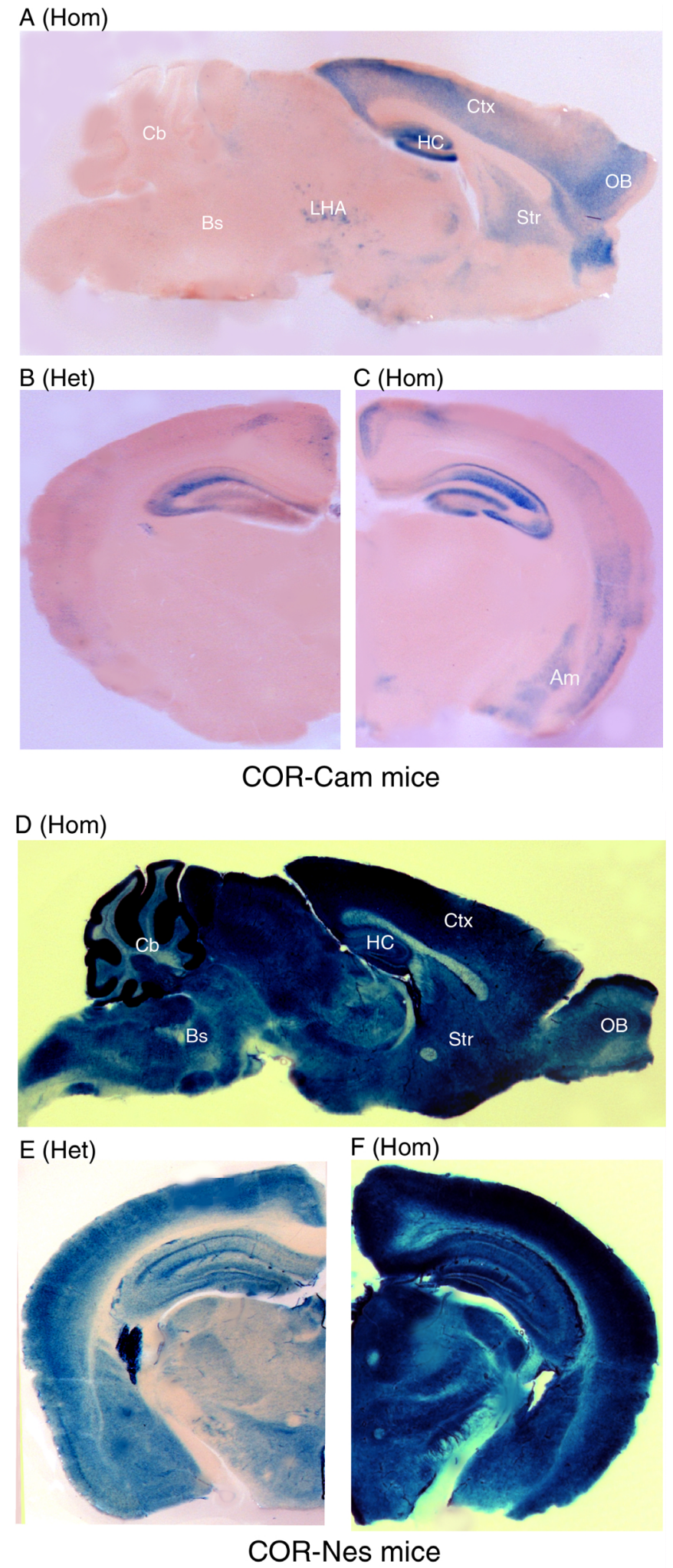

Figure 10. Analysis of Cre-dependent LacZ expression patterns by X-Gal staining in CORCam mice (A and C: homozygous mice; B: heterozygous mice), and in COR-Nes mice (D and F: homozygous mice, E: heterozygous mice). Abbreviations: Am, amygdala; Bs, brainstem; $\mathrm{Cb}$, cerebellum; Ctx, cortex; HC, hippocampus; LHA, lateral hypothalamus area; OB, olfactory bulb; Str, striatum (Het, heterozygous mice; Hom, homozygous mice) 


\subsubsection{Analysis of CRH mRNA overexpression by in situ hybridization}

Conditional CRH overexpression was verified by means of in situ hybridization with a CRH-specific probe on sagittal and coronal sections of mouse brains of different genotypes from both conditional mouse lines. In control mice, endogenous $\mathrm{CRH}$ expression was detected heterogeneously throughout the central nervous system (CNS). The highest density of CRH expression was found in the PVN, the piriform cortex (Pir) and noradrenergic neurons in the brainstem including nucleus ambiguus, locus coerulus, lateral dorsal tegmental and parabrachial nucleus. Its localization also included the hypothalamus, central nucleus of amygdala (CeA), bed nucleus of the stria terminalis (BNST), septum, cerebellum, supraoptic nucleus and cerebral cortex as previously described (Cummings et al., 1983) (Imaki et al., 1991) (Mezey and Palkovits, 1991) (Vamvakopoulos et al., 1990) (Figure 11A and D). For both CRH overexpressing mouse lines, the $\mathrm{CRH}$ overexpression patterns were similar to that of Cre activity as demonstrated by X-Gal staining (Figure 10). According to the expression of CRH from both or one R26 allele, CRH expression was stronger in homozygous mice than heterozygous mice. Moreover, high and specific $\mathrm{CRH}$ expression was observed in the cortex, hippocampus and amygdala in COR-Cam mice (Figure 11B, C, E, F). COR-Nes mice displayed high intensities of overexpressed $\mathrm{CRH}$ in olfactory bulb (OB), brainstem and cerebellum besides in the cortex, hippocampus and amygdala (Figure 12B,C, E). 


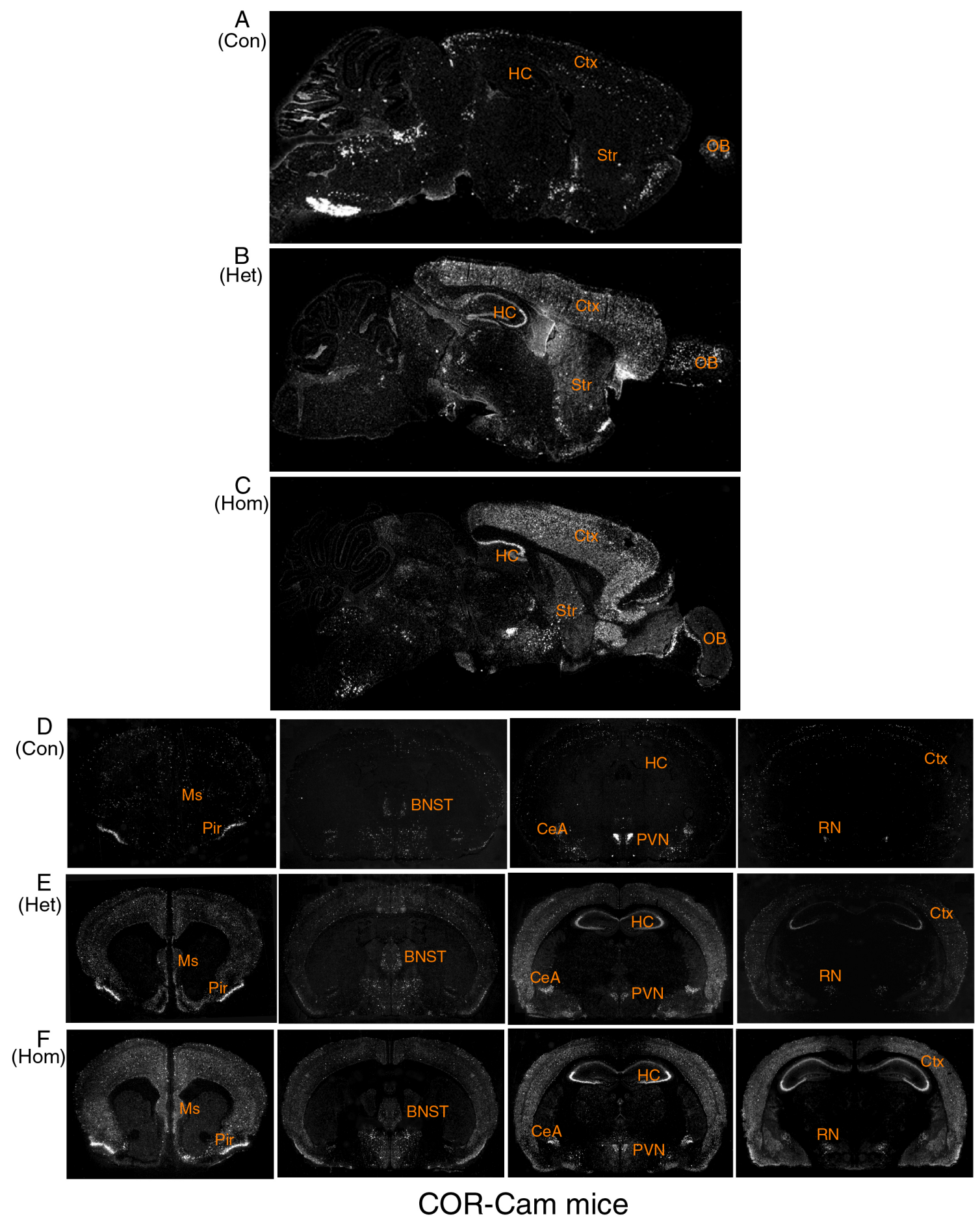

Figure 11. Representative overview of CRH mRNA expression in the brain of control, heterozygous and homozygous COR-Cam mice (A and D, control mice; $\mathrm{B}$ and $\mathrm{E}$, heterozygous mice; $\mathrm{C}$ and $\mathrm{F}$, homozygous mice). In COR-Cam mice, $\mathrm{CRH}$ was overexpressed selectively in the anterior forebrain, not in the cerebellum and brainstem. Abbreviations: BNST, bed nucleus of striatum terminalis; $\mathrm{Cb}$, cerebellum; $\mathrm{Ctx}$, cortex; $\mathrm{CeA}$, central nucleus of amygdala; Pir, piriform cortex; Str, striatum; MS, medial septal nucleus; HC, hippocampus; RN, Retical nucleus; OB, olfactory bulb; PVN, paraventricular nucleus. 


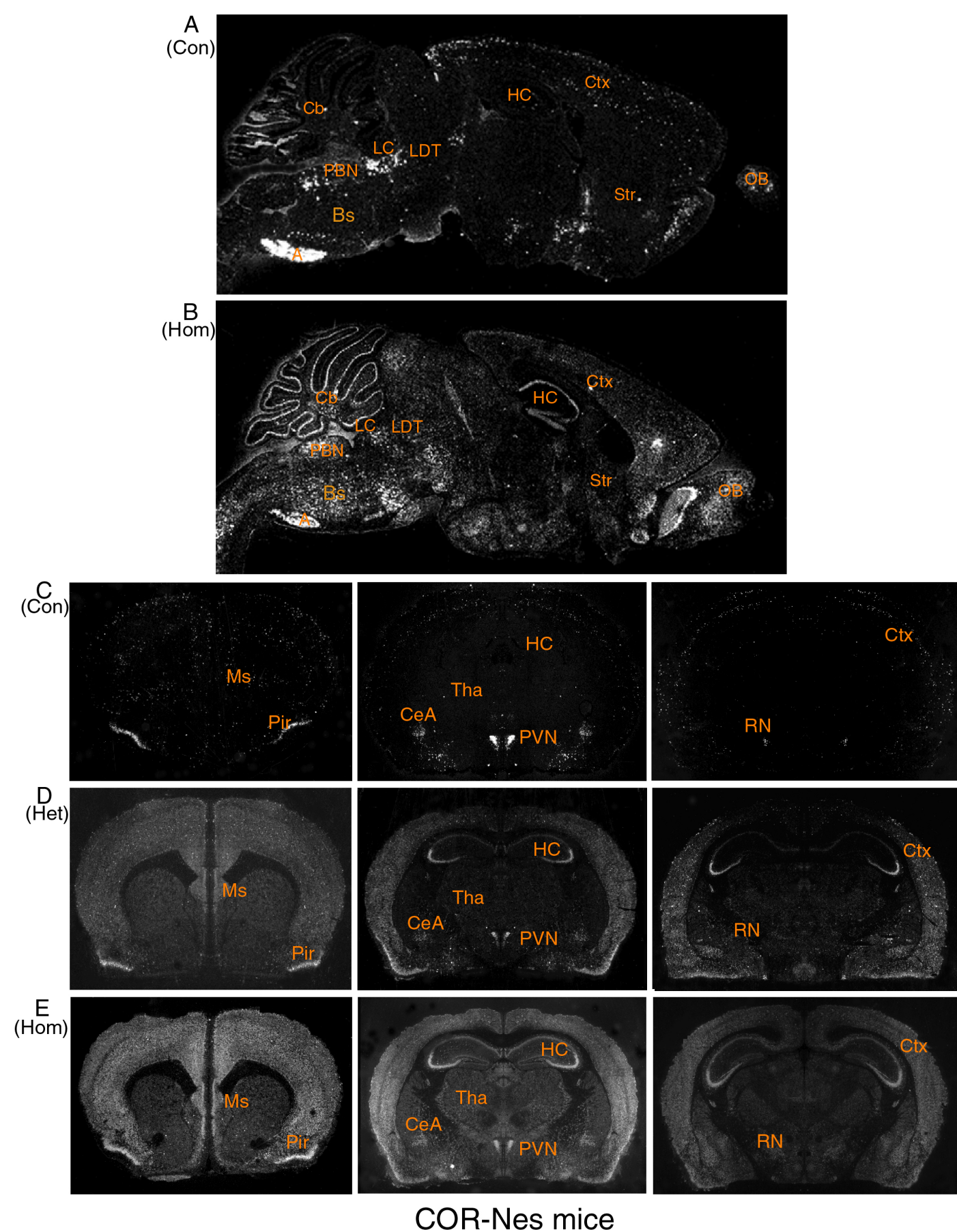

Figure 12. Representative overview of CRH mRNA expression in the brains of control, heterozygous and homozygous COR-Nes mice (A and $\mathrm{C}$, control mice; $\mathrm{B}$ and $\mathrm{D}$, heterozygous mice; E, homozygous mice). In COR-Nes mice, $\mathrm{CRH}$ was overexpressed almost entire brain, strongly in the olfactory bulb, cortex, hippocampus, cerebellum and spinal cord. Abbreviations: A, nucleus ambiguus; Bs, brain stem; $\mathrm{Cb}$, cerebellum; Ctx, cortex; CeA, central nucleus of amygdala; Pir, piriform cortex; Str, striatum; Tha, thalamus; MS, medial septal nucleus; HC, hippocampus; RN, Retical nucleus; OB, olfactory bulb; LC, locus coerulus; LDT, lateral dorsal tegmental; PBN, parabrachial nucleus; PVN, paraventricular nucleus. 


\subsubsection{Analysis of CRH protein expression by Radioimmunoassay}

We quantified $\mathrm{CRH}$ protein expression in the total brain of control and $\mathrm{CRH}$ overexpressing mice by radioimmunoassay (RIA). Compared to control mice, $\mathrm{CRH}$ content was increased about 1.2- and 1.6-fold in heterozygous and homozygous CORCam mice respectively (Figure 13A), and 1.4- and 2.1-fold in heterozygous and homozygous COR-Nes mice respectively (Figure 13B).
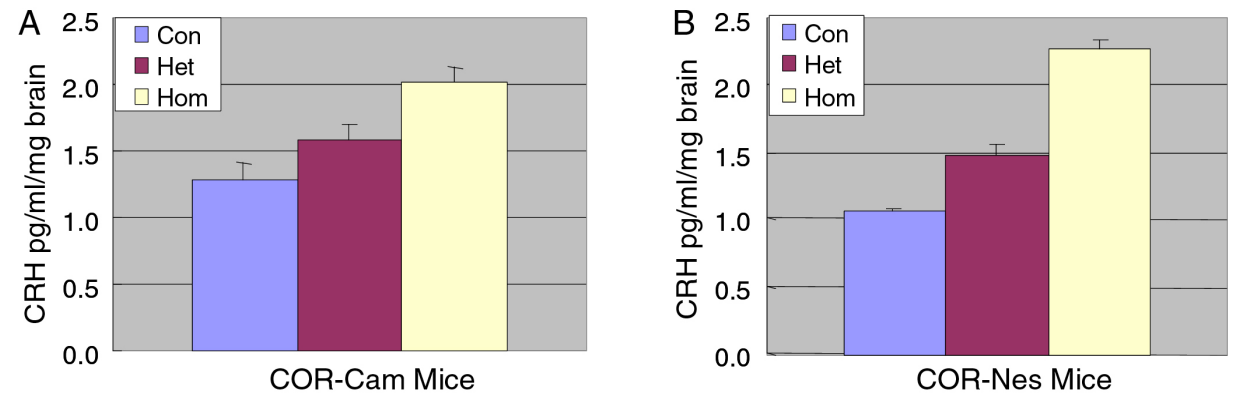

Figure 13. $\mathrm{CRH}$ protein expression in the total brain of COR-Cam (A) and COR-Nes (B) mice (Con: control mice; Het: heterozygous mice; Hom: homozygous mice).

CRH protein expression was also quantified in different brain regions by RIA. In control mice, $\mathrm{CRH}$ was strongly expressed in thalamus, moderately in hippocampus, cortex and weakly in cerebellum. CRH was increased by 1.9-, 4.6- and 1.6-fold and by 5.6-, 2.4- and 1.8-fold in heterozygous and homozygous COR-Cam mice in hippocampus, cortex and thalamus respectively. No change was observed in cerebellum (Figure 14A). CRH was increased by 2.9-, 5.1-, 2.2- and 5.8-fold and by 7.7-, 4.3-, 3.5- and 6.3-fold in heterozygous and homozygous COR-Nes mice in hippocampus, cortex, thalamus and cerebellum respectively (Figure 14B).
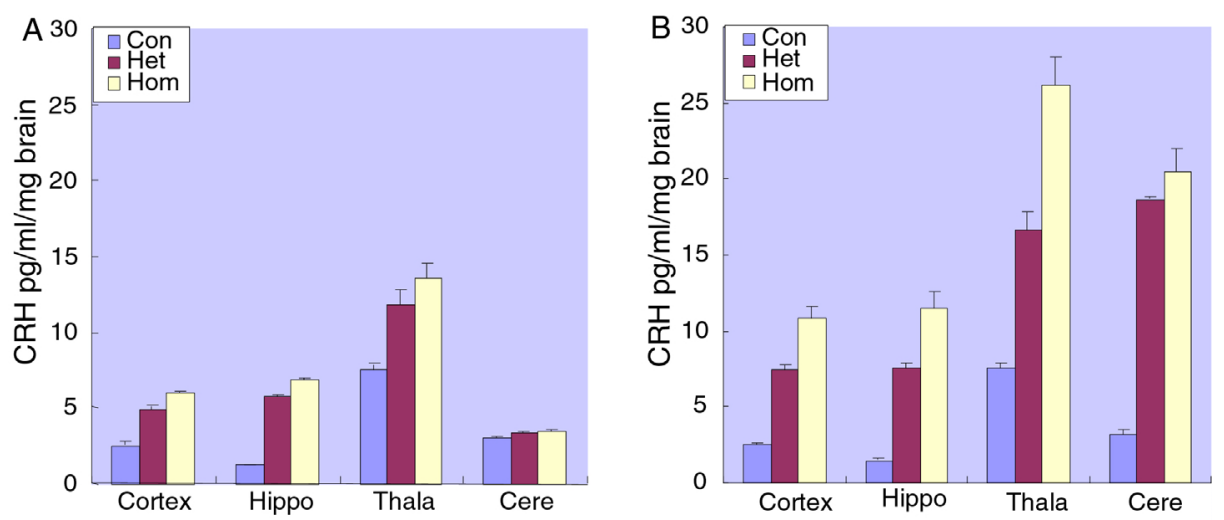

Figure 14. Analysis of $\mathrm{CRH}$ expression in various brain regions (cortex, hippocampus, thalamus and cerebellum) of COR-Cam (A) and COR-Nes (B) mice with rat CRH serum, showing the difference in $\mathrm{CRH}$ overexpression and reflecting the spatial expression pattern of CamKIIL-Cre and Nestin-Cre. 


\subsubsection{Analysis of Cre-recombinase mediated excision of the transcriptional terminator sequence by Southern blot}

The Cre-recombinase mediated excision of the transcriptional terminator sequence on the gemonic levels was verified by Southern blot with the ROSA26 5', external probe in different tissues of both $\mathrm{CRH}$ overexpressing mouse lines. Cre mediated excision of the transcriptional terminator sequences resulted in expression of $\mathrm{CRH}$ as indicated by X-Gal staining and in situ (Figure 10 and Figure 11 and 12). In homozygous COR-Cam mice, Cre-mediated recombination took place in more than half of the cells in the cortex, in about half of cells in hippocampus and in less half of cells in the thalamus. No Cre-mediated recombination was observed in the cerebellum, tail and liver (Figure 15A). However, in most of cells in the cortex, hippocampus, cerebellum and in about half of cells in the thalamus of homozygous COR-Nes mice, Cre-mediated recombination was observed. Moreover, the same as COR-Cam homozygous mice, no Cre-mediated recombination was observed in the tail and liver of COR-Nes mice (Figure 15B).

A

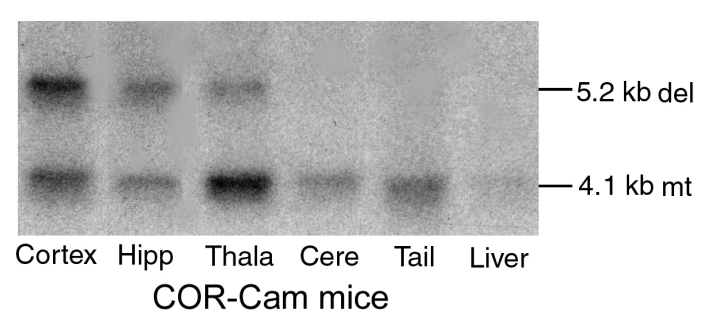

B

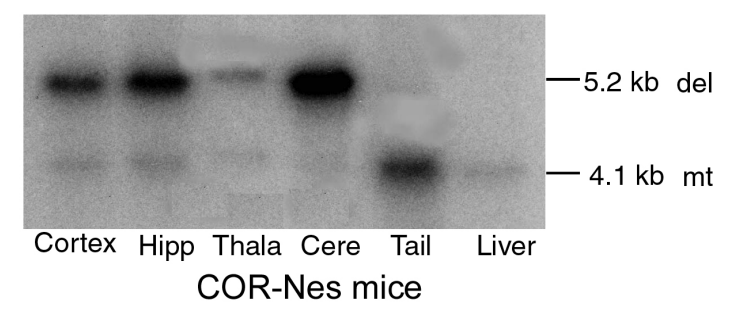

Figure 15. Southern blot analysis of $E c o R V$-digested DNA from various tissues of homozygous COR-Cam animals (A) and homozygous COR-Nes animals (B) by ROSA26 5, external probe, showing the extent of $\mathrm{Cre}$-mediated deletion of the transcriptional terminator sequence in depicted tissues (cortex, hippocampus, thalamus, cerebellum, tail and liver). Removal of the transcriptional terminator sequence was indicated by the presence of an additional $5.2 \mathrm{~kb}$ fragment. 


\subsection{Altered expression of genes related to the CRH system}

\subsubsection{CRH expression in PVN and CeA}

ISH experiments showed that CRH overexpression in the entire CNS (COR-Nes) decreased endogenous CRH expression in the PVN in a dose dependent manner. The reduction was also observed in mice expressing $\mathrm{CRH}$ in the forebrain (COR-Cam) but to a less extent (Figure 16A and B). Expression of CRH in the forebrain (COR-Cam) slightly increased endogenous CRH expression in the CeA (Figure 16C), however, overexpression of $\mathrm{CRH}$ in the entire CNS (COR-Nes) decreased endogenous $\mathrm{CRH}$ expression in this brain area (Figure 16D).
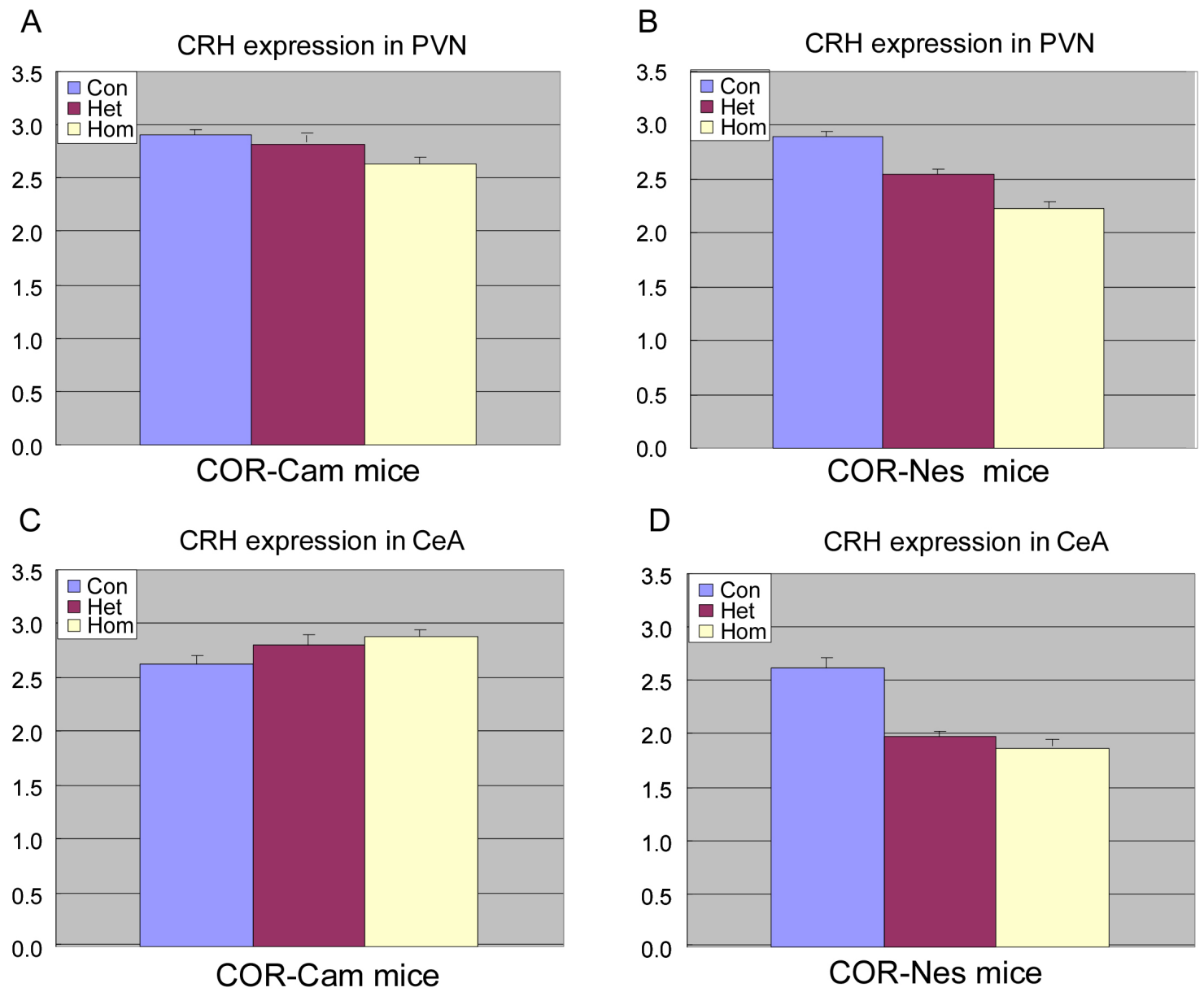

Figure 16. Quantification of $C R H$ mRNA expression in $P V N(A$ and $B)$ and $C e A(C$ and $D)$ in brains of control and COR-Cam (A and B) and COR-Nes (C and D) mice. 


\subsubsection{Expression of CRH-R1}

One intriguing question was whether the $\mathrm{CRH}$ overexpression in the forebrain of COR-Cam mice and in the entire brain of COR-Nes mice would lead to alterations in the expression of $\mathrm{CRH}$ system related genes that are involved in the endocrine, metabolic and behavioral response to stress.

CRH initiates its biological effects through two receptors which are coupled to $G$ proteins and activate adenylate cyclase. In control mice, ISH revealed that the neocortex comprised the dominant site of CRH-R1 mRNA expression in the mouse forebrain. CRH-R1 mRNA expression in the hippocampus displayed a moderate signal continuously over the pyramidal cell layers of Ammon's Horn and the subicular complex. In addition, a moderate number of hybridizing cells were localized principally to the hilar region of the dentate gyrus and a low density of labeled cells seen in the medial nucleus of amygdala (MeA). The dominant site of CRH-R1 expression in the mouse thalamus was the reticular nucleus (RT). In the brainstem regions, CRH-R1 mRNA was intensively expressed in pontine gray (pG) (Figure 17A and D). In both CRH overexpressing mouse lines, CRH-R1 mRNA was decreased in the neocortex, CA1, CA2 and CA3 of hippocampus and the reticular nucleus of the thalamus (RT), whereas, CRH-R1 mRNA was increased in the dentate gray (DG). Interestingly, we observed CRH-R1 expression in the pontine gyrus was decreased in COR-Cam mice. When CRH overexpressed in the entire brain (COR-Nes), CRH-R1 mRNA in the pontine was decreased only in heterozygous mice, whereas, increased in homozygous mice (Figure 17B, C, E, F and Figure 18A and B). 


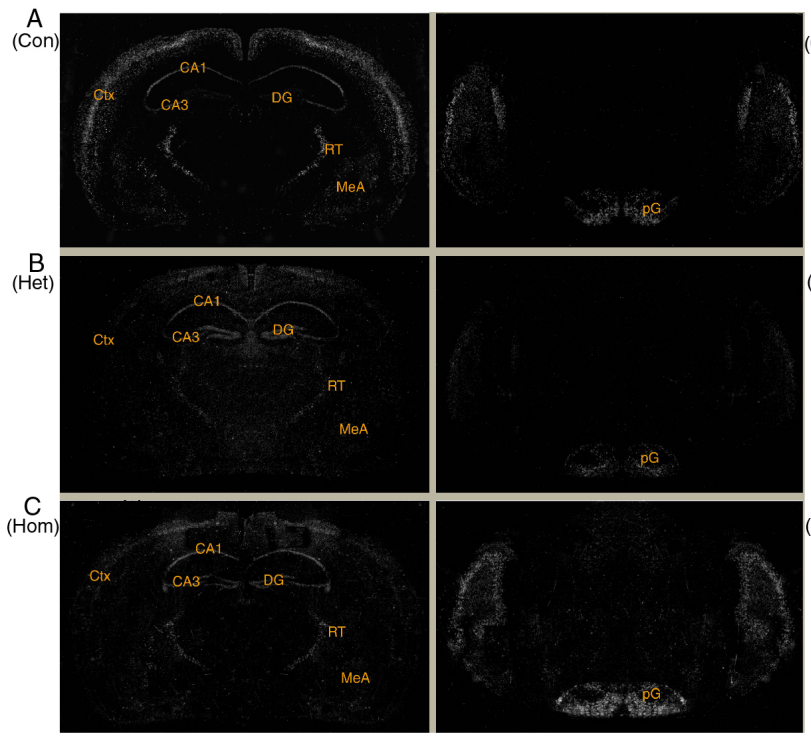

COR-Cam mice
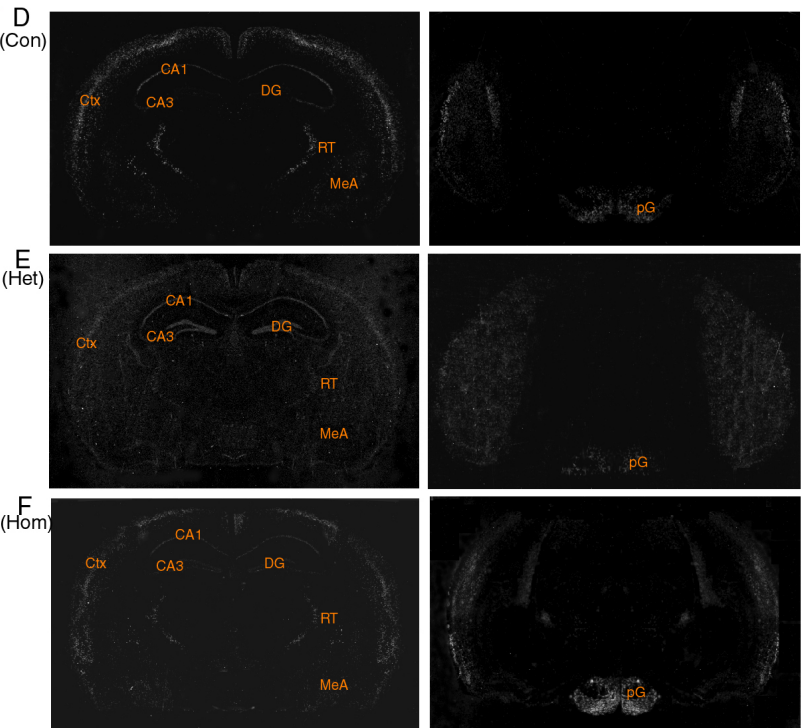

COR-Nes mice

Figure 17. Expression of CRH-R1 mRNA in COR-Cam (A-C) and COR-Nes (D-F) mice (A and D: control mice; $\mathrm{B}$ and $\mathrm{E}$ : heterozygous mice; $\mathrm{C}$ and $\mathrm{F}$ : homozygous mice). Abbreviations: Ctx, cortex; DG, dentate gyrus; MeA, medial nucleus of amygdala; RT, reticular nucleus (thalamus); $\mathrm{pG}$, pontine gray.
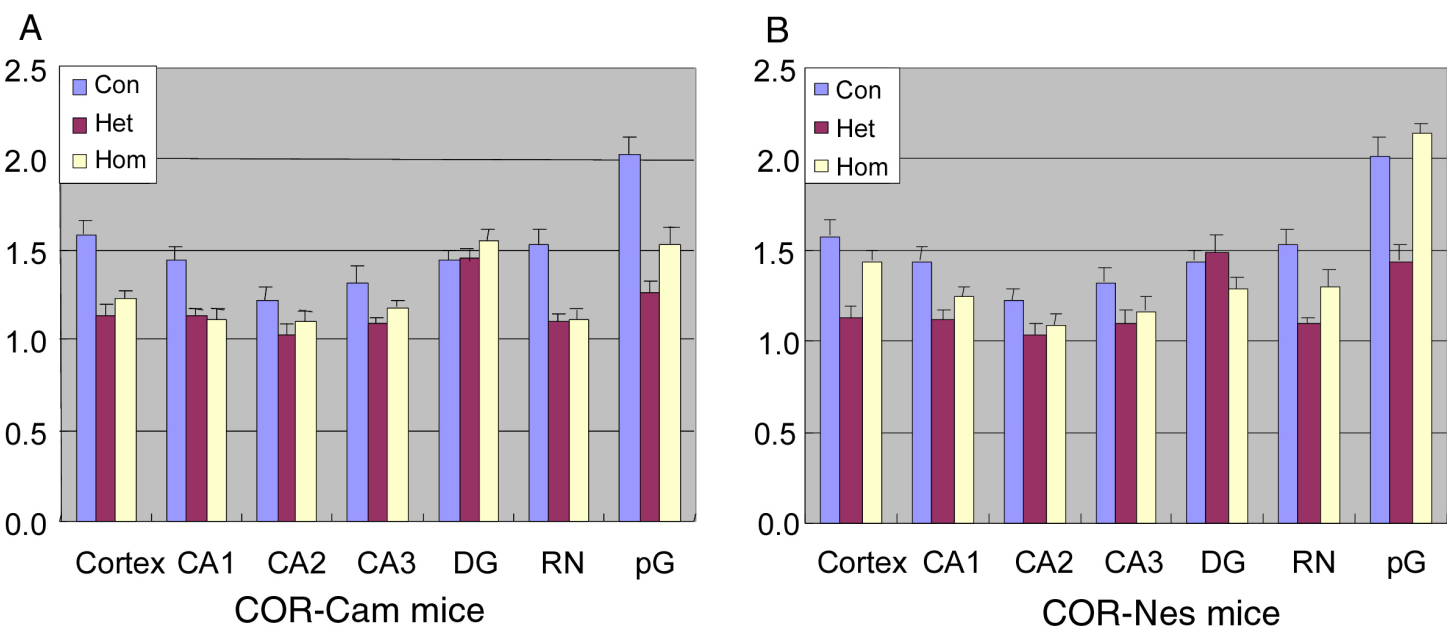

Figure 18. Quantification of CRH-R1 mRNA expression in indicated brain regions of CORCam (A) and COR-Nes (B) mice. 


\subsubsection{Expression of CRH-R2}

CRH-R2 mRNA was also found to express in the cortex. In the cortex, this was manifested mainly as positively hybridizing neurons in deeper layers. Major sites of CRH-R2 expression in mouse brain were evident in the intermediate lateral septal nucleus (LSi) and ventral lateral septal nucleus (LSv). In the hippocampal formation, a sparse signal was seen over the principal cell layers of both the dentate gyrus and Ammon's horn. In addition, in the amygdala, CRH-R2 expression was focused in the medial nucleus, being particularly robust in its posterior aspect (MeAp) and in the basomedial nucleus. Non-neuronal elements of the choroid plexus (CP) comprised another major sites of CRH-R2 mRNA expression. We also found a moderate number of positively hybridizing cells which were localized in the lateraldorsal nucleus of thalamus (LD) and ventral lateral nucleus of thalamus (VL) (Figure 19A and D). CRH overexpression in the forebrain (COR-Cam) increased expression of CRH-R2 in the thalamus. Increased CRH-R2 mRNA expression was also found in the septum, dentate gyrus, choroids plexus only in heterozygous COR-Cam mice. However, CRH$\mathrm{R} 2$ expression in the choroid plexus was decreased in homozygous COR-Cam mice (Figure 19B and C and Figure 20A). CRH overexpression in the entire brain (CORNes) decreased CRH-R2 mRNA expression in the CP. CRH-R2 mRNA was increased in lateral septum and thalamus in homozygous COR-Nes mice compared to control (Figure 19E and $\mathrm{F}$ and Figure 20B). 


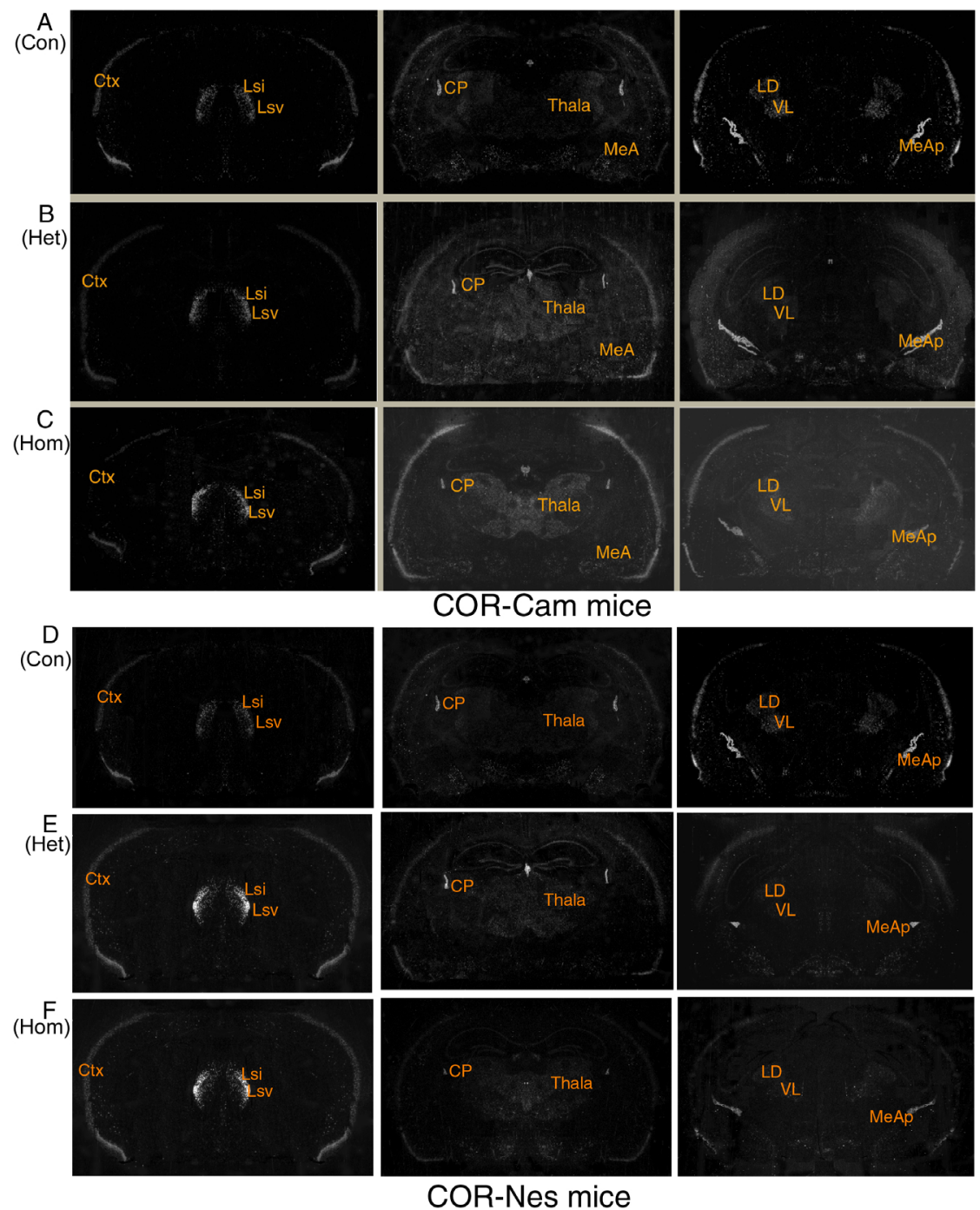

Figure 19. Expression of CRH-R2 mRNA in COR-Cam (A-C) and COR-Nes (D-F) mice (A and D: control mice; $\mathrm{B}$ and $\mathrm{E}$ : heterozygous mice; $\mathrm{C}$ and $\mathrm{F}$ : homozygous mice). Abbreviations: CP, choroid plexus; Ctx, cortex; LD, lateral dorsal nucleus of thalamus; Lsi, intermediate lateral septal nucleus; Lsv, ventral lateral septal nucleus; MeA, medial nucleus of amygdala; MeAp, medial nucleus of amygdala posterior part; Thala, thalamus; VL, ventral lateral nucleus of thalamus.
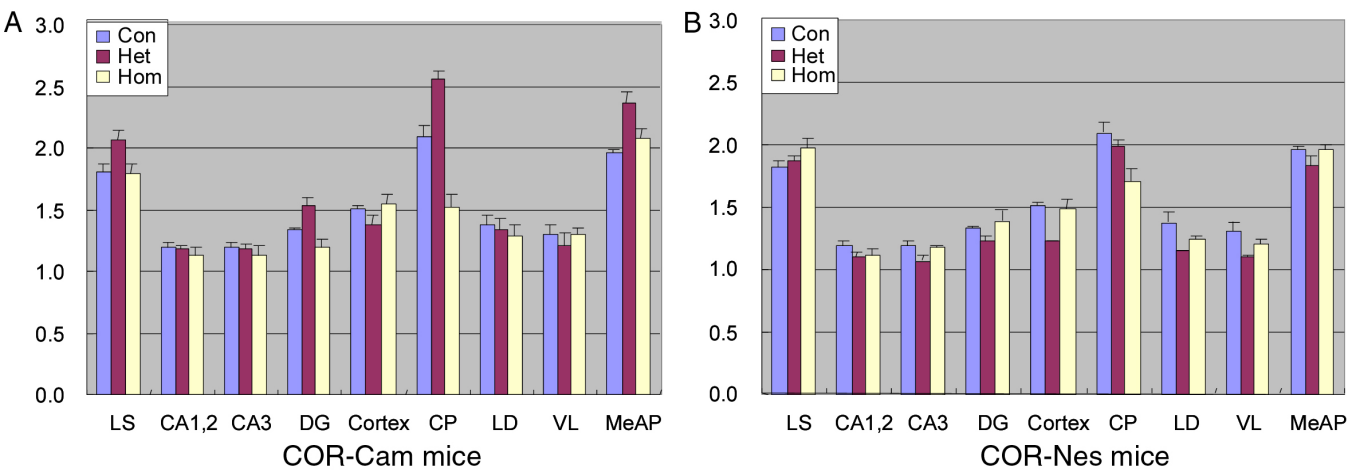

Figure 20. Quantification of CRH-R2 mRNA expression in the different brain regions of COR-Cam (A) and COR-Nes (B) mice. 


\subsubsection{Expression of AVP}

ISH experiments showed AVP expression in the magnocellular subdivisions of the PVN and in the supraoptic nucleus (SON). There was no difference detectable between the different genotype of both CRH overexpressing mouse lines (Figure 21).

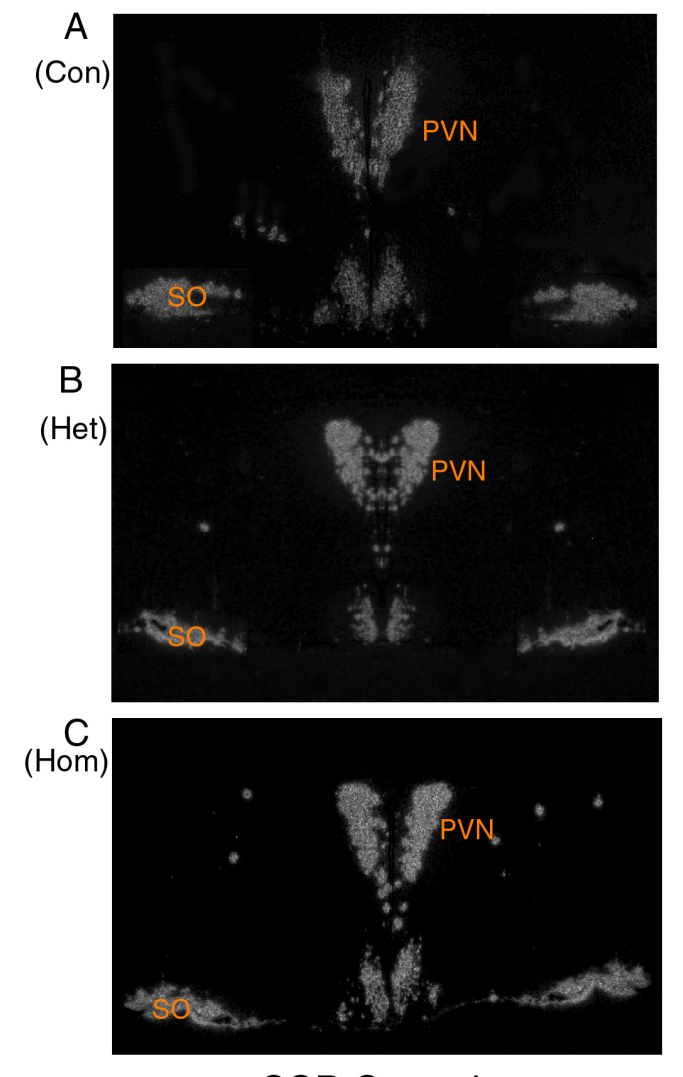

COR-Cam mice
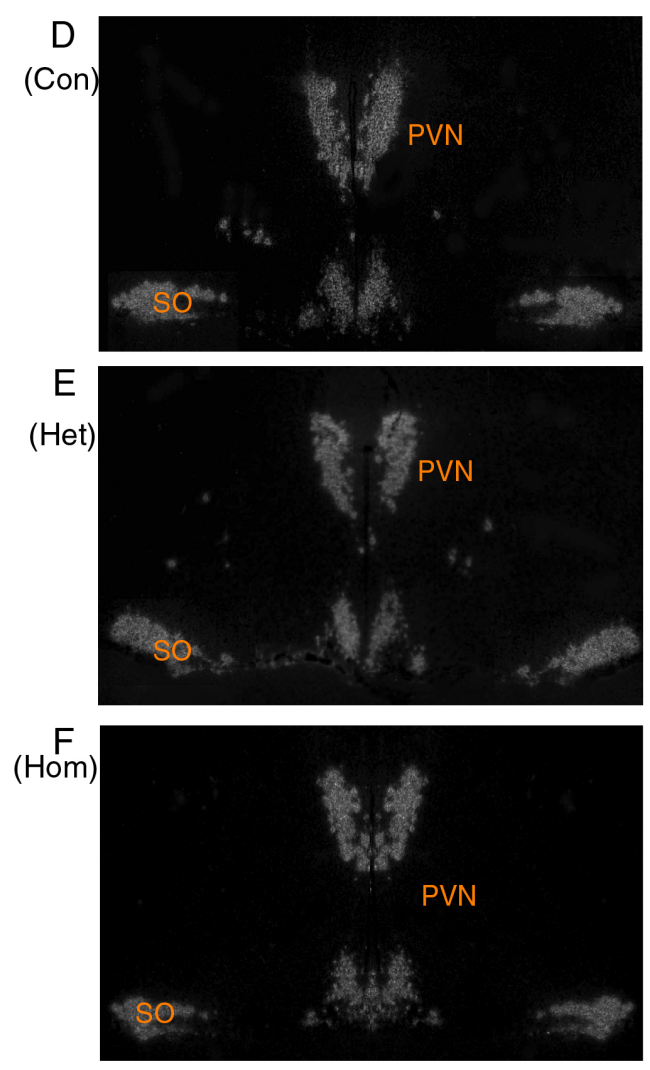

COR-Nes mice

Figure 21. Expression of AVP mRNA in COR-Cam (A-C) and COR-Nes (D-F) mice (A and $\mathrm{D}$ : control mice; $\mathrm{B}$ and $\mathrm{E}$ : heterozygous mice; $\mathrm{C}$ and $\mathrm{F}$ : homozygous mice). Abbreviations: PVN, paraventricular nucleus of hypothalamus; SON, supraoptic nucleus. 


\subsubsection{Expression of GR}

The glucocorticoid receptor (GR) is a widely expressed ligand-dependent transcription factor that belongs to the nuclear hormone receptor superfamily and modulates a broad range of neural functions, including stress responsiveness and cognitive function (Sapolsky et al., 1984) (McEwen and Sapolsky, 1995) (Meaney et al., 1996) (De Kloet et al., 1998) (Roozendaal et al., 2003). Dysregulation of GR function has been associated with depression and anxiety disorders. In control mice, layer 1 of neocortex possessed a small number of GR expressing cells, high densities of GR expressing cells were demonstrated in layers 2, 3 and layer 6 of neocortex. Layer 4 and 5 of neocortex showed a moderate number of hybridized cells. In the Ammon's horn, very high densities of GR expressing cells were present in the CA1 and CA2, in contrast, the CA3 had lower densities of GR expressing cells. A large number of hybridizing cells were recognized in the granule cell layer of the dentate gyrus (DG). The central nucleus of the amygdala (CeA) and medial nucleus of the amygdala (MeA) possessed a large number of GR mRNA-containing cells. The intensities of the GR mRNA-containing cells in the thalamus were weak to moderate. The paraventiricular nucleus of the thalamus (PVT) and the lateral posterior nucleus (LP) possessed moderate densities of GR labeled cells. The other areas of the thalamus showed only a few GR expressing cells. The intensities of GR mRNA observed in the hypothalamus were moderate to strong, the high density of GR mRNA-containing cells was noted in the ventralmedial part of hypothalamus (VMH), the moderate density of the GR mRNA in the arcuate nucleus (ARH) and in the cells of periaqueductal gray (PAG). The other zones of the hypothalamus showed low densities of GR expressing cells (Figure 22A and D). CRH overexpression decreased GR mRNA expression in both CRH overexpressing mouse lines (Figure 22B, C, E, F and Figure 23A and B).

These results suggested that overexpression of CRH in the forebrain or in the entire brain substantially altered basal mRNA expression of CRH-R1, CRH-R2 and GR in a highly region specific fashion. 


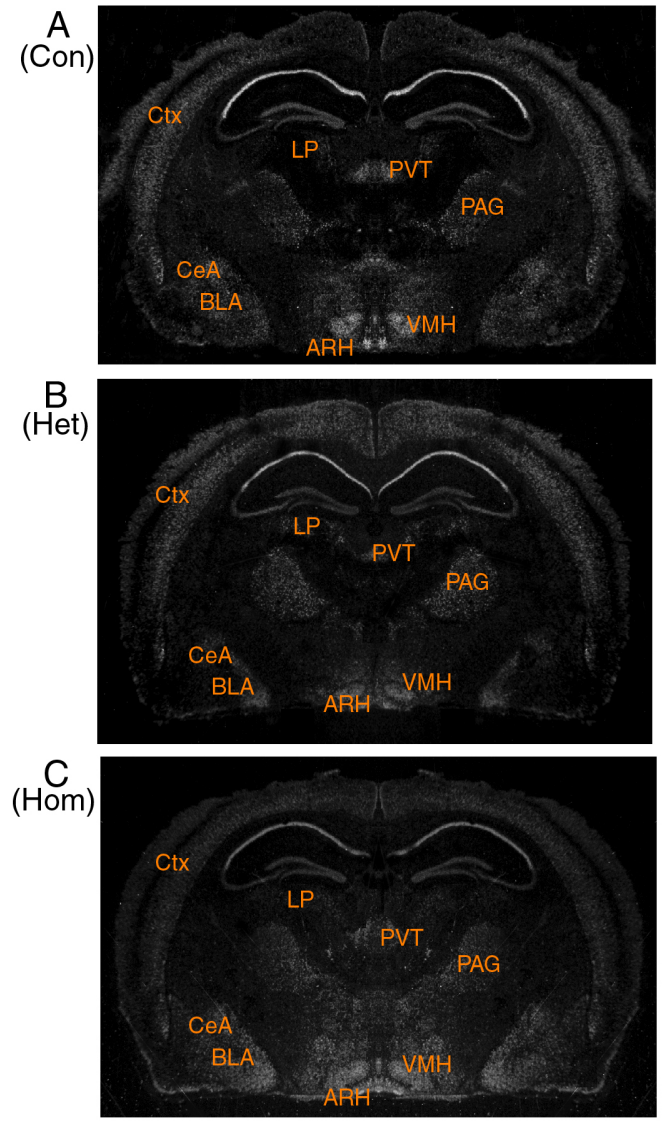

COR-Cam mice

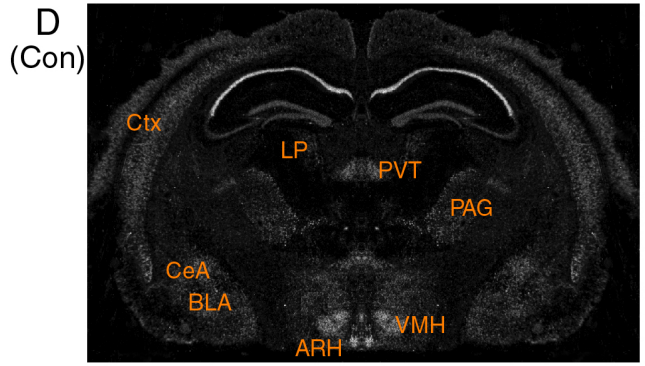

$\underset{(H e t)}{E}$
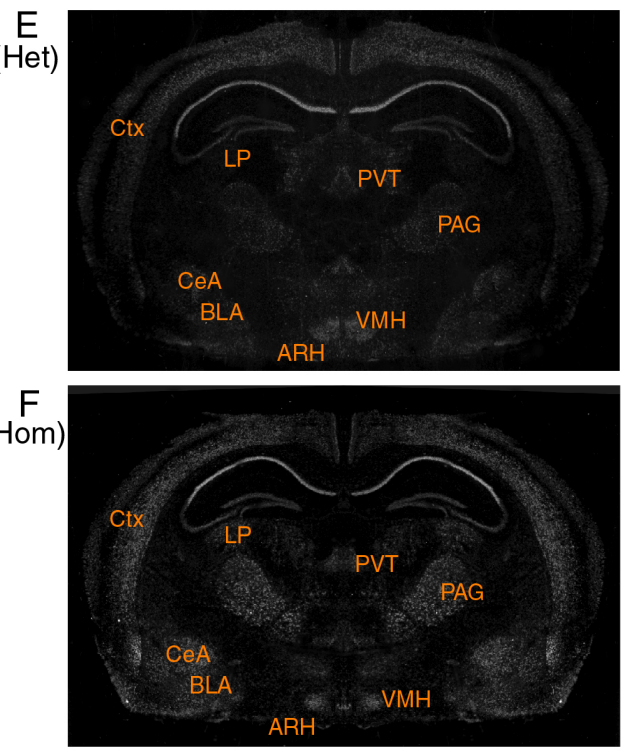

COR-Nes mice

Figure 22. Basal expression of GR mRNA in COR-Cam (A-C) and COR-Nes (D-F) mice (A and D: control mice; $\mathrm{B}$ and $\mathrm{E}$ : heterozygous mice; $\mathrm{C}$ and F: homozygous mice). Abbreviations: ARH, arcuate nucleus; BLA, basolateral nucleus of amgdala; CeA, central nucleus of amygdala; LP, lateral posterior nucleus thalamus; PAG, periaqueductal gray; PVT, paraventricular nucleus thalamus; VMH, ventromedial nucleus hypothalamus.
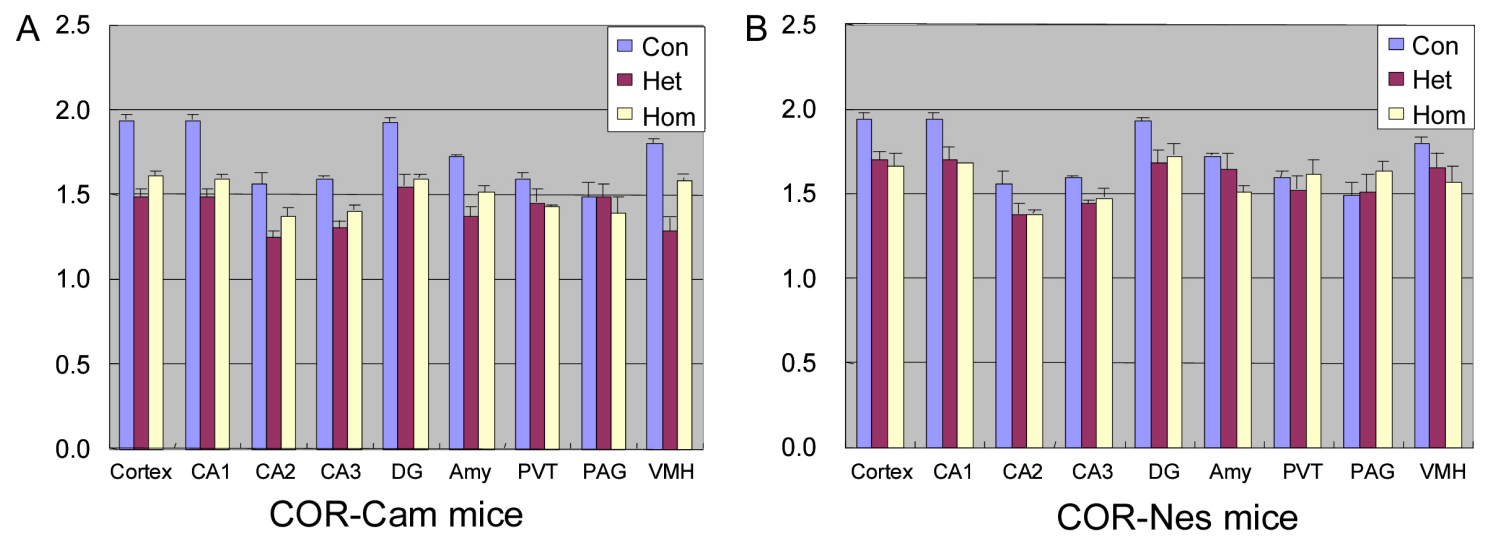

Figure 23. Quantification of GR mRNA expression in the different brain regions of CORCam (A) and COR-Nes (B) mice. 


\subsection{Hypothalamic-Pituitary-Adrenal axis activity}

To investigate the effect of long-term central CRH overexpression on HPA axis regulation, basal plasma corticosterone concentrations were measured. In COR-Cam mice, corticosterone in the morning was slightly increased in heterozygous mice, and increased 1.6-fold in homozygous mice compared to control mice (Figure 24A). In COR-Nes mice, corticosterone in the morning was increased 1.8- and 2.4-fold in heterozygous and homozygous mice respectively compared to control mice (Figure 24B).
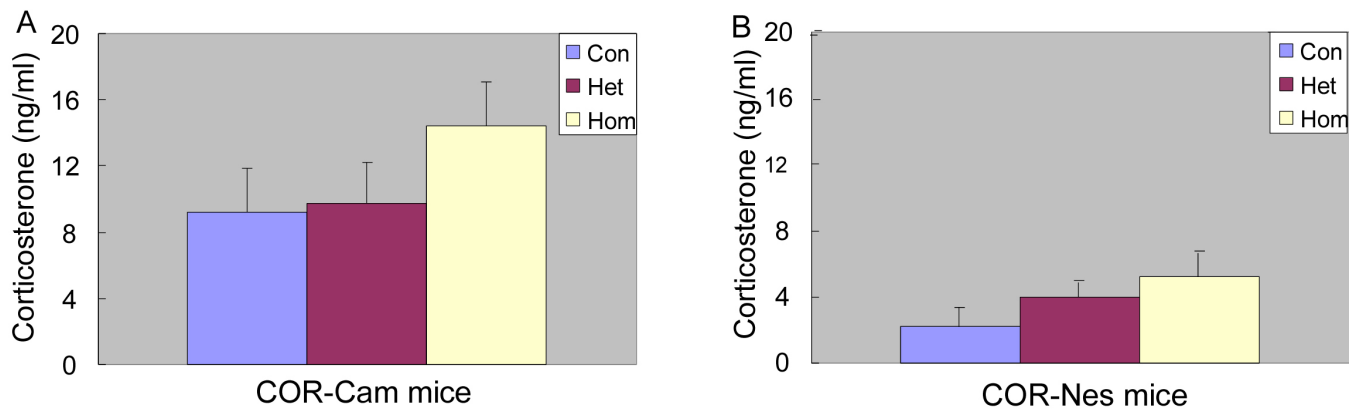

Figure 24. Plasma corticosterone concentrations in control and COR-Cam (A) and COR-Nes (B) mice under basal conditions in the morning $(8: 00 \mathrm{am})$.

\subsection{Body weight}

In addition to stress-related behaviors, $\mathrm{CRH}$ is also thought to have an important role in control of food intake and energy balance (Richard, 1993) (Rothwell, 1990). Administration of exogenous CRH (injected into third ventricular (i3vt)) reduced food intake and body weight (De Souza, 1987) and increased thermogenesis (Richard, 1993). The first described CRH overexpressing mouse line (Stenzel-Poore et al., 1992) displayed truncal obesity compared to control mice because of the increased corticosterone resembling a Cushing syndrome-like phenotype. However, the second $\mathrm{CRH}$ overexpressing mouse line generated revealed significantly lower body weights than control mice (Dirks et al., 2002b). To assess the body weight of our CRH overexpressing mice, we weighted 4-month old mice. Forebrain specific overexpression of CRH (COR-Cam) decreased body weight slightly compared to control mice (Figure 25A); CNS wide overexpression of CRH (COR-Nes) decreased body weight significantly compared to control mice (Figure 25B). 

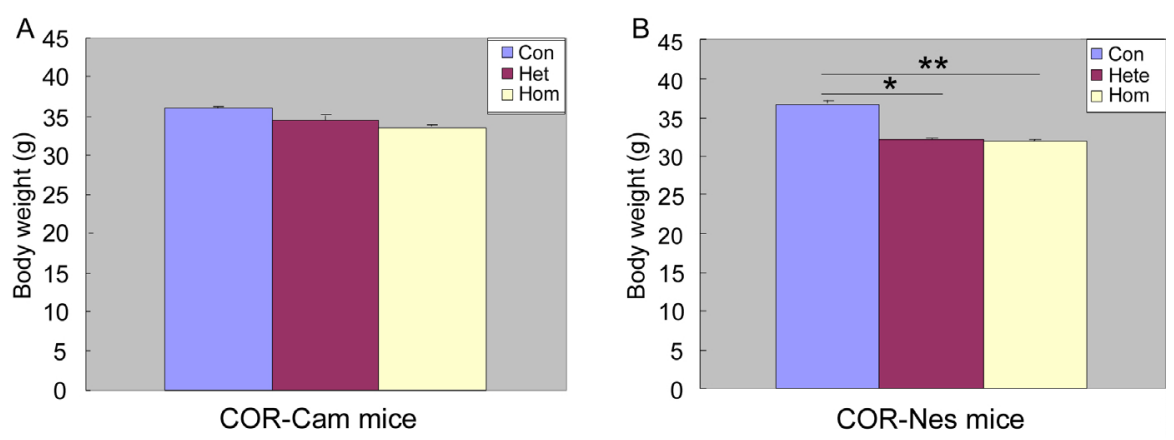

Figure 25. Body weight of COR-Cam (A) and COR-Nes (B) mice. ${ }^{*} \mathrm{P}<0.05,{ }^{*} \mathrm{P}<0.01$. $\mathrm{n}=15$.

\subsection{Acoustic startle response (ASR)}

\subsubsection{Startle reactivity}

Startle is a fast twitch of facial and body muscles evoked by a sudden and intense tactile, visual or acoustic stimulus. The startle pattern consists of eye-lid closure and a contraction of facial, neck and skeletal muscles, as well as an arrest of ongoing behaviors and an acceleration of the heart rate (Koch, 1999). This response pattern is suggestive of a protective function of startle against injury from a predator or from a blow, and of the preparation of a flight/fight response. It serves as a valuable behavioral tool to assess mechanism of sensorimotor response plasticity (Koch, 1999). To investigate the effects of chronic CRH excess on sensory information processing of startling stimuli, both $\mathrm{CRH}$ overexpressing mouse lines were analyzed in the acoustic startling paradigm. Increased startle magnitudes to increasing stimulus intensities were observed in both CRH overexpressing mouse lines (Figure 26A and B). Post hoc indicated that only mice overexpressing $\mathrm{CRH}$ just from a single allele in the anterior forebrain (COR-Cam) showed significantly increased startle magnitude at high stimulus intensities (100-120 dB) (Figure 26A).

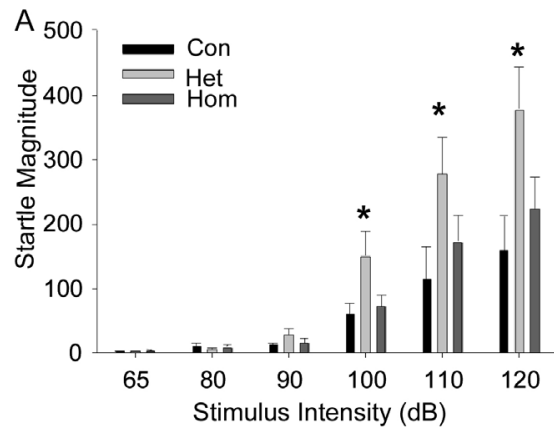

COR-Cam mice

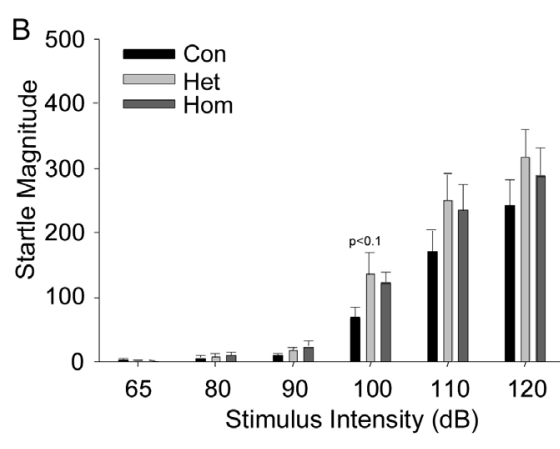

COR-Nes mice

Figure 26. Startle reactivity of COR-Cam (A) and COR-Nes (B) mice. Mean startle magnitude as function of stimulus intensity $(\mathrm{dB}) .{ }^{*} \mathrm{P}<0.05$ versus control, $\mathrm{n}=11$. 


\subsubsection{Habituation}

Habituation is a theoretical construct referring to the reduction in magnitude of the ASR after repeated presentation of the startling stimulus that is not due to muscle fatigue or blunting of sensory receptor responsiveness (Christoffersen, 1997). The response during the 5 trials reflects the response to the initial acoustic stimuli. CORCam mice and COR-Nes mice did not show any normal habituation (Figure 27), only homozygous COR-Nes mice showed a deficit habituation in the trials 3-5 (Figure 27B). Overall, the startle magnitude was higher in both CRH overexpressing mouse lines compared to control mice.

Post hoc tests showed that, startle magnitude was significantly increased in block 2-3 in heterozygous COR-Cam mice (Figure 27A), and in block 5 in homozygous COR-Nes mice (Figure 27B) compared to control mice. A slightly increased startle magnitude was observed in homozygous COR-Cam and heterozygous COR-Nes mice.
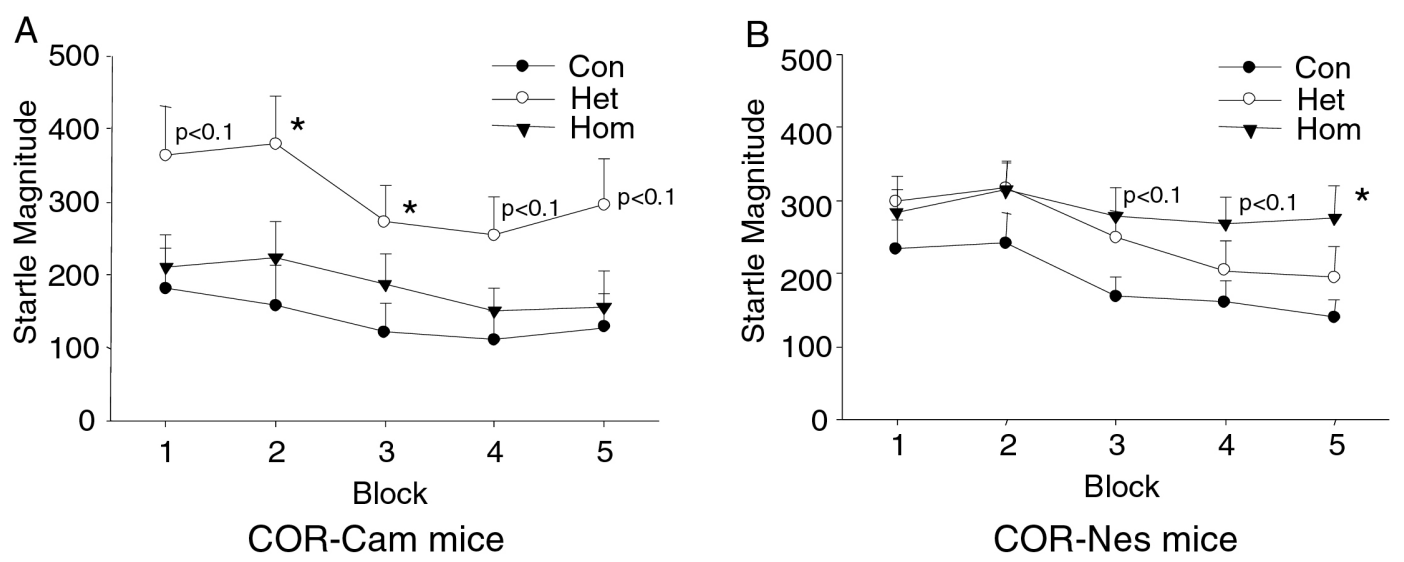

Figure 27. Habituation of the acoustic startle response in COR-Cam (A) and COR-Nes (B) mice. Mean startle magnitude (in arbitrary units, \pm SEM) as function of blocks of control and CRH overexpressing mice, ${ }^{*} \mathrm{P}<0.05$ versus control, $\mathrm{n}=11$.

\subsubsection{The CRH-R1 antagonist (NBI-30775) reversed CRH-induced startle response in COR-Nes but not in COR-Cam mice}

Figure 28 showed the effects of the CRH-R1 specific antagonist (NBI-30775) on startle magnitude. NBI30775 was infused into the lateral ventricle at different concentration $(2 \mathrm{mg} / \mathrm{kg}, 20 \mathrm{mg} / \mathrm{kg})$ and animals were compared to vehicle treated mice. Any concentration of NBI-30775 did not reverse the increased startle magnitude 
in COR-Cam mice (Figure 28A). However, the startle magnitude was reversed with increasing NBI-30775 concentration in COR-Nes mice (Figure 28B).

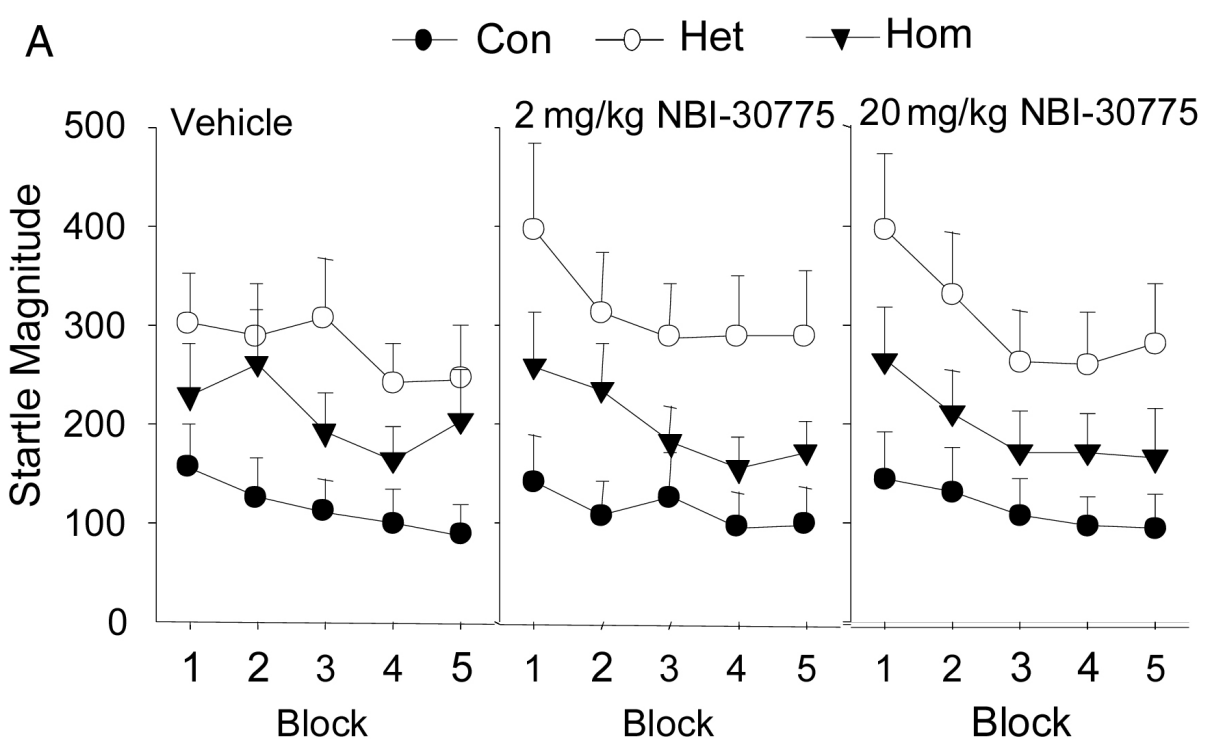

COR-Cam mice

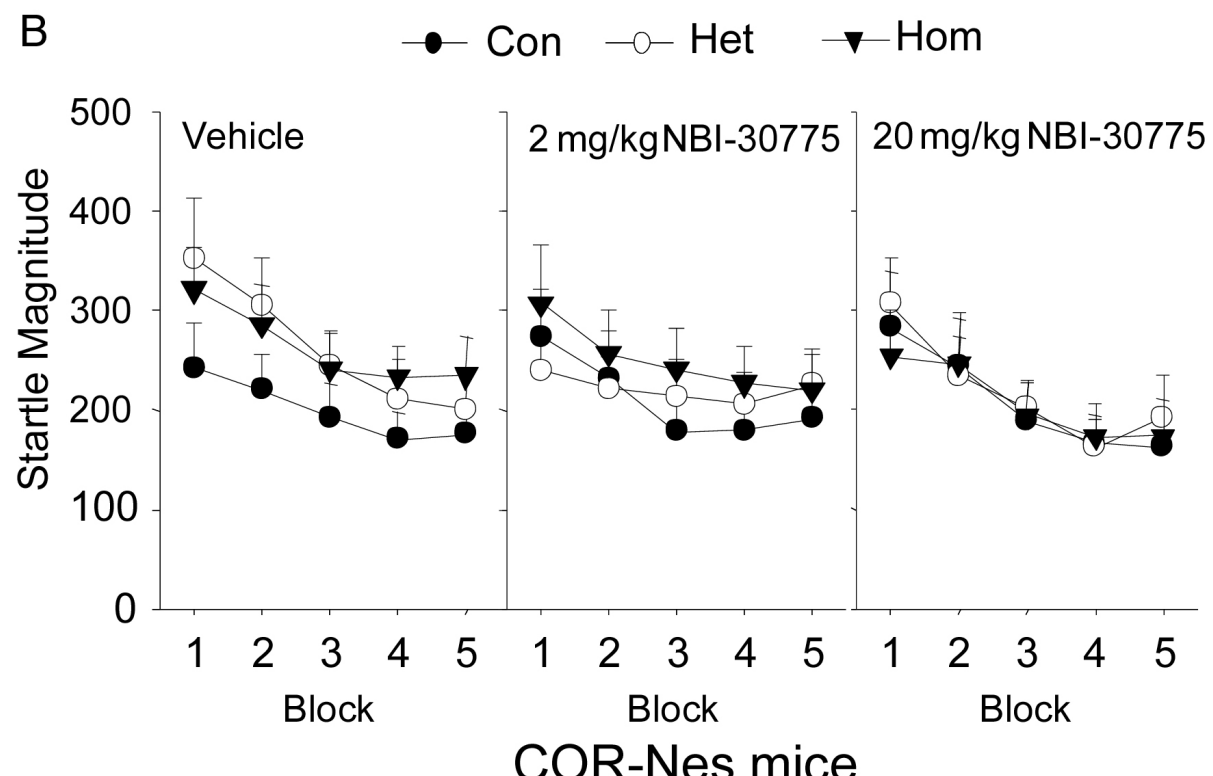

Figure 28. Effect of CRH-R1 antagonist (NBI-30775) on habituation and magnitude of startle response in COR-Cam (A) and COR-Nes (B) mice, $\mathrm{n}=11$. 


\subsubsection{Reduced prepulse inhibition (PPI) in COR-Nes but not in COR-Cam mice}

The ASR magnitude is reduced if a distinctive non-startling tactile, visual (Campeau and Davis, 1995) or acoustic (Hoffman and Ison, 1980) stimulus is presented $30-500 \mathrm{msec}$ before the startling stimulus. This phenomenon is termed as PPI and is used as an operational measure for sensorimotor gating mechanisms. PPI of the ASR is reduced in a variety of neuropsychiatric disorders that are characterized by a general reduction of the ability to gate intrusive sensory, motor or cognitive information, for example in schizophrenia, schizotypal personality disorder, Huntington's disease, obsessive compulsive disorder, Tourette's syndrome and attention deficit disorder (Swerdlow and Geyer, 1998).

To investigate role of chronic CRH excess on sensorimotor gating mechanism, two different procedures were used in our study: one examined the effects of prepulse with varying intensities on PPI, and the other was designed to study the effects of different intervals between the onset of the prepulse and that of the startle stimulus on PPI.

With increasing prepulse intensities, the percent of PPI was increased in all genotypes of both CRH overexpressing mouse lines. The percent of PPI was increased slightly in heterozygous COR-Cam mice, and slightly decreased in homozygous COR-Cam (Figure 29A). Heterozygous the homozygous COR-Nes mice displayed lower PPI levels compared to control mice. At a prepulse intensity of $16 \mathrm{~dB}$ above background, this decrease is significant in homozygous COR-Nes mice (Figure 29B).

The percent PPI as a function of the interval between prepulse onset and startle stimulus onset could be described as a u-shaped curve in control and both CRH overexpressing mice. No big difference was observed between control, heterozygous and homozygous COR-Cam mice. Heterozygous and homozygous COR-Nes mice showed lower percent of PPI compared to control mice at different intervals between prepulse and stimulus (from 20-1080 msec) (Figure 29C and D). 

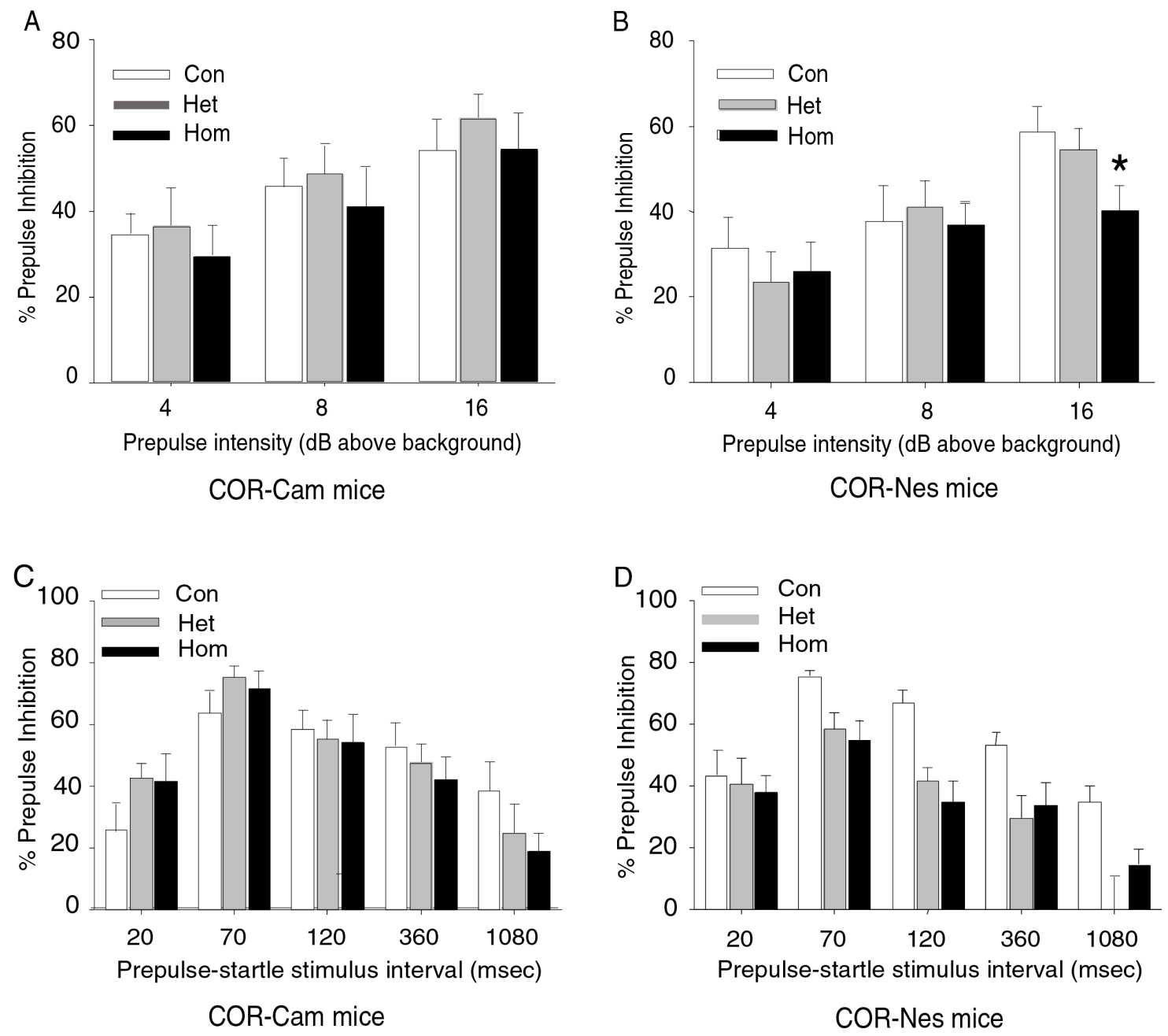

Figure 29. Prepulse inhibition of the acoustic startle response in COR-Cam (A and C) and COR-Nes (B and D) mice. A and B: Percent PPI as function of prepulse intensity ( $d B$ above background); C and D: Percent PPI as function of prepulse-startle stimulus interval (msec). ${ }^{*} \mathrm{P}<0.05$ versus control, $\mathrm{n}=11$. 


\subsubsection{CRH-R1 antagonist increased PPI in COR-Nes mice, but not in COR-Cam mice}

COR-Nes mice displayed decreased levels of PPI (Figure 29B and D), therefore, we hypothesized that activation of CRH-R1 via $\mathrm{CRH}$ overexpression in the entire CNS was responsible for the CRH-induced decreases in PPI. We injected a CRH-R1 antagonist (NBI-30775) into the lateral ventricle with different concentration (2 $\mathrm{mg} / \mathrm{kg}$ and $20 \mathrm{mg} / \mathrm{kg}$ ), and found NBI-30775 did not have an effect on PPI in CORCam mice (Figure 30A). However, NBI-30775 reverted the decrease of PPI observed in heterozygous and homozygous COR-Nes mice dose-dependently in comparison with vehicle treated throughout all prepulse-startle stimulus intervals (Figure 30B).
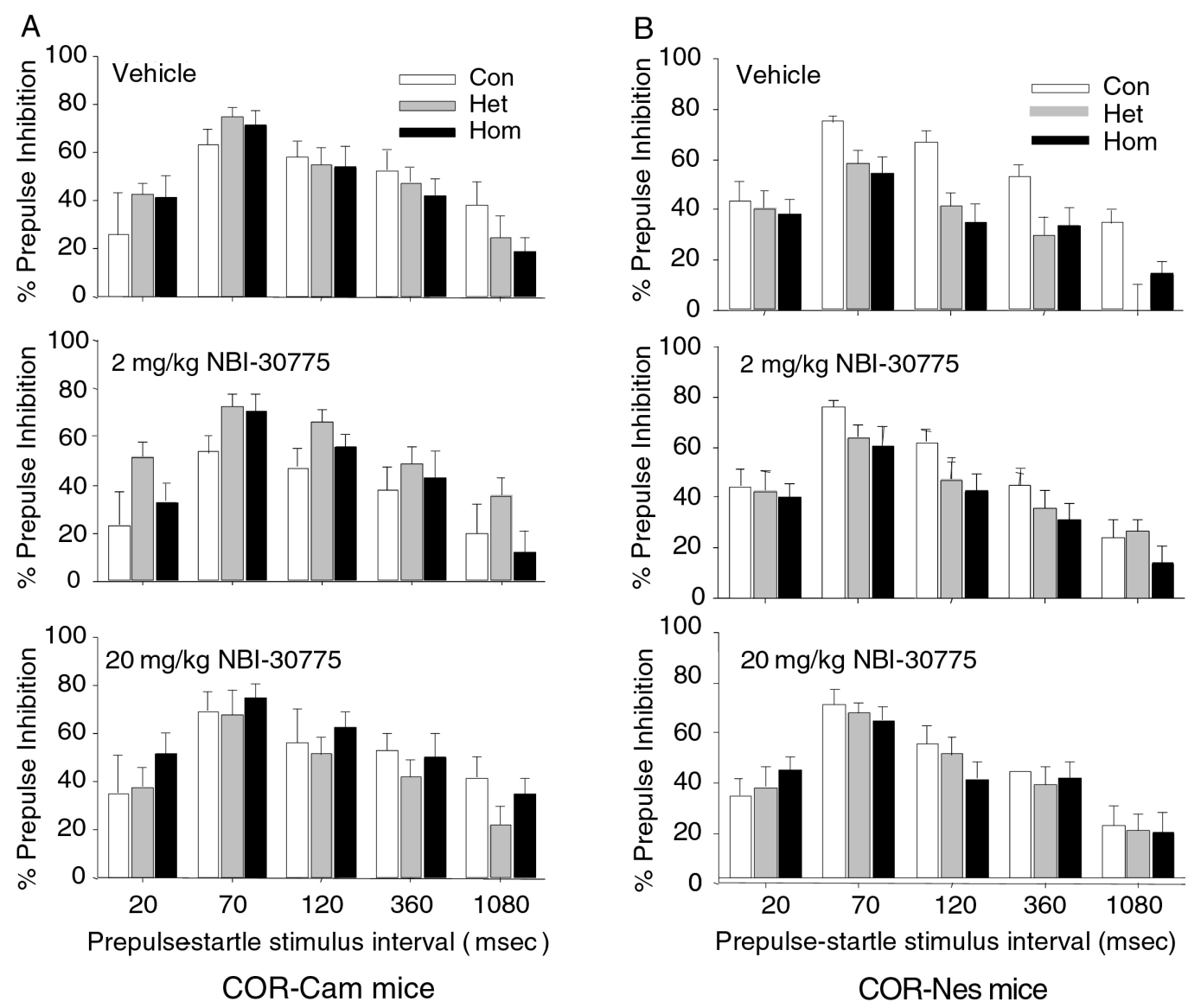

Figure 30. Effect of CRH-R1 antagonist (NBI-30775) at different concentration ( $2 \mathrm{mg} / \mathrm{kg}$ and $20 \mathrm{mg} / \mathrm{kg}$ ) on prepulse inhibition of the acoustic startle response in COR-Cam (A) and CORNes (B) mice compared to control mice, $\mathrm{n}=11$. 


\subsection{Assessment of conditioned fear in COR-Nes mice}

The fear-potentiated startle paradigm was introduced in 1951 (Brown et al., 1991). In this model, the animals are trained to associate a neutral stimulus, for example, a light or a tone, with an aversive stimulus such as a mild electric footshock. As a result of this association, the condition stimulus will evoke a variety of behavioral, endocrine and autonomic responses that are typically elicited in dangerous situations (LeDoux, 2000). In the last decades, fear conditioning has emerged as a leading paradigm for studying cellular correlates of learning and memory (Tang et al., 2001).

To assess the involvement of CRH in modulation of learning and memory, CORNes mice were tested in auditory fear conditioning. Mice were trained to associate a tone with a foot shock (conditioning). The relative time not moving was analyzed at different time point after providing the tone. Heterozygous and homozygous CORNes mice showed less freezing compared to control mice at 1 day (d1) after conditioning. The result also revealed an effect of time, because heterozygous and homozygous COR-Nes mice did not differ in their freezing response at 6 (d6) and 21 day (d21) after conditioning compared to control littermates (Figure 31A). Moreover, heterozygous and homozygous COR-Nes mice also showed less freezing than control mice at $24 \mathrm{~h}$ later by re-exposing to the conditioning chamber for $3 \mathrm{~min}$ without tone presentation after conditioning (Figure 31B).
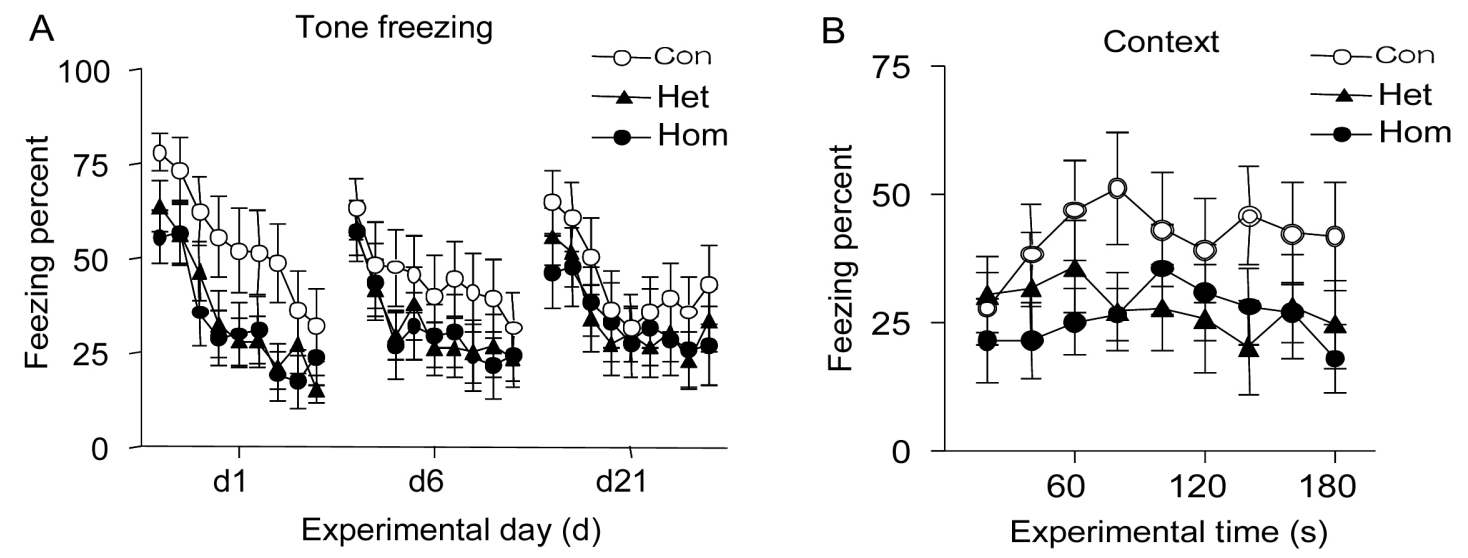

COR-Nes mice

Figure 31. Response to tone at $d 1, d 6$ and $d 21$ (A) and to contextual at $d 1$ (B) after fear conditioning of COR-Nes mice. 


\subsection{Forced swimming test (FST) in COR-Nes mice}

The FST is utilized to reproduce passive coping responses to stress that may model a relevant aspect of human depression in rodent species (Porsolt, 2000). Animals showing high levels of passive responses to the FST are assumed to model pathologically depressed individuals. Among various theoretical models, forced swimming is widely used for an antidepressant screening test (Porsolt et al., 1977).

In order to investigate the role of $\mathrm{CRH}$ in this depression model, COR-Nes mice were tested in $24-26{ }^{\circ} \mathrm{C}$ warm water (depth $15 \mathrm{~cm}$, a 6-min test duration) firstly. A significant decrease of immobility (floating) time (Figure 32A) and increase of struggling time (Figure 32B) was observed in heterozygous and homozygous CORNes mice compared to control mice.

Water temperature influences the degree of immobility time in the FST (PetitDemouliere et al., 2005). The influence of water temperature on immobility time of the mice was also studied in COR-Nes mice. Homozygous COR-Nes mice showed less immobility in compared to control mice as observed in the $24-26{ }^{\circ} \mathrm{C}$ warm water (Figure 32C). However, no difference in the struggling time was observed between different genotypes (Figure 32D) suggesting an effect of water temperature.

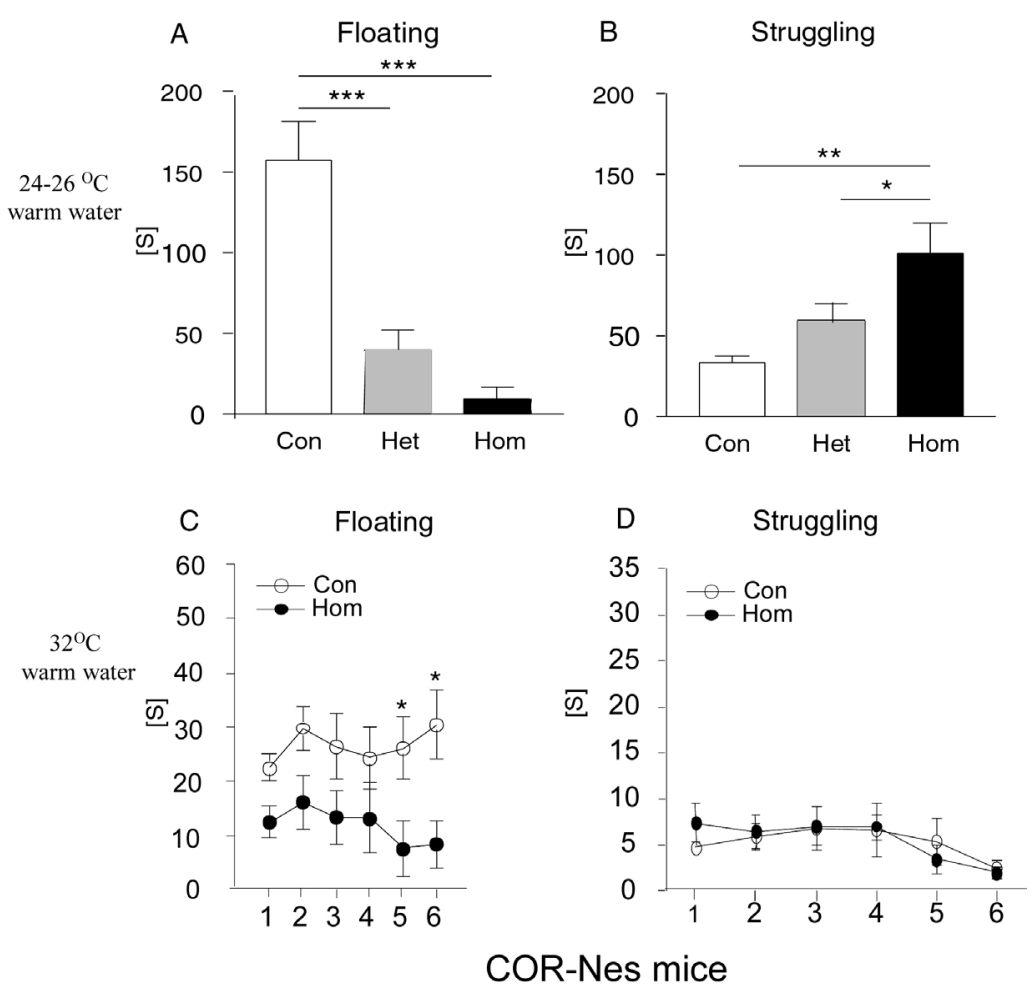

Figure 32. Immobility (A and C) and struggling ( $B$ and $D$ ) time during the last $3 \mathrm{~min}$ in 24-26 ${ }^{\circ} \mathrm{C}(\mathrm{A}$ and $\mathrm{B})$ and $32{ }^{\circ} \mathrm{C}(\mathrm{C}$ and $\mathrm{D})$ warm water in COR-Nes mice. Data were presented as mean \pm SEMs, ${ }^{* * *} \mathrm{p}<0.001,{ }^{* *} \mathrm{p}<0.01,{ }^{*} \mathrm{p}<0.05, \mathrm{n}=11$. 


\subsection{Tail suspension test (TST) in COR-Nes mice}

The tail suspension test (TST) shares a common theoretical basis and behavioral measure with the FST (Steru et al., 1985). In the TST, mice are suspended by the tail using adhesive tape to a horizontal bar. The presence or absence of immobility, defined (Steru et al., 1985) as the absence of limb movement. Typically, mice immediately engage in several "agitation- or escape-like" behaviors, followed temporally by increasing bouts of immobility that is reversed by antidepressant treatments. The TST has been shown to be sensitive to various antidepressants.

COR-Nes mice were analyzed. Mice were securely fastened with medical adhesive tape by the tip $(1.0-1.5 \mathrm{~cm})$ of the tail to a round metallic bar and suspended $30 \mathrm{~cm}$ above the ground, a 6-min test duration was used. A significant decrease of immobility was observed from 2-5 min during 6-min test period in homozygous COR-Nes mice compared to control mice (Figure 33).

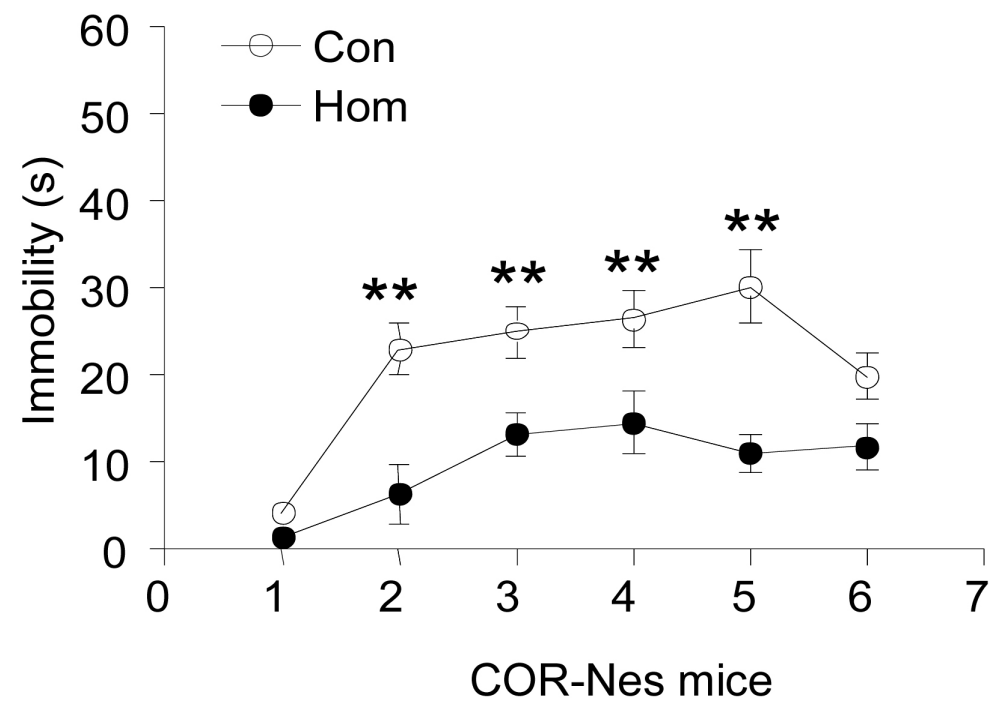

Figure 33. Immobility time during $6 \mathrm{~min}$ in tail suspension test in COR-Nes mice. Data were presented as mean $\pm \mathrm{SEMs}, \mathrm{n}=11, * * \mathrm{P}<0.01$. 


\section{Discussion}

\subsection{Generation of site-specific CRH overexpressing mice}

The CRH system is involved in mediating behavioral, autonomic, neuroendocrine, and immune responses to stress. Chronically elevated levels of CRH are implicated in human stress-related and affective disorders, including generalized anxiety disorder and major depression (Arborelius et al., 1999) (Mitchell, 1998). In previously established CRH transgenic mouse lines (Stenzel-Poore et al., 1992) (Dirks et al., 2002a). CRH overexpression results in elevated ACTH and glucocorticoids levels accompanied by symptoms of Cushing-like syndrome (Stenzel-Poore et al., 1992) (Groenink et al., 2002). These CRH overexpressing mice showed enhanced anxietylike behavior, although it can not be excluded that part of the CRH effects on anxietyrelated behavior may be mediated via its chronic activation of the HPA-system. Moreover, it has been shown that the number of copies integrated and the site of integration into the genome in classic transgenics can have an effect on the level and spatio-temporal pattern of transgene expression. To gain more insight into the relationship between hyperactivity of the CRH system and associated physiological changes in particular neuroendocrine, autonomic, and behavioral alterations/ consequences, we utilized the properties of the retroviral-trapped ROSA26 (R26) locus, which has proven as a useful tool to achieve ubiquitous expression during embryonic development and in the adult. In addition to the mCRH cDNA we introduced a IRES-LacZ reporter gene into the ROSA26 locus, the $\beta$-galactosidase ( $\beta$ gal) activity constitutes an excellent marker for labeling of expressing cells (Friedrich and Soriano, 1991) (Zambrowicz et al., 1997). Homozygous ROSA26 mutant mice have no overt phenotype (Soriano, 1999).

Combining the knock-in of a single copy of the murine CRH cDNA into the ROSA26 locus with the Cre/loxP system enabled us to overexpress CRH in a spatially regulated fashion at different dosages. We developed two conditioned CRH overexpressing mouse lines: COR-Cam with $\mathrm{CRH}$ overexpression restricted in the anterior forebrain and COR-Nes with $\mathrm{CRH}$ overexpression in the entire central nervous system. In COR-Cam mice, CRH was not overexpressed in the PVN thus regulation of basal and stress-associated activation of the HPA system showed remain unaltered. These two CRH overexpressing mouse lines provide powerful genetic tools to study the site-specific and dose-dependent effect of chronic CRH hyperactivity. 


\subsection{Alterations in expression of CRH and CRH related genes}

\subsubsection{CRH mRNA and protein expression}

Endogenously, the highest density of CRH-containing cell bodies was found in the nucleus ambiguus (A) and PVN, moderate density of CRH-containing cell bodies was found in piriform cortex and locus coerulus (Figure 11A and D). In COR-Cam mice, $\mathrm{CRH}$ was strongly overexpressed in the neocortex, hippocampus, medial septal nucleus, CeA and BNST (Figure 11B, C, E, F). In COR-Nes mice, CRH was strongly overexpressed in the neocortex, hippocampus, medial spetal nucleus, BNST, cerebellum, brainstem (Figure 12B, D, E). CRH-containing interneurons distributed in the neocortex are believed to be important in several behavioral actions of the peptide, including effects on cognitive processing (Lee and Davis, 1997); CRH was strongly overexpressed in the hippocampus, which contains different amounts of CRH-R1, CRH-R2, and CRH-BP. The hippocampus appears to be required for contextdependent (Kim and Fanselow, 1992) (Phillips and LeDoux, 1992) and tonedependent fear conditioning (Maren et al., 1997). Hippocampal function is particularly influenced by glucocorticoids (de Kloet et al., 1999) (McEwen, 1999). By acute modulation of neuronal excitability, glucocorticoids affect hippocampusdependent behavior such as spatial memory. Chronic changes in glucocorticoid levels impair hippocampal function and morphology, which ultimately leads to cognitive impairments (McEwen and Sapolsky, 1995). The BNST is another potential site of $\mathrm{CRH}$ action and potential $\mathrm{CRH} /$ norepinephrine interaction. $\mathrm{CRH}$ injected directly into the BNST enhances the startle response, and neurotoxin cell-body-specific lesions of the BNST or microinfusion of a $\mathrm{CRH}$ receptor antagonist blocked the effects of icv administered CRH on the startle response (Lee and Davis, 1997). Moreover, it has been proposed that $\mathrm{CRH}$ cell bodies in the BNST processed cue information to activates the CeA (Davis, 1998). The CeA in turn activates hypothalamic and brainstem target areas involved in conditioned fear or anxiety, respectively. In CORNes mice, CRH is strongly overexpressed in the cerebellum, spinal cord, and limbic parts of the telencephalon, thalamus, and autonomic-related cell groups in the brainstem. Cells and fibers in many of these sites are associated with systems that regulate the output of the autonomic nervous system. $\mathrm{CRH}$ projections to the brainstem (specifically LC, A1 catecholamine cell groups, and dorsal vagal complex) 
and spinal cord stimulate sympathetic tone to the adrenal medulla resulting in epinephrine secretion, stimulation of sympathetic noradrenergic outflow, and inhibit parasympathetic nervous activity (Fisher, 1989).

Gold and colleagues indicated that stress initially activates the hypothalamic CRH system (i.e. CRH in the PVN), resulting in the hypersecretion of glucocorticoids from the adrenal gland. In addition, the psychological component of the stressor stimulates the amygdaloid CRH system (i.e. CRH in the central nucleus of the amygdala). Glucocorticoids exert GR-mediated negative feedback effects on the biosynthesis and release of CRH in the PVN and ACTH in the anterior pituitary (AP) directly or indirectly through the brainstem catecholaminergic nuclei such as the LC, resulting in the termination of stress-induced HPA axis activation. In the chronic phase of stress, down-regulation of GR in the PVN and other brain structures such as the LC fails to restrain hyperfunction of the HPA axis. The persistent activation of the HPA axis further up-regulates the amygdaloid CRH system involved in the expression of fear and anxiety. Additionally the amygdala may have stimulatory effects on the HPA axis. Thus, the hypothalamic and the amygdaloid CRH systems cooperatively constitute a stress-responsive, anxiety-producing neurocircuitry during chronic stress (Makino et al., 1994). Expression of the CRH system is regulated in a complex manner by glucocorticoids (Bruhn et al., 1986). There is evidence that during periods of stress, glucocorticoids may augment PVN CRH gene expression (Plotsky et al., 1986).

In a similar way to other hypothalamic peptides known to regulate their own secretion, $\mathrm{CRH}$ autoregulates $\mathrm{CRH}$ neurons in the PVN. We found that expression of CRH in the PVN was slightly decreased in COR-Cam mice, and was decreased by 12 $\%$ and $23 \%$ in heterozygous and homozygous COR-Nes mice respectively (Figure 16A and B). In COR-Cam mice, CRH is not overexpressed in the PVN (Figure $10 \mathrm{~B}$ and C), leaving the HPA axis unaffected. Therefore, the decreased CRH expression in the PVN was thought as endogenous CRH. Although CRH is overexpressed in the entire CNS in COR-Nes mice (Figure 10E and F), CRH expression in the PVN was also found to be decreased. This might be due to counter regulatory effects on endogenous $\mathrm{CRH}$. To understand the molecular mechanism behind this observation, further investigation is needed. These results were consistent with that of Metallothionein promoter CRH-Tg mice (Stenzel-Poore et al., 1992), Stenzel-Poore and colleagues found that in contrast to the robust expression of $\mathrm{CRH}$ mRNA 
elsewhere in the central nervous system, the strength of the hybridization signal in the PVN was equivalent, or only marginally elevated. When they used a transgenespecific oligonucleotide probe, they found the transgene expressed in the PVN, indicating a reduction of the endogenous CRH. Decreased CRH expression in the PVN of our CRH overexpressing mice also exhibited marked glucocorticoid downregulation.

It should be noted that the alteration of $\mathrm{CRH}$ expressing neurons in various regions of the brain depends on the type and intensity of the stressor. On the other hand, the effects of glucocorticoids on CRH gene expression are diverse depending on the tissue and the level of gene expression when the glucocorticoids affect the cell (Makino et al., 1994). The CRH neurons in the CeA project to the BNST, the lateral hypothalamus and midbrain reticular formation (Sakanaka et al., 1986), medial and lateral parts of the parabrachial nucleus (Moga and Gray, 1985), and the mesencephalic nucleus of the trigeminal nerve patterns. In the amygdala, the effects of glucocorticoids are not consistent in vivo, investigators have demonstrated that glucocorticoids can positively or negatively regulate amygdalar CRH levels (Makino et al., 1994). Kalin and colleagues (Kalin et al., 1994) reported that acute restraint increased CRH mRNA in the CeA using both RNase protection assay and in situ hybridization (Hsu et al., 1998). A study using in vivo microdialysis demonstrated increased $\mathrm{CRH}$ levels in the $\mathrm{CeA}$ following restraint stress or ethanol withdrawal (Merlo Pich et al., 1995) (Merali et al., 1998) (Richter et al., 2000). Some stressors, which contain more physical or metabolic components, such as salt-loading (Watts, 1992), cold or starvation (Makino et al., 2001) can lead to decreased CRH mRNA in the CeA. Chronic administration of the triazolobenzodiazepine agonist alprazolam decreased CRH mRNA in the CeA and CRH-R1 mRNA expression and receptor binding in the basolateral amygdala (Skelton et al., 2000), whereas adrenalectomy does not affect amygdalar CRH expression (Beyer et al., 1988). Expression of CRH in the forebrain (COR-Cam) increased CRH expression slightly in the $\mathrm{CeA}$ in heterozygous and homozygouse mice (Figure 16C), however, overexpression of CRH in the entire CNS (COR-Nes) decreased CRH expression in the CeA by $25 \%$ and 30 $\%$ in heterozygous and homozygous mice respectively (Figure 16D).

The mechanisms underlying positive or negative glucocorticoid effects on CRH in the $\mathrm{CeA}$ are uncertain, but differential combinations of glucocorticoid-responsive neurotransmitters or transcription factors in the CeA or the PVN may be responsible 
for it.

The careful measurement of protein levels is a critical step in understanding how environmental effects on gene expression are translated into actual changes in the organism's behavior. In the total brain, the $\mathrm{CRH}$ content was increased about 1.2-fold in heterozygous and 1.6-fold in homozygous COR-Cam mice (Figure 13A) compared to control mice. The CRH content was increased 1.4-fold in heterozygous and 2.1fold in homozygous COR-Nes mice compared to control mice (Figure 13B). CRH overexpression at the protein level in various brain regions confirmed the pattern of oeverexpression observed by in situ. CRH is overexpressed strongly in the hippocampus, cortex and thalamus in COR-Cam mice (Figure 14A), and in the hippocampus, cerebellum, cortex and thalamus in COR-Nes mice (Figure 14B).

\subsubsection{Expression of CRH-R1 and CRH-R2 mRNA}

$\mathrm{CRH}$ acting upon its receptors at hypothalamic and extra-hypothalamic sites mediates behavioral and autonomic responses to stress (Holmes et al., 1987) (Vale et al., 1983a).

Information about the regulation of the expression of $\mathrm{CRH}$ itself, both in the hypothalamus and limbic regions, has been forthcoming (Hatalski et al., 1998) (Hatalski et al., 2000) (Makino et al., 1994) (Smith et al., 1997). Imaki and Mansi also found that central administration of CRH increases both CRH mRNA and CRH-R1 mRNA in the PVN (Imaki et al., 1996) (Mansi et al., 1996). CRH may be capable of up-regulating CRHR-1 and enhance its own biosynthesis in the PVN in a paracrine or autocrine manner. In this context, positive effects of $\mathrm{CRH}$ on its own receptor (CRHR-1), and vice versa, may represent one mechanism of persistent activation of $\mathrm{CRH}$ neurons in the PVN during stress. The regulation of CRH-R1 and CRH-R2 expression in many regions of brain has remained relatively unexplored. The majority of studies investigating regulation of $\mathrm{CRH}$ receptors have centered on the PVN. CRHR1 mRNA expression in the PVN is extremely low, but the expression of both CRH and CRH-R1 mRNA in the parvocellular PVN is substantially increased by stress (Luo et al., 1994) (Makino et al., 1995), icv administered CRH (Imaki et al., 1996) (Mansi et al., 1996) and immune challenge (Rivest et al., 1995). Only limited information is available on the regulation of $\mathrm{CRH}$ receptors in limbic structures such as hippocampus, amygdala, and cortex. In essence, a single study has suggested that 
chronic stress in adult rats resulted in a decrease in CRH-R1 mRNA in frontal cortex while increasing CRH-R1 expression has been found in the hippocampus (Iredale et al., 1996). Brunson and colleagues found that, compared to vehicle-treated controls after $\mathrm{CRH}$ administration in immature rats, CRH-R1 mRNA levels were significantly upregulated in cingulate cortex at the $4 \mathrm{~h}$ time point, in layers II/III of frontal cortex by $2 \mathrm{~h}$ (returned to control values by $4 \mathrm{~h}$ ), in the CA3 pyramidal cell layer of hippocampus at the $4 \mathrm{~h}$ time point, no changes in layer V/VI of neocortex, CA1 and CA2 of hippocampus and in the amygdala.

Dysfunctioning of CRH and its receptors has been linked to the development of stress-related disorders, such as mood disorders. We analyzed CRH-R1 and CRH-R2 expression in $\mathrm{CRH}$ overexpressing mice, which are excellent models to analyze how chronic hyperactivity of $\mathrm{CRH}$ itself is able to regulate $\mathrm{CRH}$ receptors in vivo.

CRH-R1 mRNA was decreased in the neocortex, CA1, CA2 and CA3 of hippocampus and the reticular nucleus of the thalamus (RT) in both CRH overexpressing mouse lines (Figure 17 and 18). These findings may reflect one mechanism to adapt to the changed physiological demands caused by CRH hyperactivity. Such loss of CRH-R1 may be also due to increased exposure to CRH, involveing the consequences of receptor occupation and activation by $\mathrm{CRH}$, as well as "downstream" cellular activation. Vale and colleagues reported that exposure of pituitary cells to CRH in vitro led to sustained decreases in CRH-R1 mRNA levels (Pozzoli et al., 1996). Aguilera and colleagues showed that infusion of CRH leading to increased levels of circulating peptide caused CRH-R1 down-regulation and desensitization (Aguilera, 1994). Down-regulated CRH-R1 expression in the cortex in $\mathrm{CRH}$ overexpressing mice is particularly interesting, because alteration of both CRH and its receptors in the cortex has been demonstrated in a number of human disorders (Imaki et al., 1993). For example, reduced CRH receptor binding capacity in frontal cortex has been reported in depressed suicide victims (Imaki et al., 1995), in whom cerebrospinal fluid CRH levels are increased (Roseboom et al., 2001). Other laboratories showed that CRH-R1 mRNA levels in the hippocampal CA3 pyramidal layer were highly enhanced by high dose icv CRH administration (Luo et al., 1994) (Makino et al., 1995). CRH-R1 mRNA was lower expressed in the CA1, CA2 and CA3 of hippocampus in our CRH overexpressing mice compared to control mice, this probably because of different patterns of stress, chronic stress in CRH overexpressing mice and acute stress (icv) by infusion of CRH. 
Very limited reports exist about how CRH regulates its receptor in dentate gyrus, where new neurons are generated even in the adult. CRH-R1 mRNA was increased in the dentate gyrus in both $\mathrm{CRH}$ overexpressing mouse lines. This upregulation may have important physiological consequences. Brunson and colleagues found high dose of $\mathrm{CRH}$ infused icv to developing rats leaded to hippocampal pyramidal cell injury and contributed to stress related neurological disorder (Brunson et al., 2001).

CRH-R1 mRNA in the pontine gyrus was decreased in COR-Cam mice. When CRH overexpressed in the entire brain (COR-Nes), CRH-R1 mRNA in the pontine was decreased only in heterozygous mice, whereas, increased in homozygous mice (Figure 17B, C, E, F and Figure 18A and B). Finally, we did not find any regulation of CRH-R1 in PVN by CRH overexpression.

Bronson and colleagues found that CRH-R2 binding and mRNA levels were not altered by CRH administration (Brunson et al., 2001). Whereas, we found CRH overexpression also modulated CRH-R2 mRNA expression in both $\mathrm{CRH}$ overexpressing mouse lines. $\mathrm{CRH}$ overexpression in the forebrain (COR-Cam) increased expression of CRH-R2 in the thalamus. Increased CRH-R2 mRNA expression was also found in the septum, dentate gyrus, choroids plexus only in heterozygous COR-Cam mice. However, CRH-R2 expression in the choroid plexus was decreased in homozygous COR-Cam mice (Figure 19B and C and Figure 20A). $\mathrm{CRH}$ overexpression in the entire brain (COR-Nes) decreased CRH-R2 mRNA expression in the CP. CRH-R2 mRNA was increased in lateral septum and thalamus in homozygous COR-Nes mice compared to control (Figure 19E and F and Figure 20B). The decrease of CRH-R2 mRNA is most likely the consequences of the excess occupation by its ligand $\mathrm{CRH}$ an effect similar as observed for CRH-R1. Moreover, increased CRH-R2 mRNA expression in the cortex, septum, dentate gyrus and choroids plexus was found only in heterozygous COR-Cam mice, while CRH-R2 expression in the dentate gyrus and choroids plexus was decreased in homozygous COR-Cam mice (Figure 19A-C and Figure 20A). The two members of the CRH receptor family demonstrate differing regulatory mechanisms, consistent with their subserving distinct and separate functions.

Our results in terms of $\mathrm{CRH}$ receptors expression under conditions of CRH excess are different from previous reports. This is mostly likely due to the experimental setup. Other studies used (1) adult or immature rats (Luo et al., 1994) (Konishi et al., 2003). (2) stressed the mice by immobilization or forced swimming or 
icv CRH administeration (Konishi et al., 2003) (Imaki et al., 1996) (Mansi et al., 1996); (3) or even studied this point in vitro by cell culture (Iredale et al., 1996). In our case, the results were obtained from transgenic mice. Firstly, mice are different from rats. Even for the mice, differences in $\mathrm{CRH}$ receptors gene expression have been observed between different strains, for example, C57BL/6 mice show a higher baseline and stress-induced increases in CRH-R1 mRNA levels than DBA mice (Giardino et al., 1996). Moreover, these various strains display a differential responsiveness to stress with regard to $\mathrm{CRH}$ system gene regulation. Secondly, CRH overexpression in our animal model was chronic, it was different from the acute effect of immobilization or forced swimming stress and icv exogenous $\mathrm{CRH}$ administeration. Finally, it is much easier to understand that the in vivo interactions of CRH with its receptors differed from the ones observed in vitro.

$\mathrm{CRH}$ regulated CRH receptors in a region-specific manner. This is in agreement with the in vitro studies where it has been shown that $\mathrm{CRH}$ regulates its receptor in a cell type dependent way, for example, Duman and colleagues (Iredale et al., 1996) reported that $\mathrm{CRH}$ treatment decreased CRH-R1 mRNA in CATH.a cells, a neuronderived cell line. However, Kalin and colleagues (Roseboom et al., 2001) found CRH treatment did not change CRH-R1 mRNA in the human neuroblastoma cell line IMR32.

As $\mathrm{CRH}$ is considered to be the prime mediator of psychopathological processes and neuroendocine symptoms of affective disorders, strategies targeted against the biosynthesis of $\mathrm{CRH}$ and its receptors have a strong potential to provide insight into the underlying mechanisms.

It can be gathered from these studies that the state of knowledge about CRH receptor gene regulation in response to stress is less consistent and less well characterized than that about the $\mathrm{CRH}$ gene. It seems that the findings with repeated stress and CRH receptor mRNA levels are not easily reproduced across laboratories. In general, much less is known about the different experimental conditions that influence the expression of the $\mathrm{CRH}$ receptors genes. Some of the aforementioned discrepancies in the literature may derive from subtle methodological differences regarding the strength and, perhaps, anatomic pattern of the signal being measured. The type and duration of the stressor, the post-stress delay before animal sacrifice, the strain and age of the subjects, and the time of day for testing and sacrifice are just 
among a few of the many factors that can profoundly affect the nature of stressinduced gene expression changes.

\subsubsection{Expression of AVP mRNA}

Evidence has accumulated during the last two decades indicating that AVP is coexpressed in some of CRH neurons. AVP plays an important role in augmenting the actions of CRH in activating the HPA axis in the chronic stress condition (de Goeij et al., 1992). In vivo and in vitro studies have shown that the rate of release of immunoreactive AVP from median eminence terminals increases in response to repeated or chronic stress (de Goeij et al., 1991) (Aguilera et al., 1993). Basal levels of CRH and AVP expression are under feedback inhibition by glucocorticoids because bilateral adrenalectomy markedly increases the number of $\mathrm{CRH}$ neurons that coexpress vasopressin (Ma et al., 1997). Furthermore, overexpression of AVP after adrenalectomy was suppressed by supplementation with glucocorticoids in parallel with $\mathrm{CRH}$, indicating a potent inhibition effect of glucocorticoid on vasopressin expression (Itoi et al., 1987).

No change of AVP expression was observed in both CRH overexpressing mouse lines compared to respective control mice although corticorsterone levels are slightly increased. We can not explain why and how AVP escapes from glucocorticoidmediated negative feedback. One explanation might be that chronic effect leads to adaption/normalization of AVP.

\subsubsection{Expression of GR mRNA}

Glucocorticoids, final products of the HPA axis, are secreted from the adrenal cortex and exert a negative feedback effect on the biosynthesis and release of CRH in the PVN and ACTH in the anterior pituitary, resulting in the termination of stressinduced HPA axis activation (Akana et al., 1992a) (Akana et al., 1992b).

Chronic stress negatively influences cognitive performance (McEwen, 1999) (McEwen and Sapolsky, 1995), and glucocorticoids participate in this effect. Longterm treatment of patients with glucocorticoids and chronic increased glucocorticoid levels in patients with Cushing's syndrome are associated with cognitive dysfunction, including memory deficits (Avishai-Eliner et al., 2002). As previously mentioned, 
chronically increased glucocorticoid levels in aged rats and humans correlate with a decreased hippocampal volume and memory deficits (Lupien et al., 1998).

In addition, glucocorticoids are importantly involved in modulating fear and anxiety-related behavior (Korte et al., 1996) (Korte, 2001). Disruption of glucocorticoid receptor signaling in the central nervous system reduces anxiety-related behavior in mice (Tronche et al., 1999).

Several in vitro studies have shown a glucocorticoid-induced decrease in GR transcription (Okret et al., 1986) (Dong et al., 1988) (Vedeckis et al., 1989). We also found GR was down-regulated in both CRH overexpressing mouse lines. This kind of glucocorticoid-dependent reduction of GR mRNA in multiple regions in the brain may be associated with suppression of stress-induced hyperactivity of the HPA axis at the level of the PVN, anterior pituitary, but also at the hippocampal level (De Goeij et al., 1992). Thus, it has been suggested that the adaptive function of the HPA axis is critically dependent on glucocorticoid feedback mechanisms to dampen the stressorinduced activation of the HPA axis and to shut off further glucocorticoid secretion (Jacobson and Sapolsky, 1991).

Our investigation to the altered expression of CRH and molecules related to the $\mathrm{CRH}$-system in CRH overexpressing mice provided new insights into their involvement in the hyperactivity of the CRH system and the HPA axis in depression. Furthermore, elucidating molecular mechanisms of persistent activation of the central CRH and system could lead to the development of more effective drugs for stressaccociated disorder by shutting down the vicious circle via multiple feedback loops upon these system, by the functional modulation of either corticosteroid receptors or CRH receptors.

\section{3. Hyperactivity of HPA axis in CRH overexpressing mice}

$\mathrm{CRH}$ plays a major role in the regulation of basal and stress-induced activation of the HPA axis (Muglia et al., 2001). CRH stimulates the release of ACTH from corticotrope cells of the anterior pituitary gland, which in turn stimulates secretion of glucocorticoids from the cortex of the adrenal gland.

Targeted manipulations of specific CRH system elements (peptides, receptors, or binding protein) have proven as very useful to understand HPA axis biological actions during both physiological and pathological conditions. Dysregulation of the HPA axis 
is a well-known phenomenon observed in depressed patients (Blackburn-Munro and Blackburn-Munro, 2001). To investigate the effect of long-term central CRH overexpression on HPA axis regulation, basal plasma corticosterone concentrations were measured. Corticosterone in the morning was slightly increased in the heterozygous and homozygous COR-Cam mice compared to control mice (Figure 24A). The increased corticosterone may be caused by long-term hypersecretion of $\mathrm{CRH}$ in the extra hypothalamic sites. For example, CRH cells located in the CeA project to the BNST (Sakanaka et al., 1986), the latter of which sends CRH projections to PVN, in addition, the PVN also receives CRH input from various other hypothalamic areas, as well as from the dorsal raphe (Champagne et al., 1998), subsequently leading to activation of the HPA axis. HPA axis activation resulted in increased corticosterone release. In COR-Nes mice, corticosterone in the morning was increased 1.8- and 2.4-fold in heterozygous and homozygous mice respectively compared to control mice (Figure 24B). Corticostrone levels were increased in CORNes mice compared to COR-Cam mice, most likely because CRH is overexpressed in the PVN in COR-Nes mice. Furthermore, CRH was much strongly and more widely overexpressed in COR-Nes mice than in COR-Cam mice. In both CRH overexpressing mouse lines, the increased corticosterone levels mediate negative feedback at multiple levels of the HPA axis to return the system to homeostasis. Especially at the level of parvocellular neurons of the PVN, increased corticosterone levels might lead to a down-regulation of CRH expression in the PVN (Figure 16A and B). These increased corticosterone secretion indicates a slightly hyperactive HPA axis. The hyperactive HPA axis was associated with CRH-R downregulation and desensitization, indicating that $\mathrm{CRH}$ receptor number is not a major determinant of corticotroph responsiveness in vivo. In presence of CRH, a small number of CRH-R1 are required for the pituitary gland to respond to most stressors (Perrin and Vale, 1999) (Turnbull and Rivier, 1997) (Venihaki and Majzoub, 1999), and other factors must be responsible for the facilitation of ACTH response during chronic stress (Aguilera, 1994). Moreover, it seems that the enhanced corticosterone levels is CRH-dose dependent. Corticosterone in the morning was slightly increased in heterozygous COR-Cam mice, and increased 1.6-fold in homozygous COR-Cam mice. Corticosterone was increased by 1.8 - and 2.4-fold in heterozygous and homozygous COR-Nes mice respectively (Figure 24A and B). In contrast, the two previously published $\mathrm{CRH}$ overexpressing mouse lines displayed significantly elevated 
corticosterone levels: 4.4-fold in Thy-1 promoter driven CRH-Tg mice (Groenink et al., 2002) and 10-fold in Metallothionin-promoter driven CRH-Tg mice respectively (Stenzel-Poore et al., 1992).

Evidences from both clinical and preclinical studies strongly supports that $\mathrm{CRH}$ from both hypothalamic and extrahypothalamic neurons is hypersecreted in depression. 40 years ago, Board and colleagues (Board et al., 1956) reported that plasma cortisol concentrations were elevated in a majority of patients with major depressive disorder, a finding that has been repeatedly replicated. Therefore, our CRH overexpressing mice may serve as an animal model for the HPA axis abnormalities occurring in major depressive disorder.

\subsection{CRH overexpression decreased body weigh}

Numerous studies demonstrate a role for $\mathrm{CRH}$ in appetite regulation, energy balance, and the etiology of eating disorders. Enhanced CRH within the CNS, is known to suppress appetitive behavior (Gosnell et al., 1983) (Spina et al., 1996), to decrease food consumption (Morley and Levine, 1982), to blunt energy storage by reducing energy intake and to augment energy expenditure resulting in decreased weight gain, and reduced body fat and protein content (Richard et al., 2000). CRH overexpression in the forebrain (COR-Cam) decreased body weight slightly compared to control mice (Figure 25A); $\mathrm{CRH}$ overexpression in the entire brain (COR-Nes) decreased body weight significantly compared to control mice (Figure 25B). Both CRH overexpressing mouse lines did not show any signs of Cushing-like syndrome even when they were 9 months old. Our mice are different compared to Stenzel-Poore group's CRH-Tg mice (Stenzel-Poore et al., 1992), which showed Cushingoid features: truncal obesity with large adipose deposits, muscle wasting, bilateral symmetric hair loss, and abnormally transparent skin. Our CRH overexpressing mice showed decreased body weight compared to control mice comparable to the second published CRH-Tg mouse line (Dirks et al., 2002b). However, the latter also showed Cushing-like syndrome after 5-6 months of age with fat deposition and hair loss. Studies from our CRH overexpressing mouse lines and previous published other two CRH-Tg mouse lines showed the correlation between body weight, Cushing syndrome and $\mathrm{CRH}$ content. The Metallothionein (MT) promtor driving CRH transgene overexpressed $\mathrm{CRH}$ in all areas of the brain and in the peripheral tissues 
(Stenzel-Poore et al., 1992). Thy-1 promotor driving CRH transgene overexpressed $\mathrm{CRH}$ in the entire CNS. For both CRH-Tg mice, it is not known how many copies and where the transgene was inserted into the genome. In our CRH overexpressing mice, only a single copy of murine CRH cDNA was inserted into ROSA26 locus, CRH was overexpressed 1.2- and 1.6-fold in heterozygous and homozygous COR-CAM mice respectively, and 1.4- and 2.1-fold in heterozygous and homozygous COR-Nes mice. However, CRH was overexpressed 3.2 fold even in hemizygous MT CRH-Tg mice (not data shown). Therefore, our results strongly suggested that CRH overexpression decreased body weight in dose dependent manner. The Cushing-like syndrome showed by other two previously CRH-Tg mice might be caused by the significant increased corticosterone.

\subsection{Acoustic startle response}

The neuropeptide CRH functions as a key mediator of the responses to stress (Vale et al., 1981), it has been increasingly recognized, however, in addition to its neuroendocrine effects, CRH acts as a neuromodulator in stress-associated limbic regions to propagate and integrate stress-induced behaviors including arousal, motor function, food intake, reproduction and anxiety-related behavior (Heinrichs and De Souza, 1999) (Dunn and Berridge, 1990b). Because CRH is released from limbic neuronal terminals during stress, this regulation might play a crucial role in the mechanisms by which stress contributes to human neuropsychiatric conditions such as depression or posttraumatic stress disorder.

Chronically elevated levels of $\mathrm{CRH}$ in the brain appear to be associated with alterations commonly associated with major depressive disorder, as well as with sensorimotor gating deficits commonly associated with schizophrenia (Conti et al., 2002). Centrally administered CRH in rats increased acoustic startle response (Jones et al., 1998) (Liang et al., 1992) (Swerdlow et al., 1986). There are only a few reports showing that acoustic startle reactivity is increased after chronic stress (Gewirtz et al., 1998) (Servatius et al., 1994), whereas others report no alterations in startle reactivity after sustained stress (Sipos et al., 2000).

In the present study, we used startling acoustic stimuli to investigate the consequences of chronic CRH hyperactivity on sensory information processing mechanisms in mice. 


\subsubsection{Increased startle magnitude in COR mice was dose-dependent}

The startle reflex is a fast, short-latency response, involuntary contraction of facial and body muscles accompanied by eye-lid closure as well as an arrest of ongoing behaviors and an acceleration of the heart rate, evoked by sudden and intense acoustic stimuli (Koch, 1999). The ASR has been used as a behavioral tool to assess the neuronal basis of behavioral plasticity and to model neuropathological dysfunctions of sensormotor information processing. The ASR is also enhanced in human patients suffering from anxiety disorders (Grillon et al., 1994) (Grillon et al., 1996), in humans anticipating shock (Grillon et al., 1991), in the presence of an unpleasant odor (Ehrlichman et al., 1995), or while viewing aversive pictures (Lang, 1995) (Patrick et al., 1996). As a matter of fact, an enhanced startle response is one of the diagnostic criteria for post-traumatic stress disorder (Diagnostic and Statistical Manual IV of Mental Disorders, American Psychiatric Association).

The ASR magnitude and latency are influenced by the stimulus intensity (Pilz et al., 1987) (Pilz et al., 1988), the interstimulus interval (Davis, 1970), ongoing motor behavior (Ison et al., 1986), and is variable among individuals (Plappert et al., 1993). It is also influenced by genetic differences (Glowa and Hansen, 1994), by the rhythm, by stress, fear, or other negative affective states (Davis, 1988). The ASR magnitude can be enhanced by conditioned and unconditioned aversive events (Davis et al., 1997b) (Davis et al., 1997a). It can be attenuated by the repeated presentation of startling stimuli (Davis et al., 1993). Icv infusion of CRH elicits a constellation of behavioral, physiological, and endocrinological changes normally observed after stress (Dunn and Berridge, 1990b). Interestingly, some of these changes are similar to symptoms seen in certain psychiatric disorders, such as post-traumatic stress disorder (PTSD). For example, infusion of CRH causes a profound, dose-related increase in the acoustic startle response (CRH-enhanced startle) (Swerdlow et al., 1986) (Liang et al., 1992). Similarly, patients with PTSD have elevated CSF levels of CRH and show increased startle responses under appropriate test conditions (Davis et al., 1993).

Our results showed that CRH increased startle magnitude in a dose-dependent manner. Increased startle magnitudes to increasing stimulus intensities were observed in both CRH overexpressing mouse lines (Figure 26A and B). Only mice overexpressing $\mathrm{CRH}$ just from a single R26 allele in the anterior forebrain (COR-Cam) showed significantly increased startle magnitude at high stimulus intensities (100-120 
dB) (Figure 26A). This was consistent with previous reports that icv infusion of CRH produces a pronounced, dose-dependent increase of the acoustic startle reflex (Jones et al., 1998) (Liang et al., 1992) (Swerdlow et al., 1986). We also can say that, in some range, low dosage $\mathrm{CRH}$ increased startle magnitude and high dosage $\mathrm{CRH}$ inhibited it in vivo. This could explain why Thy-1 promoter CRH-Tg mice showed reduced startle reactivity (Dirks et al., 2002b). In addition, probably, it was also related to increased $\mathrm{CRH}$ expression in CeA in COR-Cam mice and decreased $\mathrm{CRH}$ expression in CeA in COR-Nes mice, because the CeA has been implicated in CRHenhanced startle. CRH infused into CeA enhanced startle, however, electrolytic lesions of the CeA blocked CRH-enhanced startle (Liang et al., 1992). Furthermore, the difference in ASR between our two CRH overexpressing mouse lines and Thy-1 promoter CRH-Tg mice may be because of the different $\mathrm{CRH}$ overexpressing pattern. In Thy-1 promoter CRH-Tg mice, $\mathrm{CRH}$ was overexpressed strongly in cortex, CA3 of hippocampus, VMH and habenula. In our COR-Cam mice, CRH was overexpressed strongly in cortex, the whole hippocampus, dentate gyrus, amygdala, and striatum. In COR-Nes mice, CRH was overexpressed strongly in the entire brain.

The ASR is mediated by a relatively simple neuronal circuit located in the lower brainstem. Neurons of the caudal pontine reticular nucleus (PnC) are key elements of this primary ASR pathway what was confirmed by a series of studies in cats (Wu et al., 1988), rats (Koch et al., 1992) (Yeomans et al., 1993), and mice (Carlson and Willott, 1998). Detailed electrophysiological and neuroanatomical studies revealed that the subpopulation of giant (soma diameter $>40 \mathrm{~mm}$ ) reticulospinal neurons of the $\mathrm{PnC}$ receive direct acoustic input from different nuclei of the central auditory pathway, including the dorsal and ventral cochlear nucleus, the lateral superior olive and from neurons of the cochlear root nucleus, a ganglion located within the auditory nerve, reticular relay nuclei (RT), or the ventral tegmental area (VTA) (Kandler and Herbert, 1991) (Lingenhohl and Friauf, 1992) (Lingenhohl and Friauf, 1994) (Lee et al., 1996) (Davis et al., 1982). A long-lasting enhancement of the ASR has been shown by infusion of CRH into the PnC (Birnbaum and Davis, 1998), injection of $\alpha$-helical $\mathrm{CRH}$, the specific antagonist of CRH (Fendt et al., 1997) into the PnC prevented fearpotentiation of the ASR. Since the BNST projects to the $\mathrm{PnC}$, it is conceivable that at least the BNST also involve the ASR. Moreover, the hippocampus is also involved in the enhancement of the ASR by CRH. Recent studies indicate that synaptic relays are interposed between the amygdala and the $\mathrm{PnC}$, which are also important for fear- 
potentiation of the ASR and for the enhancement of the ASR by footshocks. Therefore, it will be very important to investigate the expression of $\mathrm{CRH}$ in the $\mathrm{PnC}$, BNST, amygdala and other brainstem regions (such as VTA, LC) in both CRH overexpressing mouse lines.

\subsubsection{The CRH-R1 antagonist (NBI-30775) reversed CRH-induced startle response in COR-Nes but not in COR-Cam mice}

The most influential theory of habituation is the dual-process theory (Groves and Thompson, 1970), which postulates the existence of two independent and opposing mechanisms in the central nervous system (habituation and sensitization), the net result of which is measured as the decline of the response magnitude across the different trials. Habituation is regarded as a form of non-associative learning, in which an animal learns to differentiate behaviorally meaningful from irrelevant stimuli. This habituation occurs during a single session of multiple stimuli (short-term or withinsession habituation) and across several sessions (long-term or between-session habituation). Sensitization is the enhancement of a response following a strong stimulus that is probably mediated by heterosynaptic facilitation (Kandel et al., 1976). In another word, the term sensitization should be used for the enhancement of the ASR.

COR-Cam and COR-Nes mice did not show any normal habituation, only homozygous COR-Nes mice showed a deficit habituation in the trials 3-5 (Figure 27). Post hoc tests showed that, startle magnitude was significantly increased in block 2-3 in heterozygous COR-Cam mice (Figure 27A), and in block 5 in homozygous CORNes mice (Figure 27B) compared to control mice. A slightly increased startle magnitude was observed in homozygous COR-Cam and heterozygous COR-Nes mice. The increased startle reactivity suggests mechanisms of sensitization caused by CRH overexpression. This result is different with Dirks and collegues, who did not find any habituation in $\mathrm{CRH}-\mathrm{Tg}$ mice. Their $\mathrm{CRH}$ overexpressing mice showed lower startle magnitudes than control mice through all trials (Dirks et al., 2002b). This perhaps was caused by different $\mathrm{CRH}$ dosage in $\mathrm{CRH}$ overexpressing mice as discussed above.

Recent efforts have been directed toward the development of CRH-R1 antagonists for the treatment of stress-related psychiatric disorders such as depression. The first clinical trial of such a compound was recently completed, and revealed that 
administration of a CRH-R1 antagonist significantly reduced depression and anxiety scores in depressed patients (Zobel et al., 2000).

To test whether such increased startle reactivity was due to an effect of the $\mathrm{CRH}$ overexpression in these transgenics, the CRH-R1 antagonist (NBI-30775) was infused into the lateral ventricles prior to testing startle magnitude and habituation. Administration of a dose of $20 \mathrm{mg} / \mathrm{kg}$ of the CRH-R1 antagonist (NBI-30775) decreased CRH-induced startle response in COR-Nes mice (Figure 28). The result was consistent with Geyer and colleagues result (Risbrough et al., 2004). NBI-30775 did not decrease startle magnitude in COR-Cam mice may be because NBI-30775 attenuated the increase in startle from the high but not low dose of CRH.

\subsubsection{Impaired prepulse inhibition (PPI) in COR-Nes, but not in COR-Cam mice}

Prepulse inhibition (PPI) is the reduction of the startle response that occurs if the startle stimulus is preceded $30-500$ msec by a distinctive, non-startling stimulus (prepulse) (Graham, 1975). It is used as an operational measure for early sensorimotor gating mechanisms (Braff and Geyer, 1990), which is a neural mechanism theorized to maintain mental and behavioral integration by inhibiting irrelevant sensory and cognitive information and motor programs (Dulawa and Geyer, 2000). Levels of PPI are considered as an index for the integrity of sensorimotor gating mechanisms by measuring the extent to which information processing routines - which is elicited by the prepulse are interrupted by the subsequent startling stimulus (Dulawa and Geyer, 2000). PPI of the ASR is reduced in a variety of neuropsychiatric disorder that are characterized by a general reduction of the ability to gate intrusive sensory, motor or cognitive information, for example in schizophrenia, Tourette syndrome, obsessivecompulsive disorder, and Huntington disease and attention deficit disorder (Braff et al., 2001). Since PPI can be studied in rodents with procedures that are nearly identical to those employed in studies with human subjects, the paradigm is widely used to examine the potential roles of specific neurotransmitters in schizophrenia, as well as in pharmacological and pharmacogenetic studies.

No difference in PPI between heterozygous and homozygous COR-Cam mice was observed compared to control with respect to the prepulse intensity and the interval between prepulse and stimulus (Figure 29A and C). Homozygous COR-Nes 
mice displayed impaired levels of PPI as a function of the prepulse intensity, and there was a difference between control and heterozygous and homozygous COR-Nes mice with respect to their percent PPI as a function of the interval between prepulse and stimulus (Figure 29B and D). Administration of a $20 \mathrm{mg} / \mathrm{kg}$ dose of the CRH-R1 antagonist (NBI-30775) reversed the impaired PPI (Figure 30B). Our results were consistent with Dirks and colleagues Dirks (Dirks et al., 2002), they also found impaired PPI in CRH-Tg mice with respect to the prepulse intensity and prepulsestartle stimulus interval. Our results also fitted to previous results that acutely administered CRH reduces PPI in rats and mice (Conti et al., 2002). Independent of its effects on startle reactivity, low dose of CRH decreased PPI at low prepulse stimuli intensity, high dose of CRH decreased PPI at all prepulse stimulus intensity. These findings also indicate that both acute and chronic elevated levels of CRH have similar disruptive effects on PPI.

The brain mechanisms underlying the mediation of PPI are still not fully understood. PPI of the acoustic startle response is perhaps altered by manipulations that affect brain monoamine neurotransmission. In both CRH overexpressing mouse lines, $\mathrm{CRH}$ was overexpressed in cortex, striatum, hippocampus and the central nucleus of the amygdala (Chalmers et al., 1995) (De Souza, 1987) (Radulovic et al., 1998), areas shown to be important for control of PPI (Swerdlow et al., 1994) (Bakshi and Geyer, 1999). Several investigators found that the nucleus accumbens septum (NAC) is one of the centers of convergence of several transmitter systems that regulate PPI. In rats, $\mathrm{CRH}$ (icv) increased both dopamine (DA) utilization and DA concentration in frontal cortex, NAC, hippocampus and amydala (Kalivas et al., 1987) (Lavicky and Dunn, 1993). The NAC receives a dense dopaminergic innervation from the VTA. Excessive DA receptor stimulation or a lesion-induced DA receptor supersensitivity in the NAC reduces PPI (Swerdlow et al., 1992). The NAC also receives a direct projection from the ventral hippocampus (Groenewegen et al., 1987). PPI-disruptive effect is also seen after transsynaptic stimulation of ACh release in the ventral hippocampus via the medial septum (Koch, 1996). Moreover, Leitner and colleagues found that lesions of the inferior/or superior colliculus disrupted PPI by auditory prepulses (Leitner et al., 1980) (Leitner et al., 1981) (Leitner and Cohen, 1985) (Li et al., 1998) suggesting that the ascending auditory pathway activates a PPI circuit at the level of the midbrain. Therefore, our CRH overexpressing models might help us to understand the molecular mechanisms underlying PPI. 
The neurodevelopmental hypothesis of schizophrenia suggests that an abnormal development of the brain connectivity resulting from a genetic predisposition in combination with pre- or early postnatal environmental factors (Ellenbroek et al., 1998) (Lipska and Weinberger, 2000). In our CRH overexpressing mice, the onset of transgene expression occured about 20 days after birth in COR-Cam mice, and around embryonic 7.75-day stage in COR-Nes mice. The overexpression was retained throughout adult life. Hence, the early pre-/or post-natal onset of CRH overexpression and associated consequences for neuroendocrine, neurochemical, autonomic, and developmental processes, could be regarded comparable to other developmental manipulations such as maternal deprivation, neonatal hippocampus lesion, and isolation rearing. All these manipulations result in sensorimotor gating deficits in adult life (Geyer et al., 1993) (Ellenbroek et al., 1998) (Lipska and Weinberger, 2000).

Deficits in habituation of the startle response and impaired PPI have been demonstrated in patients with several neuropsychiatric disorders, most notably schizophrenia (Braff and Geyer, 1990) (Geyer et al., 1990). The results of the present study suggest that our CRH overexpressing mouse model might be an additional animal model to study the long-term effects of early postnatal homeostatic disturbances on sensorimotor gating. The effects of centrally overexpressed CRH on impaired PPI can be reversed by CRH receptor antagonists, supporting the usefulness of $\mathrm{CRH}$ receptor antagonists as a potential novel class of antidepressants and/or anxiolytics.

\subsection{Less freezing exhibited by COR-Nes mice in the fear conditioning test}

Multiple lines of evidence indicate a role for the CRH system in the neural pathways underlying learning and memory processes. In Alzheimer's disease (AD) patients, CSF levels of CRH may correlate with the degree of cognitive impairment in that greater cognitive deficits are associated with lower CSF CRH concentrations (Pomara et al., 1989). Reports showed that CRH can modulate learning and memory, either enhancing or impairing memory in a dose dependent and site specific manner (Koob and Bloom, 1985) (Radulovic et al., 1999). 
In order to characterize learning and memory capacity under conditions of chronic constitutive $\mathrm{CRH}$ overexpression, COR-Nes mice were analysed in the fearconditioning, forced swimming and tail suspension tests.

In the classical fear-conditioning task, animals form an association between a neutral conditioned stimulus (CS; e.g. tone, light or odour) and an aversive unconditioned stimulus (US; e.g. electric foot shock or air puff). As a result of this association, the CS will evoke a variety of behavioral, endocrine and autonomic responses that are typically elicited in dangerous situations (LeDoux, 2000). In the last decades, fear conditioning has emerged as a leading paradigm for studying cellular correlates of learning and memory. Icv infusion of $\mathrm{CRH}$ elicits a pattern of behavioral changes typically observed during states of fear or anxiety (Dunn and Berridge, 1990a). Fear is a natural, adaptive change elicited by a potentially threatening stimulus, which prepares an animal to cope with provocation. Fear generally is elicited by an identifiable stimulus and subsides shortly after its offset, and is also used as an index of freezing.

The freezing time was reduced in heterozygous and homozygous COR-Nes mice compared to control mice although the difference in both tone-freezing and contextfreezing tests was not significant (Figure 31). This result was consistent with the data from the Steckler's laboratory (van Gaalen et al., 2002), they found the MT CRH-Tg mice exhibited reduced freezing time in comparision with control mice. This reduced freezing time in COR-Nes mice perhaps was related to the decreased CRH expression in the CeA. A great deal of data indicate that the amygdala is critically involved in explicit cue conditioning (Henke, 1980) (Liang et al., 1986), the CeA projects directly to hypothalamic and brainstem target areas critically involved in specific signs and symptoms of fear. In addition, the natural pattern of behaviors produced by conditioned fear can be blocked by lesions of the amygdala and produced by electrical stimulation of the amygdala (Davis et al., 1997a).

The results from fear-conditioning consisted that $\mathrm{CRH}$ facilitated learning and memory, enhancing retention at low doses and impairing performance at higher doses (Koob and Bloom, 1985). Long-term or intense activation of the HPA axis impairs learning and memory (Cahill et al., 1994) (Luine et al., 1993) (McGaugh, 1983). Moreover, these behavior test results were perhaps also related to decreased GR and increased glucocorticoid in CRH overexpressing mice, because blockade of brain GR impairs the storage of new information (Oitzl and de Kloet, 1992), (Sandi et al., 1997). 
Mutant mice with a point mutation in GR, which obliterates binding to DNA, are unable to store learned information (Oitzl et al., 2001). Moreover, mice exposed to chronic stress and high corticosterone deteriorate in spatial learning because high corticosterone induced structural changes in the hippocampus, which may impair memory encoding and or consolidation as sustained hypercortisolemia in patients with Cushing's syndrome, depression, or aging associated with a reduced hippocampal volume and impaired cognitive performance (Starkman et al., 1992) (Sheline et al., 1996) (Lupien et al., 1998).

\subsection{More activity exhibited by COR-Nes mice in forced swimming test (FST)}

The forced swimming test (also known as Porsolt's test; behavioral despair test) is probably the most widely and most frequently used to assess depression and antidepressant-related phenotypes in genetically altered mice (Cryan et al., 2002) (Porsolt, 2000) (Seong et al., 2002), largely due to its relative reliability across laboratories and it's ability to detect activity in a broad spectrum of clinically effective antidepressants (Cryan et al., 2002). This test is based on the observation that rodents, following initial escape-oriented movements, develop an immobile posture, which can be regarded as an energy-conserving or stress-coping behavioral strategy, because the animal has learned that escape is impossible (Korte et al., 1996) in an escapable cylinder filled with water. Hughes and colleagues (Hughes et al., 1978) and Prince and Anisman (Prince and Anisman, 1984) reported that vigorous swimming is a maladaptive response style to an inescapable water situation, since this behavior may facilitate energy expenditure, and hence decrease the possibility of survival due to fatigue.

Since chronic hyperactivity of the CRH system is implicated in human affective disorders, including major depression (Mitchell, 1998), we predicted increased depression-like behavior in our CRH overexpressing mice - one animal models in which antidepressant-like behavior can be detected. However, we found heterozygous and homozygous COR-Nes mice spent less time in floating and more time in struggling in $24-26{ }^{\circ} \mathrm{C}$ warm water compared to control mice (Figure 32A and $\mathrm{B}$ ). This result is in accordance to the data from the other two CRH-Tg mouse lines (van Gaalen et al., 2002) (Dirks et al., 2001) and this finding was also in agreement with 
studies showing that icv $\mathrm{CRH}$ administration reduces immobility time in forced swimming in rats and it has been proposed that this may also be the result of increased anxiety (Butler et al., 1990).

Furthermore, heterozygous and homozygous COR-Nes mice showed decreased floating time compared to control mice in $32{ }^{\circ} \mathrm{C}$ warm water (Figure $32 \mathrm{C}$ ), similarly in $24-26{ }^{\circ} \mathrm{C}$ warm water, however, they spent almost the same time in struggling as the control mice (Figure 32D). In addition, all the genotypes of COR-Nes mice showed less time in floating and struggling in $32{ }^{\circ} \mathrm{C}$ than in $25{ }^{\circ} \mathrm{C}$ warm water. Therefore, we can conclude water temperature influenced the degree of immobility time in the forced swimming test. Otomo and colleagues also found that mice showed less immobility in $35^{\circ} \mathrm{C}$ water than in $25^{\circ} \mathrm{C}$ water. They explained this effect by the low water temperature which decrease the body temperature, resulting in decreased behavior (Arai et al., 2000).

\subsection{Less immobility exhibited by COR-Nes mice in tail suspension test (TST)}

The tail suspension test is theoretically similar to the FST and acute antidepressant treatment will decrease immobility in this paradigm. Advantages of this test include its ability to detect a broad spectrum of antidepressants, it is inexpensive, methodologically unsophisticated and easily open to automation. This automation enables the assessment of additional parameters such as power and energy of movement (Porsolt et al., 1987) (Steru et al., 1987). Similar to the FST, it validity is questioned by one fact that acute antidepressant treatments reverse the behavioral 'depression'. Although both of FST and TST are similar in the constructs that they purport to assess, they are probably different in terms of the biological substrates that underline the observed behavior and often offer converging data on a potential antidepressant (Porsolt, 2000) (Bai et al., 2001) (Renard et al., 2003). Further, the TST avoids any possible confounds induced by hypothermic exposure that may be problematic in the FST, especially if a targeted gene is involved in thermoregulatory processes. Heterozygous and homozygous COR-Nes mice and control littermates were analyzed, a significant decrease of immobility was observed from 2-5 min during $6 \mathrm{~min}$ test in heterozygous and homozygous COR-Nes mice compared to control mice (Figure 33). Dirks and colleagues found that in tail suspension test, 
CRH-Tg mice exhibited similar amount of immobility with control mice (Dirks et al., 2001). The difference between two CRH overexpressing mouse lines in tail suspension test may be caused by variety of procedural parameters such as experimental system. Another explanation was the different CRH-overexpression pattern as discussed above.

As CRH overexpressing mice overproduced $\mathrm{CRH}$ throughout postnatal development, numerous neurochemical and developmental changes may have occurred to compensate for the increased levels of this neuropeptide. Thus, it cannot be ruled out that the observed phenotype is not the direct consequence of chronically $\mathrm{CRH}$ excess, but rather the result of compensatory adaptations in other neurotransmitter systems involved in startle reactivity, startle and learning plasticity.

In summary, (1) Our model of CRH overexpressing mice is different with others because only one copy of the murine CRH cDNA was inserted into the genome; (2) The CRH overexpressing mice we have developed provide an opportunity to investigate the physiological consequences of CRH overproduction. (3) Chronic CRH overproduction in the transgenic mice appeared to be associated with chronic stresslike alterations, including altered HPA axis activity, reflected in increased basal plasma corticosterone concentrations, it may lead to the development of new and selective drugs targeting a range of psychiatric disorders associated with hyperactivity of the HPA axis. (4) In addition, CRH overexpressing mice provide a means to assess the relative importance of central $\mathrm{CRH}$ excess and glucocorticoid elevation in modulation of behavior and endocrine function. Such studies offer strong prospects for the development and testing of novel treatment agents and specific pharmacological interventions designed to block chronic CRH and CRH-R1 to predict anti-depressive drugs effects, which may be useful in treatment of anxiety and depression patients. (5) Furthermore, the mouse model of CRH overexpression may represent an important tool for the further investigation of psychotic depression, and could be a valuable tool for research addressing the impact of chronically elevated levels of CRH on information processing. (6) Finally, CRH overexpressing mice also allow the investigation of the specific role for each element of the $\mathrm{CRH}$ system in modulating ingestive behaviors.

Multiple studies indicate a crucial role for brain CRH pathways in mediating anxiety-like behaviors. Icv administration of $\mathrm{CRH}$ increases the expression of anxiety-like behaviors in rats and mice, and $\mathrm{CRH}$ receptor antagonist can block 
anxiogenice effects of stressful events (Britton et al., 1986) (Berridge and Dunn, 1989) (Heinrichs et al., 1992). In humans, elevated CRH levels in the CSF have been demonstrated in pathological conditions characterized by heightened anxiety, such as post-traumatic stress disorders and alcohol withdrawal (Adinoff et al., 1996), (Bremner et al., 1997) (Baker et al., 1999), so it will be very interesting to investigate anxiety-related behaviors in our $\mathrm{CRH}$ overexpressing mice in the future.

Moreover, it is important to note that inactivation or overexpression of a gene affects the whole organism and may result in a compensatory response. In our CRH overexpressing mice, compensatory responses can develop from the early embryonic or postnatal stage. As a result, the phenotypical characterization of $\mathrm{CRH}$ overexpressing mice can not necessarily reveal the function of the gene in the wild-type situation, but it shows the reaction of the organism to the modification. Occasionally, this leaded to the paradoxical situation of conflicting phenotypes or the absence of expected phenotypes. Inducible and temporally controlled expression of transgenes in adult mice will partly circumvent this problem of compensation because the period of genetic interference is shorter, and many physiological systems are setup during embryonic development. The flexibility of the system allows us to generate tamoxifen-inducible CRH overexpressing Cre-mouse lines with the CamKII $\alpha$ promoter, which is worth achieving in the next step.

\section{Summary}

$\mathrm{CRH}$ is a key regulator of the HPA system and has a prominent role in mediating neuroendocrine, behavioral, autonomic and immune responses to stress. Chronic $\mathrm{CRH}$ hyperactivity is implicated in human stress-related and affective disorders, including major depression. Central administration of $\mathrm{CRH}$ increases anxiety-like behavior and arousal in rodents. Existing transgenic mouse models of chronic CRH overexpression displayed elevated levels of ACTH and glucocorticoids accompanied by symptoms of Cushing-like syndrome (Stenzel-Poore et al., 1992) (Groenink et al., 2002) due to their widespread expression pattern - whole body or entire CNS respectively. Therefore, it can not be ruled out that part of the observed $\mathrm{CRH}$ effects e.g. on anxiety-related behavior may be mediated via its chronic activation of the HPA-system and resulting elevated plasma glucocorticoid levels. 
The aim of our work was to study the function of CRH at specific sites in the CNS by its site-specific overexpression utilizing the R26 locus (Zambrowicz et al., 1997), which has proven as a useful tool to achieve ubiquitous expression during development or in the adult. These mice were crossed wit CaMKII $\alpha$-Cre or NestinCre transgenic mice resulting in a constitutive expression of $\mathrm{CRH}$ in all $\mathrm{Cre}$ expressing cells of the anterior forebrain or within the entire CNS respectively. The specific pattern of $\mathrm{CRH}$ overexpression was initially demonstrated by monitoring $\beta$ galactosidase reporter gene activation. The detailed pattern of $\mathrm{CRH}$ overexpression was analyzed on the mRNA level by in situ hybridization and on the protein level by region specific RIA. We found that $\mathrm{CRH}$ overexpression led to disturbances of the central $\mathrm{CRH} / \mathrm{CRH}$ receptor system reflected by alterations in expression levels of CRH-R1, CRH-R2 and endogenous CRH in specific brain regions. Additionally, GR was also found to be downregulated in the entire brain. The basal plasma corticosterone concentration in the morning was increased slightly in heterozygous and homozygous COR-Cam mice, as well as in heterozygous (1.8-fold) and homozygous (2.4-fold) COR-Nes mice, indicating a hyperactivity of the HPA axis despite high levels of $\mathrm{CRH}$ overexpression. Analysis of the acoustic startle response/reflex revealed increased startle activity in both CRH overexpressing mouse lines. Additionally, COR-Nes mice showed partially impaired PPI with respect to the prepulse intensity. These effects were reversable by the CRH-R1 specific antagonist (NBI-30775). Therefore our CRH overexpressing mice could be a valuable tool for research to address the impact of chronically elevated levels of CRH on information processing, and it is also a useful model to test the clinical potential of novel therapies that target $\mathrm{CRH}$ and its receptors. Moreover, heterozygous and homozygous CORNes mice displayed less freezing in the fear conditioning paradigm, less floating but more struggling in the forced swimming test and less immobility in the tail suspension test compared to control mice. In these three tests, the effect was correlated to CRH expression levels. These results suggested that $\mathrm{CRH}$ overexpression mice showed more activity compared to control mice, it can be proposed to be the result of increased anxiety.

In conclusion, our $\mathrm{CRH}$ overexpressing mice are a suitable model of $\mathrm{CRH}$ chronic hyperactivity and might give us the opportunity to investigate the consequences of $\mathrm{CRH}$ excess in situations of chronic stress. 


\section{References}

Abremski, K., Hoess, R., and Sternberg, N. (1983). Studies on the properties of P1 sitespecific recombination: evidence for topologically unlinked products following recombination. Cell 32, 1301-1311.

Adinoff, B., Anton, R., Linnoila, M., Guidotti, A., Nemeroff, C. B., and Bissette, G. (1996). Cerebrospinal fluid concentrations of corticotropin-releasing hormone $(\mathrm{CRH})$ and diazepam-binding inhibitor (DBI) during alcohol withdrawal and abstinence. Neuropsychopharmacology 15, 288-295.

Aguilera, G. (1994). Regulation of pituitary ACTH secretion during chronic stress. Front Neuroendocrinol 15, 321-350.

Aguilera, G., Lightman, S. L., and Kiss, A. (1993). Regulation of the hypothalamicpituitary-adrenal axis during water deprivation. Endocrinology 132, 241-248.

Aguilera, G., Rabadan-Diehl, C., and Nikodemova, M. (2001). Regulation of pituitary corticotropin releasing hormone receptors. Peptides 22, 769-774.

Akana, S. F., Dallman, M. F., Bradbury, M. J., Scribner, K. A., Strack, A. M., and Walker, C. D. (1992a). Feedback and facilitation in the adrenocortical system: unmasking facilitation by partial inhibition of the glucocorticoid response to prior stress. Endocrinology 131, 57-68.

Akana, S. F., Scribner, K. A., Bradbury, M. J., Strack, A. M., Walker, C. D., and Dallman, M. F. (1992b). Feedback sensitivity of the rat hypothalamo-pituitary-adrenal axis and its capacity to adjust to exogenous corticosterone. Endocrinology 131, 585-594.

Arai, I., Tsuyuki, Y., Shiomoto, H., Satoh, M., and Otomo, S. (2000). Decreased body temperature dependent appearance of behavioral despair in the forced swimming test in mice. Pharmacol Res 42, 171-176.

Arai, M., Assil, I. Q., and Abou-Samra, A. B. (2001). Characterization of three corticotropin-releasing factor receptors in catfish: a novel third receptor is predominantly expressed in pituitary and urophysis. Endocrinology 142, 446-454.

Arborelius, L., Owens, M. J., Plotsky, P. M., and Nemeroff, C. B. (1999). The role of corticotropin-releasing factor in depression and anxiety disorders. J Endocrinol 160, 112.

Arriza, J. L., Weinberger, C., Cerelli, G., Glaser, T. M., Handelin, B. L., Housman, D. E., and Evans, R. M. (1987). Cloning of human mineralocorticoid receptor complementary DNA: structural and functional kinship with the glucocorticoid receptor. Science 237, 268-275.

Avishai-Eliner, S., Brunson, K. L., Sandman, C. A., and Baram, T. Z. (2002). Stressed-out, or in (utero)? Trends Neurosci 25, 518-524.

Bai, F., Li, X., Clay, M., Lindstrom, T., and Skolnick, P. (2001). Intra- and interstrain differences in models of "behavioral despair". Pharmacol Biochem Behav 70, 187-192.

Baker, D. G., West, S. A., Nicholson, W. E., Ekhator, N. N., Kasckow, J. W., Hill, K. K., Bruce, A. B., Orth, D. N., and Geracioti, T. D., Jr. (1999). Serial CSF corticotropinreleasing hormone levels and adrenocortical activity in combat veterans with posttraumatic stress disorder. Am J Psychiatry 156, 585-588.

Bakshi, V. P., and Geyer, M. A. (1999). Alpha-1-adrenergic receptors mediate sensorimotor gating deficits produced by intracerebral dizocilpine administration in rats. Neuroscience 92, 113-121.

Bale, T. L., Contarino, A., Smith, G. W., Chan, R., Gold, L. H., Sawchenko, P. E., Koob, G. F., Vale, W. W., and Lee, K. F. (2000). Mice deficient for corticotropin-releasing hormone receptor-2 display anxiety-like behaviour and are hypersensitive to stress. Nat Genet 24, 410-414.

Bale, T. L., Picetti, R., Contarino, A., Koob, G. F., Vale, W. W., and Lee, K. F. (2002). Mice deficient for both corticotropin-releasing factor receptor 1 (CRFR1) and CRFR2 have an impaired stress response and display sexually dichotomous anxiety-like behavior. J Neurosci 22, 193-199. 
Bartlett, R. G., Jr., and Miller, M. A. (1956). The adrenal cortex in restraint hypothermia and in adaptation to the stress of restraint. J Endocrinol 14, 181-187.

Behan, D. P., Grigoriadis, D. E., Lovenberg, T., Chalmers, D., Heinrichs, S., Liaw, C., and De Souza, E. B. (1996). Neurobiology of corticotropin releasing factor (CRF) receptors and CRF-binding protein: implications for the treatment of CNS disorders. Mol Psychiatry 1, 265-277.

Berridge, C. W., and Dunn, A. J. (1989). CRF and restraint-stress decrease exploratory behavior in hypophysectomized mice. Pharmacol Biochem Behav 34, 517-519.

Beyer, H. S., Matta, S. G., and Sharp, B. M. (1988). Regulation of the messenger ribonucleic acid for corticotropin-releasing factor in the paraventricular nucleus and other brain sites of the rat. Endocrinology 123, 2117-2123.

Birnbaum, S. G., and Davis, M. (1998). Modulation of the acoustic startle reflex by infusion of corticotropin-releasing hormone into the nucleus reticularis pontis caudalis. Brain Res 782, 318-323.

Bittencourt, J. C., Vaughan, J., Arias, C., Rissman, R. A., Vale, W. W., and Sawchenko, P. E. (1999). Urocortin expression in rat brain: evidence against a pervasive relationship of urocortin-containing projections with targets bearing type 2 CRF receptors. J Comp Neurol 415, 285-312.

Blackburn-Munro, G., and Blackburn-Munro, R. E. (2001). Chronic pain, chronic stress and depression: coincidence or consequence? J Neuroendocrinol 13, 1009-1023.

Board, F., Persky, H., and Hamburg, D. A. (1956). Psychological stress and endocrine functions; blood levels of adrenocortical and thyroid hormones in acutely disturbed patients. Psychosom Med 18, 324-333.

Braff, D. L., and Geyer, M. A. (1990). Sensorimotor gating and schizophrenia. Human and animal model studies. Arch Gen Psychiatry 47, 181-188.

Braff, D. L., Geyer, M. A., and Swerdlow, N. R. (2001). Human studies of prepulse inhibition of startle: normal subjects, patient groups, and pharmacological studies. Psychopharmacology (Berl) 156, 234-258.

Bremner, J. D., Licinio, J., Darnell, A., Krystal, J. H., Owens, M. J., Southwick, S. M., Nemeroff, C. B., and Charney, D. S. (1997). Elevated CSF corticotropin-releasing factor concentrations in posttraumatic stress disorder. Am J Psychiatry 154, 624-629.

Britton, K. T., Lee, G., Vale, W., Rivier, J., and Koob, G. F. (1986). Corticotropin releasing factor (CRF) receptor antagonist blocks activating and 'anxiogenic' actions of CRF in the rat. Brain Res 369, 303-306.

Broccardo, M., Erspamer, V., Falconieri Erspamer, G., Improta, G., Linari, G., Melchiorri, P., and Montecucchi, P. C. (1981). Pharmacological data on dermorphins, a new class of potent opioid peptides from amphibian skin. Br J Pharmacol 73, 625-631.

Brown, G. W., Bifulco, A., and Harris, T. O. (1987). Life events, vulnerability and onset of depression: some refinements. Br J Psychiatry 150, 30-42.

Brown, P., Rothwell, J. C., Thompson, P. D., Britton, T. C., Day, B. L., and Marsden, C. D. (1991). New observations on the normal auditory startle reflex in man. Brain 114 ( Pt 4), 1891-1902.

Bruhn, T. O., Sutton, S. W., Plotsky, P. M., and Vale, W. W. (1986). Central administration of corticotropin-releasing factor modulates oxytocin secretion in the rat. Endocrinology 119, 1558-1563.

Brunson, K. L., Eghbal-Ahmadi, M., Bender, R., Chen, Y., and Baram, T. Z. (2001). Longterm, progressive hippocampal cell loss and dysfunction induced by early-life administration of corticotropin-releasing hormone reproduce the effects of early-life stress. Proc Natl Acad Sci U S A 98, 8856-8861.

Butler, P. D., Weiss, J. M., Stout, J. C., and Nemeroff, C. B. (1990). Corticotropinreleasing factor produces fear-enhancing and behavioral activating effects following infusion into the locus coeruleus. J Neurosci 10, 176-183.

Cahill, L., Prins, B., Weber, M., and McGaugh, J. L. (1994). Beta-adrenergic activation and memory for emotional events. Nature 371, 702-704. 
Campeau, S., and Davis, M. (1995). Prepulse inhibition of the acoustic startle reflex using visual and auditory prepulses: disruption by apomorphine. Psychopharmacology (Berl) 117, 267-274.

Capecchi, M. R. (1989). Altering the genome by homologous recombination. Science 244, 1288-1292.

Carlson, S., and Willott, J. F. (1998). Caudal pontine reticular formation of C57BL/6J mice: responses to startle stimuli, inhibition by tones, and plasticity. J Neurophysiol 79, 26032614.

Casanova, E., Fehsenfeld, S., Lemberger, T., Shimshek, D. R., Sprengel, R., and Mantamadiotis, T. (2002). ER-based double iCre fusion protein allows partial recombination in forebrain. Genesis $34,208-214$.

Chalmers, D. T., Lovenberg, T. W., and De Souza, E. B. (1995). Localization of novel corticotropin-releasing factor receptor (CRF2) mRNA expression to specific subcortical nuclei in rat brain: comparison with CRF1 receptor mRNA expression. J Neurosci 15, 6340-6350.

Champagne, D., Beaulieu, J., and Drolet, G. (1998). CRFergic innervation of the paraventricular nucleus of the rat hypothalamus: a tract-tracing study. J Neuroendocrinol 10, 119-131.

Chang, C. P., Pearse, R. V., 2nd, O'Connell, S., and Rosenfeld, M. G. (1993). Identification of a seven transmembrane helix receptor for corticotropin-releasing factor and sauvagine in mammalian brain. Neuron 11, 1187-1195.

Checkley, S. (1996). The neuroendocrinology of depression and chronic stress. Br Med Bull 52, 597-617.

Chen, C., Dagnino, R., Jr., De Souza, E. B., Grigoriadis, D. E., Huang, C. Q., Kim, K. I., Liu, Z., Moran, T., Webb, T. R., Whitten, J. P., et al. (1996). Design and synthesis of a series of non-peptide high-affinity human corticotropin-releasing factorl receptor antagonists. J Med Chem 39, 4358-4360.

Chen, R., Lewis, K. A., Perrin, M. H., and Vale, W. W. (1993). Expression cloning of a human corticotropin-releasing-factor receptor. Proc Natl Acad Sci U S A 90, 8967-8971.

Chomczynski, P., and Sacchi, N. (1987). Single-step method of RNA isolation by acid guanidinium thiocyanate-phenol-chloroform extraction. Anal Biochem 162, 156-159.

Chowdrey, H. S., Jessop, D. S., Patel, H., and Lightman, S. L. (1991). Altered adrenocorticotropin, corticosterone and oxytocin responses to stress during chronic salt load. Neuroendocrinology 54, 635-638.

Christoffersen, G. R. (1997). Habituation: events in the history of its characterization and linkage to synaptic depression. A new proposed kinetic criterion for its identification. Prog Neurobiol 53, 45-66.

Contarino, A., Dellu, F., Koob, G. F., Smith, G. W., Lee, K. F., Vale, W., and Gold, L. H. (1999). Reduced anxiety-like and cognitive performance in mice lacking the corticotropin-releasing factor receptor 1 . Brain Res 835, 1-9.

Conti, L. H., Murry, J. D., Ruiz, M. A., and Printz, M. P. (2002). Effects of corticotropinreleasing factor on prepulse inhibition of the acoustic startle response in two rat strains. Psychopharmacology (Berl) 161, 296-303.

Cortright, D. N., Nicoletti, A., and Seasholtz, A. F. (1995). Molecular and biochemical characterization of the mouse brain corticotropin-releasing hormone-binding protein. Mol Cell Endocrinol 111, 147-157.

Coste, S. C., Kesterson, R. A., Heldwein, K. A., Stevens, S. L., Heard, A. D., Hollis, J. H., Murray, S. E., Hill, J. K., Pantely, G. A., Hohimer, A. R., et al. (2000). Abnormal adaptations to stress and impaired cardiovascular function in mice lacking corticotropinreleasing hormone receptor-2. Nat Genet 24, 403-409.

Cryan, J. F., Markou, A., and Lucki, I. (2002). Assessing antidepressant activity in rodents: recent developments and future needs. Trends Pharmacol Sci 23, 238-245.

Cryan, J. F., and Mombereau, C. (2004). In search of a depressed mouse: utility of models for studying depression-related behavior in genetically modified mice. Mol Psychiatry 9 , 326-357. 
Cummings, S., Elde, R., Ells, J., and Lindall, A. (1983). Corticotropin-releasing factor immunoreactivity is widely distributed within the central nervous system of the rat: an immunohistochemical study. J Neurosci 3, 1355-1368.

Dahlstrand, J., Lardelli, M., and Lendahl, U. (1995). Nestin mRNA expression correlates with the central nervous system progenitor cell state in many, but not all, regions of developing central nervous system. Brain Res Dev Brain Res 84, 109-129.

Dautzenberg, F. M., Dietrich, K., Palchaudhuri, M. R., and Spiess, J. (1997). Identification of two corticotropin-releasing factor receptors from Xenopus laevis with high ligand selectivity: unusual pharmacology of the type 1 receptor. J Neurochem 69, 1640-1649.

Dautzenberg, F. M., and Hauger, R. L. (2002). The CRF peptide family and their receptors: yet more partners discovered. Trends Pharmacol Sci 23, 71-77.

Davis, M. (1970). Effects of interstimulus interval length and variability on startle-response habituation in the rat. J Comp Physiol Psychol 72, 177-192.

Davis, M. (1988). Apomorphine, d-amphetamine, strychnine and yohimbine do not alter prepulse inhibition of the acoustic startle reflex. Psychopharmacology (Berl) 95, 151156.

Davis, M. (1998). Are different parts of the extended amygdala involved in fear versus anxiety? Biol Psychiatry 44, 1239-1247.

Davis, M., Falls, W. A., Campeau, S., and Kim, M. (1993). Fear-potentiated startle: a neural and pharmacological analysis. Behav Brain Res 58, 175-198.

Davis, M., Parisi, T., Gendelman, D. S., Tischler, M., and Kehne, J. H. (1982). Habituation and sensitization of startle reflexes elicited electrically from the brainstem. Science 218, 688-690.

Davis, M., Walker, D. L., and Lee, Y. (1997a). Amygdala and bed nucleus of the stria terminalis: differential roles in fear and anxiety measured with the acoustic startle reflex. Philos Trans R Soc Lond B Biol Sci 352, 1675-1687.

Davis, T. M., Li, T. A., Tran, Q. B., Robertson, K., Dyer, J. R., Phan, T. D., Meyer, D., Beaman, M. H., and Trinh, K. A. (1997b). The hypothalamic-pituitary-adrenocortical axis in severe falciparum malaria: effects of cytokines. J Clin Endocrinol Metab 82, 3029-3033.

De Goeij, D. C., Binnekade, R., and Tilders, F. J. (1992). Chronic stress enhances vasopressin but not corticotropin-releasing factor secretion during hypoglycemia. Am J Physiol 263, E394-399.

de Goeij, D. C., Jezova, D., and Tilders, F. J. (1992). Repeated stress enhances vasopressin synthesis in corticotropin releasing factor neurons in the paraventricular nucleus. Brain Res $577,165-168$.

de Goeij, D. C., Kvetnansky, R., Whitnall, M. H., Jezova, D., Berkenbosch, F., and Tilders, F. J. (1991). Repeated stress-induced activation of corticotropin-releasing factor neurons enhances vasopressin stores and colocalization with corticotropin-releasing factor in the median eminence of rats. Neuroendocrinology 53, 150-159.

de Kloet, E. R., Oitzl, M. S., and Joels, M. (1999). Stress and cognition: are corticosteroids good or bad guys? Trends Neurosci 22, 422-426.

De Kloet, E. R., Vreugdenhil, E., Oitzl, M. S., and Joels, M. (1998). Brain corticosteroid receptor balance in health and disease. Endocr Rev 19, 269-301.

De Souza, E. B. (1987). Corticotropin-releasing factor receptors in the rat central nervous system: characterization and regional distribution. J Neurosci 7, 88-100.

Dirks, A., Groenink, L., Bouwknecht, J. A., Hijzen, T. H., Van Der Gugten, J., Ronken, E., Verbeek, J. S., Veening, J. G., Dederen, P. J., Korosi, A., et al. (2002a). Overexpression of corticotropin-releasing hormone in transgenic mice and chronic stress-like autonomic and physiological alterations. Eur J Neurosci 16, 1751-1760.

Dirks, A., Groenink, L., Schipholt, M. I., van der Gugten, J., Hijzen, T. H., Geyer, M. A., and Olivier, B. (2002b). Reduced startle reactivity and plasticity in transgenic mice overexpressing corticotropin-releasing hormone. Biol Psychiatry 51, 583-590. 
Dittmar, K. D., Banach, M., Galigniana, M. D., and Pratt, W. B. (1998). The role of DnaJlike proteins in glucocorticoid receptor.hsp90 heterocomplex assembly by the reconstituted hsp90.p60.hsp70 foldosome complex. J Biol Chem 273, 7358-7366.

Dohanics, J., Kovacs, K. J., Folly, G., and Makara, G. B. (1990). Long-term salt loading impairs pituitary responsiveness to ACTH secretagogues and stress in rats. Peptides 11, 59-63.

Dong, Y., Poellinger, L., Gustafsson, J. A., and Okret, S. (1988). Regulation of glucocorticoid receptor expression: evidence for transcriptional and posttranslational mechanisms. Mol Endocrinol 2, 1256-1264.

Dulawa, S. C., and Geyer, M. A. (2000). Effects of strain and serotonergic agents on prepulse inhibition and habituation in mice. Neuropharmacology 39, 2170-2179.

Dunn, A. J., and Berridge, C. W. (1990a). Is corticotropin-releasing factor a mediator of stress responses? Ann N Y Acad Sci 579, 183-191.

Dunn, A. J., and Berridge, C. W. (1990b). Physiological and behavioral responses to corticotropin-releasing factor administration: is CRF a mediator of anxiety or stress responses? Brain Res Brain Res Rev 15, 71-100.

Dunn, A. J., and Swiergiel, A. H. (1999). Behavioral responses to stress are intact in CRFdeficient mice. Brain Res 845, 14-20.

Dunner, D. L., Patrick, V., and Fieve, R. R. (1979). Life events at the onset of bipolar affective illness. Am J Psychiatry 136, 508-511.

Ehrlichman, H., Brown, S., Zhu, J., and Warrenburg, S. (1995). Startle reflex modulation during exposure to pleasant and unpleasant odors. Psychophysiology 32, 150-154.

Ellenbroek, B. A., van den Kroonenberg, P. T., and Cools, A. R. (1998). The effects of an early stressful life event on sensorimotor gating in adult rats. Schizophr Res 30, 251-260.

Fendt, M., Koch, M., and Schnitzler, H. U. (1997). Corticotropin-releasing factor in the caudal pontine reticular nucleus mediates the expression of fear-potentiated startle in the rat. Eur J Neurosci 9, 299-305.

Fisher, L. A. (1989). Central autonomic modulation of cardiac baroreflex by corticotropinreleasing factor. Am J Physiol 256, H949-955.

Friedrich, G., and Soriano, P. (1991). Promoter traps in embryonic stem cells: a genetic screen to identify and mutate developmental genes in mice. Genes Dev 5, 1513-1523.

Gewirtz, J. C., McNish, K. A., and Davis, M. (1998). Lesions of the bed nucleus of the stria terminalis block sensitization of the acoustic startle reflex produced by repeated stress, but not fear-potentiated startle. Prog Neuropsychopharmacol Biol Psychiatry 22, 625-648.

Geyer, M. A., Swerdlow, N. R., Mansbach, R. S., and Braff, D. L. (1990). Startle response models of sensorimotor gating and habituation deficits in schizophrenia. Brain Res Bull $25,485-498$.

Geyer, M. A., Wilkinson, L. S., Humby, T., and Robbins, T. W. (1993). Isolation rearing of rats produces a deficit in prepulse inhibition of acoustic startle similar to that in schizophrenia. Biol Psychiatry 34, 361-372.

Giardino, L., Puglisi-Allegra, S., and Ceccatelli, S. (1996). CRH-R1 mRNA expression in two strains of inbred mice and its regulation after repeated restraint stress. Brain Res Mol Brain Res 40, 310-314.

Glowa, J. R., and Hansen, C. T. (1994). Differences in response to an acoustic startle stimulus among forty-six rat strains. Behav Genet 24, 79-84.

Gosnell, B. A., Morley, J. E., and Levine, A. S. (1983). Adrenal modulation of the inhibitory effect of corticotropin releasing factor on feeding. Peptides 4, 807-812.

Graham, F. K. (1975). Presidential Address, 1974. The more or less startling effects of weak prestimulation. Psychophysiology 12, 238-248.

Grammatopoulos, D. K., Dai, Y., Randeva, H. S., Levine, M. A., Karteris, E., Easton, A. J., and Hillhouse, E. W. (1999). A novel spliced variant of the type 1 corticotropinreleasing hormone receptor with a deletion in the seventh transmembrane domain present in the human pregnant term myometrium and fetal membranes. Mol Endocrinol $13,2189-2202$. 
Grillon, C., Ameli, R., Goddard, A., Woods, S. W., and Davis, M. (1994). Baseline and fear-potentiated startle in panic disorder patients. Biol Psychiatry 35, 431-439.

Grillon, C., Ameli, R., Woods, S. W., Merikangas, K., and Davis, M. (1991). Fearpotentiated startle in humans: effects of anticipatory anxiety on the acoustic blink reflex. Psychophysiology 28, 588-595.

Grillon, C., Morgan, C. A., Southwick, S. M., Davis, M., and Charney, D. S. (1996). Baseline startle amplitude and prepulse inhibition in Vietnam veterans with posttraumatic stress disorder. Psychiatry Res 64, 169-178.

Groenewegen, H. J., Vermeulen-Van der Zee, E., te Kortschot, A., and Witter, M. P. (1987). Organization of the projections from the subiculum to the ventral striatum in the rat. A study using anterograde transport of Phaseolus vulgaris leucoagglutinin. Neuroscience 23, 103-120.

Groenink, L., Dirks, A., Verdouw, P. M., Schipholt, M., Veening, J. G., van der Gugten, J., and Olivier, B. (2002). HPA axis dysregulation in mice overexpressing corticotropin releasing hormone. Biol Psychiatry 51, 875-881.

Groves, P. M., and Thompson, R. F. (1970). Habituation: a dual-process theory. Psychol Rev 77, 419-450.

Gu, H., Marth, J. D., Orban, P. C., Mossmann, H., and Rajewsky, K. (1994). Deletion of a DNA polymerase beta gene segment in $\mathrm{T}$ cells using cell type-specific gene targeting. Science 265, 103-106.

Hadjantonakis, A. K., Pirity, M., and Nagy, A. (1999). Cre recombinase mediated alterations of the mouse genome using embryonic stem cells. Methods Mol Biol 97, 101122.

Hammen, C., Davila, J., Brown, G., Ellicott, A., and Gitlin, M. (1992). Psychiatric history and stress: predictors of severity of unipolar depression. J Abnorm Psychol 101, 45-52.

Harbuz, M. S., Conde, G. L., Marti, O., Lightman, S. L., and Jessop, D. S. (1997). The hypothalamic-pituitary-adrenal axis in autoimmunity. Ann N Y Acad Sci 823, 214-224.

Hatalski, C. G., Brunson, K. L., Tantayanubutr, B., Chen, Y., and Baram, T. Z. (2000). Neuronal activity and stress differentially regulate hippocampal and hypothalamic corticotropin-releasing hormone expression in the immature rat. Neuroscience 101, 571580 .

Hatalski, C. G., Guirguis, C., and Baram, T. Z. (1998). Corticotropin releasing factor mRNA expression in the hypothalamic paraventricular nucleus and the central nucleus of the amygdala is modulated by repeated acute stress in the immature rat. J Neuroendocrinol 10, 663-669.

Heinrichs, S. C., and De Souza, E. B. (1999). Corticotropin-releasing factor antagonists, binding-protein and receptors: implications for central nervous system disorders. Baillieres Best Pract Res Clin Endocrinol Metab 13, 541-554.

Heinrichs, S. C., Menzaghi, F., Merlo Pich, E., Britton, K. T., and Koob, G. F. (1995). The role of CRF in behavioral aspects of stress. Ann N Y Acad Sci 771, 92-104.

Heinrichs, S. C., Min, H., Tamraz, S., Carmouche, M., Boehme, S. A., and Vale, W. W. (1997). Anti-sexual and anxiogenic behavioral consequences of corticotropin-releasing factor overexpression are centrally mediated. Psychoneuroendocrinology 22, 215-224.

Heinrichs, S. C., Pich, E. M., Miczek, K. A., Britton, K. T., and Koob, G. F. (1992). Corticotropin-releasing factor antagonist reduces emotionality in socially defeated rats via direct neurotropic action. Brain Res 581, 190-197.

Heinrichs, S. C., Stenzel-Poore, M. P., Gold, L. H., Battenberg, E., Bloom, F. E., Koob, G. F., Vale, W. W., and Pich, E. M. (1996). Learning impairment in transgenic mice with central overexpression of corticotropin-releasing factor. Neuroscience 74, 303-311.

Helm, K. A., Han, J. S., and Gallagher, M. (2002). Effects of cholinergic lesions produced by infusions of 192 IgG-saporin on glucocorticoid receptor mRNA expression in hippocampus and medial prefrontal cortex of the rat. Neuroscience 115, 765-774.

Henke, P. G. (1980). The centromedial amygdala and gastric pathology in rats. Physiol Behav 25, 107-112. 
Herman, J. P., and Cullinan, W. E. (1997). Neurocircuitry of stress: central control of the hypothalamo-pituitary-adrenocortical axis. Trends Neurosci 20, 78-84.

Herman, J. P., Prewitt, C. M., and Cullinan, W. E. (1996). Neuronal circuit regulation of the hypothalamo-pituitary-adrenocortical stress axis. Crit Rev Neurobiol 10, 371-394.

Herman, J. P., Schafer, M. K., Thompson, R. C., and Watson, S. J. (1992). Rapid regulation of corticotropin-releasing hormone gene transcription in vivo. Mol Endocrinol 6, 1061-1069.

Hoffman, H. S., and Ison, J. R. (1980). Reflex modification in the domain of startle: I. Some empirical findings and their implications for how the nervous system processes sensory input. Psychol Rev 87, 175-189.

Hollenberg, S. M., Weinberger, C., Ong, E. S., Cerelli, G., Oro, A., Lebo, R., Thompson, E. B., Rosenfeld, M. G., and Evans, R. M. (1985). Primary structure and expression of a functional human glucocorticoid receptor cDNA. Nature 318, 635-641.

Holmes, A., Yang, R. J., Murphy, D. L., and Crawley, J. N. (2002). Evaluation of antidepressant-related behavioral responses in mice lacking the serotonin transporter. Neuropsychopharmacology 27, 914-923.

Holmes, M. C., Antoni, F. A., Aguilera, G., and Catt, K. J. (1986). Magnocellular axons in passage through the median eminence release vasopressin. Nature 319, 326-329.

Holmes, M. C., Catt, K. J., and Aguilera, G. (1987). Involvement of vasopressin in the down-regulation of pituitary corticotropin-releasing factor receptors after adrenalectomy. Endocrinology 121, 2093-2098.

Holsboer, F. (1999). [CRH antagonists against depression. Viagra for the mind?. Interview by Dr. Stephanie Czajka.]. MMW Fortschr Med 141, 12.

Holsboer, F. (2000). The corticosteroid receptor hypothesis of depression. Neuropsychopharmacology 23, 477-501.

Holsboer, F., and Barden, N. (1996). Antidepressants and hypothalamic-pituitaryadrenocortical regulation. Endocr Rev 17, 187-205.

Hsu, D. T., Chen, F. L., Takahashi, L. K., and Kalin, N. H. (1998). Rapid stress-induced elevations in corticotropin-releasing hormone mRNA in rat central amygdala nucleus and hypothalamic paraventricular nucleus: an in situ hybridization analysis. Brain Res 788, 305-310.

Hsu, S. Y., and Hsueh, A. J. (2001). Human stresscopin and stresscopin-related peptide are selective ligands for the type 2 corticotropin-releasing hormone receptor. Nat Med 7, 605-611.

Hughes, C. W., Stein, E. A., and Lynch, J. J. (1978). Hopelessness-induced sudden death in rats: anthropomorphism for experimentally induced drownings? J Nerv Ment Dis 166, 387-401.

Ichikawa, T., McMaster, D., Lederis, K., and Kobayashi, H. (1982). Isolation and amino acid sequence of urotensin I, a vasoactive and ACTH-releasing neuropeptide, from the carp (Cyprinus carpio) urophysis. Peptides 3, 859-867.

Imaki, J., Imaki, T., Vale, W., and Sawchenko, P. E. (1991). Distribution of corticotropinreleasing factor mRNA and immunoreactivity in the central auditory system of the rat. Brain Res 547, 28-36.

Imaki, T., Naruse, M., Harada, S., Chikada, N., Imaki, J., Onodera, H., Demura, H., and Vale, W. (1996). Corticotropin-releasing factor up-regulates its own receptor mRNA in the paraventricular nucleus of the hypothalamus. Brain Res Mol Brain Res 38, 166-170.

Imaki, T., Shibasaki, T., Hotta, M., and Demura, H. (1993). Intracerebroventricular administration of corticotropin-releasing factor induces c-fos mRNA expression in brain regions related to stress responses: comparison with pattern of c-fos mRNA induction after stress. Brain Res 616, 114-125.

Imaki, T., Shibasaki, T., Wang, X. Q., and Demura, H. (1995). Intracerebroventricular administration of corticotropin-releasing factor antagonist attenuates c-fos mRNA expression in the paraventricular nucleus after stress. Neuroendocrinology 61, 445-452. 
Iredale, P. A., Terwilliger, R., Widnell, K. L., Nestler, E. J., and Duman, R. S. (1996). Differential regulation of corticotropin-releasing factorl receptor expression by stress and agonist treatments in brain and cultured cells. Mol Pharmacol 50, 1103-1110.

Irvine, C. H., Alexander, S. L., and Donald, R. A. (1989). Effect of an osmotic stimulus on the secretion of arginine vasopressin and adrenocorticotropin in the horse. Endocrinology 124, 3102-3108.

Ison, J. R., Foss, J. A., Falcone, P., Sakovits, L., Adelson, A. A., and Burton, R. I. (1986). Reflex modification: a method for assessing cutaneous dysfunction. Percept Psychophys 40, 164-170.

Itoi, K., Mouri, T., Takahashi, K., Murakami, O., Imai, Y., Sasaki, S., Yoshinaga, K., and Sasano, N. (1987). Suppression by glucocorticoid of the immunoreactivity of corticotropin-releasing factor and vasopressin in the paraventricular nucleus of rat hypothalamus. Neurosci Lett 73, 231-236.

Jacobson, L., Muglia, L. J., Weninger, S. C., Pac inverted question markak, K., and Majzoub, J. A. (2000). CRH deficiency impairs but does not block pituitary-adrenal responses to diverse stressors. Neuroendocrinology 71, 79-87.

Jacobson, L., and Sapolsky, R. (1991). The role of the hippocampus in feedback regulation of the hypothalamic-pituitary-adrenocortical axis. Endocr Rev 12, 118-134.

Jaenisch, R. (1988). Transgenic animals. Science 240, 1468-1474.

Joels, M., and De Kloet, E. R. (1992). Coordinative mineralocorticoid and glucocorticoid receptor-mediated control of responses to serotonin in rat hippocampus. Neuroendocrinology 55, 344-350.

Jones, D. N., Kortekaas, R., Slade, P. D., Middlemiss, D. N., and Hagan, J. J. (1998). The behavioural effects of corticotropin-releasing factor-related peptides in rats. Psychopharmacology (Berl) 138, 124-132.

Kalin, N. H., Takahashi, L. K., and Chen, F. L. (1994). Restraint stress increases corticotropin-releasing hormone mRNA content in the amygdala and paraventricular nucleus. Brain Res 656, 182-186.

Kalivas, P. W., Duffy, P., and Latimer, L. G. (1987). Neurochemical and behavioral effects of corticotropin-releasing factor in the ventral tegmental area of the rat. J Pharmacol Exp Ther 242, 757-763.

Kamprath, K., and Wotjak, C. T. (2004). Nonassociative learning processes determine expression and extinction of conditioned fear in mice. Learn Mem 11, 770-786.

Kandel, H. J., Ayllon, T., and Roberts, M. D. (1976). Rapid educational rehabilitation for prison inmates. Behav Res Ther 14, 323-331.

Kandler, K., and Herbert, H. (1991). Auditory projections from the cochlear nucleus to pontine and mesencephalic reticular nuclei in the rat. Brain Res 562, 230-242.

Kim, J. J., and Fanselow, M. S. (1992). Modality-specific retrograde amnesia of fear. Science 256, 675-677.

Kishimoto, T., Pearse, R. V., 2nd, Lin, C. R., and Rosenfeld, M. G. (1995). A sauvagine/corticotropin-releasing factor receptor expressed in heart and skeletal muscle. Proc Natl Acad Sci U S A 92, 1108-1112.

Kishimoto, T., Radulovic, J., Radulovic, M., Lin, C. R., Schrick, C., Hooshmand, F., Hermanson, O., Rosenfeld, M. G., and Spiess, J. (2000). Deletion of crhr2 reveals an anxiolytic role for corticotropin-releasing hormone receptor-2. Nat Genet 24, 415-419.

Koch, M. (1996). The septohippocampal system is involved in prepulse inhibition of the acoustic startle response in rats. Behav Neurosci 110, 468-477.

Koch, M. (1999). The neurobiology of startle. Prog Neurobiol 59, 107-128.

Koch, M., Lingenhohl, K., and Pilz, P. K. (1992). Loss of the acoustic startle response following neurotoxic lesions of the caudal pontine reticular formation: possible role of giant neurons. Neuroscience 49, 617-625.

Konishi, S., Kasagi, Y., Katsumata, H., Minami, S., and Imaki, T. (2003). Regulation of corticotropin-releasing factor (CRF) type-1 receptor gene expression by CRF in the hypothalamus. Endocr J 50, 21-36. 
Koob, G. F., and Bloom, F. E. (1985). Corticotropin-releasing factor and behavior. Fed Proc 44, 259-263.

Koob, G. F., and Heinrichs, S. C. (1999). A role for corticotropin releasing factor and urocortin in behavioral responses to stressors. Brain Res 848, 141-152.

Koob, G. F., Heinrichs, S. C., Pich, E. M., Menzaghi, F., Baldwin, H., Miczek, K., and Britton, K. T. (1993). The role of corticotropin-releasing factor in behavioural responses to stress. Ciba Found Symp 172, 277-289; discussion 290-275.

Korte, S. M. (2001). Corticosteroids in relation to fear, anxiety and psychopathology. Neurosci Biobehav Rev 25, 117-142.

Korte, S. M., Korte-Bouws, G. A., Koob, G. F., De Kloet, E. R., and Bohus, B. (1996). Mineralocorticoid and glucocorticoid receptor antagonists in animal models of anxiety. Pharmacol Biochem Behav 54, 261-267.

Kostich, W. A., Chen, A., Sperle, K., and Largent, B. L. (1998). Molecular identification and analysis of a novel human corticotropin-releasing factor (CRF) receptor: the CRF2gamma receptor. Mol Endocrinol 12, 1077-1085.

Kozicz, T., Yanaihara, H., and Arimura, A. (1998). Distribution of urocortin-like immunoreactivity in the central nervous system of the rat. J Comp Neurol 391, 1-10.

Kretz, O., Schmid, W., Berger, S., and Gass, P. (2001). The mineralocorticoid receptor expression in the mouse CNS is conserved during development. Neuroreport 12, 11331137.

Lang, P. J. (1995). The emotion probe. Studies of motivation and attention. Am Psychol 50, $372-385$.

Lavicky, J., and Dunn, A. J. (1993). Corticotropin-releasing factor stimulates catecholamine release in hypothalamus and prefrontal cortex in freely moving rats as assessed by microdialysis. J Neurochem 60, 602-612.

Lederis, K., Letter, A., McMaster, D., Moore, G., and Schlesinger, D. (1982). Complete amino acid sequence of urotensin I, a hypotensive and corticotropin-releasing neuropeptide from Catostomus. Science 218, 162-165.

LeDoux, J. E. (2000). Emotion circuits in the brain. Annu Rev Neurosci 23, 155-184.

Lee, Y., and Davis, M. (1997). Role of the hippocampus, the bed nucleus of the stria terminalis, and the amygdala in the excitatory effect of corticotropin-releasing hormone on the acoustic startle reflex. J Neurosci 17, 6434-6446.

Lee, Y., Lopez, D. E., Meloni, E. G., and Davis, M. (1996). A primary acoustic startle pathway: obligatory role of cochlear root neurons and the nucleus reticularis pontis caudalis. J Neurosci 16, 3775-3789.

Leitner, D. S., and Cohen, M. E. (1985). Role of the inferior colliculus in the inhibition of acoustic startle in the rat. Physiol Behav 34, 65-70.

Leitner, D. S., Powers, A. S., and Hoffman, H. S. (1980). The neural substrate of the startle response. Physiol Behav 25, 291-297.

Leitner, D. S., Powers, A. S., Stitt, C. L., and Hoffman, H. S. (1981). Midbrain reticular formation involvement in the inhibition of acoustic startle. Physiol Behav 26, 259-268.

Lewis, K., Li, C., Perrin, M. H., Blount, A., Kunitake, K., Donaldson, C., Vaughan, J., Reyes, T. M., Gulyas, J., Fischer, W., et al. (2001). Identification of urocortin III, an additional member of the corticotropin-releasing factor (CRF) family with high affinity for the CRF2 receptor. Proc Natl Acad Sci U S A 98, 7570-7575.

Li, C., Vaughan, J., Sawchenko, P. E., and Vale, W. W. (2002). Urocortin IIIimmunoreactive projections in rat brain: partial overlap with sites of type 2 corticotrophin-releasing factor receptor expression. J Neurosci 22, 991-1001.

Li, L., Korngut, L. M., Frost, B. J., and Beninger, R. J. (1998). Prepulse inhibition following lesions of the inferior colliculus: prepulse intensity functions. Physiol Behav 65, 133-139.

Liang, K. C., Juler, R. G., and McGaugh, J. L. (1986). Modulating effects of posttraining epinephrine on memory: involvement of the amygdala noradrenergic system. Brain Res $368,125-133$. 
Liang, K. C., Melia, K. R., Miserendino, M. J., Falls, W. A., Campeau, S., and Davis, M. (1992). Corticotropin-releasing factor: long-lasting facilitation of the acoustic startle reflex. J Neurosci 12, 2303-2312.

Liaw, C. W., Lovenberg, T. W., Barry, G., Oltersdorf, T., Grigoriadis, D. E., and de Souza, E. B. (1996). Cloning and characterization of the human corticotropin-releasing factor-2 receptor complementary deoxyribonucleic acid. Endocrinology 137, 72-77.

Lingenhohl, K., and Friauf, E. (1992). Giant neurons in the caudal pontine reticular formation receive short latency acoustic input: an intracellular recording and HRP-study in the rat. J Comp Neurol 325, 473-492.

Lingenhohl, K., and Friauf, E. (1994). Giant neurons in the rat reticular formation: a sensorimotor interface in the elementary acoustic startle circuit? J Neurosci 14 , 11761194.

Lipska, B. K., and Weinberger, D. R. (2000). To model a psychiatric disorder in animals: schizophrenia as a reality test. Neuropsychopharmacology 23, 223-239.

Lovenberg, T. W., Liaw, C. W., Grigoriadis, D. E., Clevenger, W., Chalmers, D. T., De Souza, E. B., and Oltersdorf, T. (1995). Cloning and characterization of a functionally distinct corticotropin-releasing factor receptor subtype from rat brain. Proc Natl Acad Sci U S A 92, 836-840.

Lowry, P. J., Koerber, S. C., Woods, R. J., Baigent, S., Sutton, S., Behan, D. P., Vale, W., and Rivier, J. (1996). Nature of ligand affinity and dimerization of corticotrophinreleasing factor-binding protein may be detected by circular dichroism. J Mol Endocrinol 16, 39-44.

Luine, V. N., Spencer, R. L., and McEwen, B. S. (1993). Effects of chronic corticosterone ingestion on spatial memory performance and hippocampal serotonergic function. Brain Res 616, 65-70.

Luo, X., Kiss, A., Makara, G., Lolait, S. J., and Aguilera, G. (1994). Stress-specific regulation of corticotropin releasing hormone receptor expression in the paraventricular and supraoptic nuclei of the hypothalamus in the rat. J Neuroendocrinol 6, 689-696.

Lupien, S. J., de Leon, M., de Santi, S., Convit, A., Tarshish, C., Nair, N. P., Thakur, M., McEwen, B. S., Hauger, R. L., and Meaney, M. J. (1998). Cortisol levels during human aging predict hippocampal atrophy and memory deficits. Nat Neurosci 1, 69-73.

Luthi, A., Van der Putten, H., Botteri, F. M., Mansuy, I. M., Meins, M., Frey, U., Sansig, G., Portet, C., Schmutz, M., Schroder, M., et al. (1997). Endogenous serine protease inhibitor modulates epileptic activity and hippocampal long-term potentiation. J Neurosci 17, 4688-4699.

Ma, X. M., Levy, A., and Lightman, S. L. (1997). Rapid changes of heteronuclear RNA for arginine vasopressin but not for corticotropin releasing hormone in response to acute corticosterone administration. J Neuroendocrinol 9, 723-728.

Makino, S., Gold, P. W., and Schulkin, J. (1994). Corticosterone effects on corticotropinreleasing hormone mRNA in the central nucleus of the amygdala and the parvocellular region of the paraventricular nucleus of the hypothalamus. Brain Res 640, 105-112.

Makino, S., Kaneda, T., Nishiyama, M., Asaba, K., and Hashimoto, K. (2001). Lack of decrease in hypothalamic and hippocampal glucocorticoid receptor mRNA during starvation. Neuroendocrinology 74, 120-128.

Makino, S., Schulkin, J., Smith, M. A., Pacak, K., Palkovits, M., and Gold, P. W. (1995). Regulation of corticotropin-releasing hormone receptor messenger ribonucleic acid in the rat brain and pituitary by glucocorticoids and stress. Endocrinology 136, 4517-4525.

Mansi, J. A., Rivest, S., and Drolet, G. (1996). Regulation of corticotropin-releasing factor type 1 (CRF1) receptor messenger ribonucleic acid in the paraventricular nucleus of rat hypothalamus by exogenous CRF. Endocrinology 137, 4619-4629.

Mao, X., Fujiwara, Y., and Orkin, S. H. (1999). Improved reporter strain for monitoring Cre recombinase-mediated DNA excisions in mice. Proc Natl Acad Sci U S A 96, 50375042.

Maren, S., Aharonov, G., and Fanselow, M. S. (1997). Neurotoxic lesions of the dorsal hippocampus and Pavlovian fear conditioning in rats. Behav Brain Res 88, 261-274. 
Maxwell, I. H., Harrison, G. S., Wood, W. M., and Maxwell, F. (1989). A DNA cassette containing a trimerized SV40 polyadenylation signal which efficiently blocks spurious plasmid-initiated transcription. Biotechniques 7, 276-280.

McEwen, B. S. (1999). Stress and hippocampal plasticity. Annu Rev Neurosci 22, 105-122.

McEwen, B. S., and Sapolsky, R. M. (1995). Stress and cognitive function. Curr Opin Neurobiol 5, 205-216.

McGaugh, J. L. (1983). Hormonal influences on memory. Annu Rev Psychol 34, 297-323.

Meaney, M. J., Diorio, J., Francis, D., Widdowson, J., LaPlante, P., Caldji, C., Sharma, S., Seckl, J. R., and Plotsky, P. M. (1996). Early environmental regulation of forebrain glucocorticoid receptor gene expression: implications for adrenocortical responses to stress. Dev Neurosci 18, 49-72.

Merali, Z., McIntosh, J., Kent, P., Michaud, D., and Anisman, H. (1998). Aversive and appetitive events evoke the release of corticotropin-releasing hormone and bombesinlike peptides at the central nucleus of the amygdala. J Neurosci 18, 4758-4766.

Merlo Pich, E., Lorang, M., Yeganeh, M., Rodriguez de Fonseca, F., Raber, J., Koob, G. F., and Weiss, F. (1995). Increase of extracellular corticotropin-releasing factor-like immunoreactivity levels in the amygdala of awake rats during restraint stress and ethanol withdrawal as measured by microdialysis. J Neurosci 15, 5439-5447.

Metzger, D., and Feil, R. (1999). Engineering the mouse genome by site-specific recombination. Curr Opin Biotechnol 10, 470-476.

Mezey, E., and Palkovits, M. (1991). Time dependent changes in CRF and its mRNA in the neurons of the inferior olive following surgical transection of the olivocerebellar tract in the rat. Brain Res Mol Brain Res 10, 55-59.

Minichiello, L., Korte, M., Wolfer, D., Kuhn, R., Unsicker, K., Cestari, V., Rossi-Arnaud, C., Lipp, H. P., Bonhoeffer, T., and Klein, R. (1999). Essential role for TrkB receptors in hippocampus-mediated learning. Neuron 24, 401-414.

Mitchell, A. J. (1998). The role of corticotropin releasing factor in depressive illness: a critical review. Neurosci Biobehav Rev 22, 635-651.

Miyata, I., Shiota, C., Ikeda, Y., Oshida, Y., Chaki, S., Okuyama, S., and Inagami, T. (1999). Cloning and characterization of a short variant of the corticotropin-releasing factor receptor subtype from rat amygdala. Biochem Biophys Res Commun 256, 692696.

Moechars, D., Lorent, K., De Strooper, B., Dewachter, I., and Van Leuven, F. (1996). Expression in brain of amyloid precursor protein mutated in the alpha-secretase site causes disturbed behavior, neuronal degeneration and premature death in transgenic mice. Embo J 15, 1265-1274.

Moga, M. M., and Gray, T. S. (1985). Evidence for corticotropin-releasing factor, neurotensin, and somatostatin in the neural pathway from the central nucleus of the amygdala to the parabrachial nucleus. J Comp Neurol 241, 275-284.

Montecucchi, P. C., and Henschen, A. (1981). Amino acid composition and sequence analysis of sauvagine, a new active peptide from the skin of Phyllomedusa sauvagei. Int J Pept Protein Res 18, 113-120.

Moreau, J. L., Kilpatrick, G., and Jenck, F. (1997). Urocortin, a novel neuropeptide with anxiogenic-like properties. Neuroreport 8, 1697-1701.

Morley, J. E., and Levine, A. S. (1982). Corticotrophin releasing factor, grooming and ingestive behavior. Life Sci 31, 1459-1464.

Morris, R., and Grosveld, F. (1989). Expression of Thy-1 in the nervous system of the rat and mouse. Immunol Ser 45, 121-148.

Muglia, L., Jacobson, L., Dikkes, P., and Majzoub, J. A. (1995). Corticotropin-releasing hormone deficiency reveals major fetal but not adult glucocorticoid need. Nature 373, 427-432.

Muglia, L. J., Jacobson, L., Luedke, C., Vogt, S. K., Schaefer, M. L., Dikkes, P., Fukuda, S., Sakai, Y., Suda, T., and Majzoub, J. A. (2000). Corticotropin-releasing hormone links pituitary adrenocorticotropin gene expression and release during adrenal insufficiency. J Clin Invest 105, 1269-1277. 
Muglia, L. J., Jacobson, L., Weninger, S. C., Karalis, K. P., Jeong, K., and Majzoub, J. A. (2001). The physiology of corticotropin-releasing hormone deficiency in mice. Peptides $22,725-731$.

Muglia, L. J., Jacobson, L., Weninger, S. C., Luedke, C. E., Bae, D. S., Jeong, K. H., and Majzoub, J. A. (1997). Impaired diurnal adrenal rhythmicity restored by constant infusion of corticotropin-releasing hormone in corticotropin-releasing hormone-deficient mice. J Clin Invest 99, 2923-2929.

Muglia, L. J., Jenkins, N. A., Gilbert, D. J., Copeland, N. G., and Majzoub, J. A. (1994). Expression of the mouse corticotropin-releasing hormone gene in vivo and targeted inactivation in embryonic stem cells. J Clin Invest 93, 2066-2072.

Muller, M. B., Landgraf, R., Preil, J., Sillaber, I., Kresse, A. E., Keck, M. E., Zimmermann, S., Holsboer, F., and Wurst, W. (2000). Selective activation of the hypothalamic vasopressinergic system in mice deficient for the corticotropin-releasing hormone receptor 1 is dependent on glucocorticoids. Endocrinology 141, 4262-4269.

Muller, M. B., Zimmermann, S., Sillaber, I., Hagemeyer, T. P., Deussing, J. M., Timpl, P., Kormann, M. S., Droste, S. K., Kuhn, R., Reul, J. M., et al. (2003). Limbic corticotropin-releasing hormone receptor 1 mediates anxiety-related behavior and hormonal adaptation to stress. Nat Neurosci 6, 1100-1107.

Myers, D. A., Trinh, J. V., and Myers, T. R. (1998). Structure and function of the ovine type 1 corticotropin releasing factor receptor (CRF1) and a carboxyl-terminal variant. Mol Cell Endocrinol 144, 21-35.

Nagy, A. (2000). Cre recombinase: the universal reagent for genome tailoring. Genesis 26 , 99-109.

Oitzl, M. S., and de Kloet, E. R. (1992). Selective corticosteroid antagonists modulate specific aspects of spatial orientation learning. Behav Neurosci 106, 62-71.

Oitzl, M. S., Reichardt, H. M., Joels, M., and de Kloet, E. R. (2001). Point mutation in the mouse glucocorticoid receptor preventing DNA binding impairs spatial memory. Proc Natl Acad Sci U S A 98, 12790-12795.

Okret, S., Poellinger, L., Dong, Y., and Gustafsson, J. A. (1986). Down-regulation of glucocorticoid receptor mRNA by glucocorticoid hormones and recognition by the receptor of a specific binding sequence within a receptor cDNA clone. Proc Natl Acad Sci U S A 83, 5899-5903.

Oshima, A., Flachskamm, C., Reul, J. M., Holsboer, F., and Linthorst, A. C. (2003). Altered serotonergic neurotransmission but normal hypothalamic-pituitaryadrenocortical axis activity in mice chronically treated with the corticotropin-releasing hormone receptor type 1 antagonist NBI 30775. Neuropsychopharmacology 28, 21482159.

Owens, M. J., and Nemeroff, C. B. (1991). Physiology and pharmacology of corticotropinreleasing factor. Pharmacol Rev 43, 425-473.

Palchaudhuri, M. R., Hauger, R. L., Wille, S., Fuchs, E., and Dautzenberg, F. M. (1999). Isolation and pharmacological characterization of two functional splice variants of corticotropin-releasing factor type 2 receptor from Tupaia belangeri. J Neuroendocrinol 11, 419-428.

Patrick, C. J., Berthot, B. D., and Moore, J. D. (1996). Diazepam blocks fear-potentiated startle in humans. J Abnorm Psychol 105, 89-96.

Pelleymounter, M. A., Joppa, M., Ling, N., and Foster, A. C. (2002). Pharmacological evidence supporting a role for central corticotropin-releasing factor(2) receptors in behavioral, but not endocrine, response to environmental stress. J Pharmacol Exp Ther 302, 145-152.

Perrin, M., Donaldson, C., Chen, R., Blount, A., Berggren, T., Bilezikjian, L., Sawchenko, P., and Vale, W. (1995). Identification of a second corticotropin-releasing factor receptor gene and characterization of a cDNA expressed in heart. Proc Natl Acad Sci U S A 92, 2969-2973. 
Perrin, M. H., Donaldson, C. J., Chen, R., Lewis, K. A., and Vale, W. W. (1993). Cloning and functional expression of a rat brain corticotropin releasing factor (CRF) receptor. Endocrinology 133, 3058-3061.

Perrin, M. H., and Vale, W. W. (1999). Corticotropin releasing factor receptors and their ligand family. Ann N Y Acad Sci 885, 312-328.

Petit-Demouliere, B., Chenu, F., and Bourin, M. (2005). Forced swimming test in mice: a review of antidepressant activity. Psychopharmacology (Berl) 177, 245-255.

Phillips, R. G., and LeDoux, J. E. (1992). Differential contribution of amygdala and hippocampus to cued and contextual fear conditioning. Behav Neurosci 106, 274-285.

Pich, E. M., Heinrichs, S. C., Rivier, C., Miczek, K. A., Fisher, D. A., and Koob, G. F. (1993). Blockade of pituitary-adrenal axis activation induced by peripheral immunoneutralization of corticotropin-releasing factor does not affect the behavioral response to social defeat stress in rats. Psychoneuroendocrinology 18, 495-507.

Pilz, P. K., Caeser, M., and Ostwald, J. (1988). Comparative threshold studies of the acoustic pinna, jaw and startle reflex in the rat. Physiol Behav 43, 411-415.

Pilz, P. K., Schnitzler, H. U., and Menne, D. (1987). Acoustic startle threshold of the albino rat (Rattus norvegicus). J Comp Psychol 101, 67-72.

Pisarchik, A., and Slominski, A. T. (2001). Alternative splicing of CRH-R1 receptors in human and mouse skin: identification of new variants and their differential expression. Faseb J 15, 2754-2756.

Plappert, C. F., Pilz, P. K., and Schnitzler, H. U. (1993). Acoustic startle response and habituation in freezing and nonfreezing rats. Behav Neurosci 107, 981-987.

Plotsky, P. M. (1991). Hypothalamic secretion of somatostatin and growth hormonereleasing factor into the hypophysial-portal circulation is reduced in streptozotocin diabetic male rats. Neuroendocrinology 53, 433-438.

Plotsky, P. M., Kjaer, A., Sutton, S. W., Sawchenko, P. E., and Vale, W. (1991). Central activin administration modulates corticotropin-releasing hormone and adrenocorticotropin secretion. Endocrinology 128, 2520-2525.

Plotsky, P. M., Otto, S., and Sapolsky, R. M. (1986). Inhibition of immunoreactive corticotropin-releasing factor secretion into the hypophysial-portal circulation by delayed glucocorticoid feedback. Endocrinology 119, 1126-1130.

Pomara, N., Singh, R. R., Deptula, D., LeWitt, P. A., Bissette, G., Stanley, M., and Nemeroff, C. B. (1989). CSF corticotropin-releasing factor (CRF) in Alzheimer's disease: its relationship to severity of dementia and monoamine metabolites. Biol Psychiatry 26, 500-504.

Porsolt, R. D. (2000). Animal models of depression: utility for transgenic research. Rev Neurosci 11, 53-58.

Porsolt, R. D., Bertin, A., and Jalfre, M. (1977). Behavioral despair in mice: a primary screening test for antidepressants. Arch Int Pharmacodyn Ther 229, 327-336.

Porsolt, R. D., Chermat, R., Lenegre, A., Avril, I., Janvier, S., and Steru, L. (1987). Use of the automated tail suspension test for the primary screening of psychotropic agents. Arch Int Pharmacodyn Ther 288, 11-30.

Potter, E., Behan, D. P., Fischer, W. H., Linton, E. A., Lowry, P. J., and Vale, W. W. (1991). Cloning and characterization of the cDNAs for human and rat corticotropin releasing factor-binding proteins. Nature 349, 423-426.

Potter, E., Behan, D. P., Linton, E. A., Lowry, P. J., Sawchenko, P. E., and Vale, W. W. (1992). The central distribution of a corticotropin-releasing factor (CRF)-binding protein predicts multiple sites and modes of interaction with CRF. Proc Natl Acad Sci U S A 89, 4192-4196.

Potter, E., Sutton, S., Donaldson, C., Chen, R., Perrin, M., Lewis, K., Sawchenko, P. E., and Vale, W. (1994). Distribution of corticotropin-releasing factor receptor mRNA expression in the rat brain and pituitary. Proc Natl Acad Sci U S A 91, 8777-8781.

Pozzoli, G., Bilezikjian, L. M., Perrin, M. H., Blount, A. L., and Vale, W. W. (1996). Corticotropin-releasing factor $(\mathrm{CRF})$ and glucocorticoids modulate the expression of 
type $1 \mathrm{CRF}$ receptor messenger ribonucleic acid in rat anterior pituitary cell cultures. Endocrinology 137, 65-71.

Preil, J., Muller, M. B., Gesing, A., Reul, J. M., Sillaber, I., van Gaalen, M. M., Landgrebe, J., Holsboer, F., Stenzel-Poore, M., and Wurst, W. (2001). Regulation of the hypothalamic-pituitary-adrenocortical system in mice deficient for CRH receptors 1 and 2. Endocrinology 142, 4946-4955.

Prince, C. R., and Anisman, H. (1984). Acute and chronic stress effects on performance in a forced-swim task. Behav Neural Biol 42, 99-119.

Radulovic, J., Ruhmann, A., Liepold, T., and Spiess, J. (1999). Modulation of learning and anxiety by corticotropin-releasing factor (CRF) and stress: differential roles of CRF receptors 1 and 2. J Neurosci 19, 5016-5025.

Radulovic, J., Sydow, S., and Spiess, J. (1998). Characterization of native corticotropinreleasing factor receptor type 1 (CRFR1) in the rat and mouse central nervous system. $\mathrm{J}$ Neurosci Res 54, 507-521.

Ratka, A., Sutanto, W., Bloemers, M., and de Kloet, E. R. (1989). On the role of brain mineralocorticoid (type I) and glucocorticoid (type II) receptors in neuroendocrine regulation. Neuroendocrinology 50, 117-123.

Renard, C. E., Dailly, E., David, D. J., Hascoet, M., and Bourin, M. (2003). Monoamine metabolism changes following the mouse forced swimming test but not the tail suspension test. Fundam Clin Pharmacol 17, 449-455.

Reul, J. M., and de Kloet, E. R. (1985). Two receptor systems for corticosterone in rat brain: microdistribution and differential occupation. Endocrinology 117, 2505-2511.

Reul, J. M., Gesing, A., Droste, S., Stec, I. S., Weber, A., Bachmann, C., Bilang-Bleuel, A., Holsboer, F., and Linthorst, A. C. (2000). The brain mineralocorticoid receptor: greedy for ligand, mysterious in function. Eur J Pharmacol 405, 235-249.

Reyes, T. M., Lewis, K., Perrin, M. H., Kunitake, K. S., Vaughan, J., Arias, C. A., Hogenesch, J. B., Gulyas, J., Rivier, J., Vale, W. W., and Sawchenko, P. E. (2001). Urocortin II: a member of the corticotropin-releasing factor (CRF) neuropeptide family that is selectively bound by type 2 CRF receptors. Proc Natl Acad Sci U S A 98, 28432848.

Richard, D. (1993). Involvement of corticotropin-releasing factor in the control of food intake and energy expenditure. Ann N Y Acad Sci 697, 155-172.

Richard, D., Huang, Q., and Timofeeva, E. (2000). The corticotropin-releasing hormone system in the regulation of energy balance in obesity. Int J Obes Relat Metab Disord 24 Suppl 2, S36-39.

Richter, R. M., Zorrilla, E. P., Basso, A. M., Koob, G. F., and Weiss, F. (2000). Altered amygdalar CRF release and increased anxiety-like behavior in Sardinian alcoholpreferring rats: a microdialysis and behavioral study. Alcohol Clin Exp Res 24, 17651772.

Risbrough, V. B., Hauger, R. L., Pelleymounter, M. A., and Geyer, M. A. (2003). Role of corticotropin releasing factor (CRF) receptors 1 and 2 in CRF-potentiated acoustic startle in mice. Psychopharmacology (Berl) 170, 178-187.

Rivest, S., Laflamme, N., and Nappi, R. E. (1995). Immune challenge and immobilization stress induce transcription of the gene encoding the CRF receptor in selective nuclei of the rat hypothalamus. J Neurosci 15, 2680-2695.

Roche, P. J., Crawford, R. J., Fernley, R. T., Tregear, G. W., and Coghlan, J. P. (1988). Nucleotide sequence of the gene coding for ovine corticotropin-releasing factor and regulation of its mRNA levels by glucocorticoids. Gene 71, 421-431.

Roozendaal, B., Griffith, Q. K., Buranday, J., De Quervain, D. J., and McGaugh, J. L. (2003). The hippocampus mediates glucocorticoid-induced impairment of spatial memory retrieval: dependence on the basolateral amygdala. Proc Natl Acad Sci U S A 100, 1328-1333.

Roseboom, P. H., Urben, C. M., and Kalin, N. H. (2001). Persistent corticotropin-releasing factor(1) receptor desensitization and downregulation in the human neuroblastoma cell line IMR-32. Brain Res Mol Brain Res 92, 115-127. 
Ross, P. C., Kostas, C. M., and Ramabhadran, T. V. (1994). A variant of the human corticotropin-releasing factor (CRF) receptor: cloning, expression and pharmacology. Biochem Biophys Res Commun 205, 1836-1842.

Rothwell, N. J. (1990). Central effects of CRF on metabolism and energy balance. Neurosci Biobehav Rev 14, 263-271.

Sakanaka, M., Shibasaki, T., and Lederis, K. (1986). Distribution and efferent projections of corticotropin-releasing factor-like immunoreactivity in the rat amygdaloid complex. Brain Res 382, 213-238.

Salas, M. A., Brown, O. A., Perone, M. J., Castro, M. G., and Goya, R. G. (1997). Effect of the corticotrophin releasing hormone precursor on interleukin- 6 release by human mononuclear cells. Clin Immunol Immunopathol 85, 35-39.

Sandi, C., Loscertales, M., and Guaza, C. (1997). Experience-dependent facilitating effect of corticosterone on spatial memory formation in the water maze. Eur J Neurosci 9, 637642.

Sapolsky, R. M., Krey, L. C., and McEwen, B. S. (1984). Glucocorticoid-sensitive hippocampal neurons are involved in terminating the adrenocortical stress response. Proc Natl Acad Sci U S A 81, 6174-6177.

Schmidt, E. D., Janszen, A. W., Binnekade, R., and Tilders, F. J. (1997). Transient suppression of resting corticosterone levels induces sustained increase of AVP stores in hypothalamic CRH-neurons of rats. J Neuroendocrinol 9, 69-77.

Seasholtz, A. F., Thompson, R. C., and Douglass, J. O. (1988). Identification of a cyclic adenosine monophosphate-responsive element in the rat corticotropin-releasing hormone gene. Mol Endocrinol 2, 1311-1319.

Seong, E., Seasholtz, A. F., and Burmeister, M. (2002). Mouse models for psychiatric disorders. Trends Genet 18, 643-650.

Servatius, R. J., Ottenweller, J. E., Bergen, M. T., Soldan, S., and Natelson, B. H. (1994). Persistent stress-induced sensitization of adrenocortical and startle responses. Physiol Behav 56, 945-954.

Shanks, N., Harbuz, M. S., Jessop, D. S., Perks, P., Moore, P. M., and Lightman, S. L. (1998). Inflammatory disease as chronic stress. Ann N Y Acad Sci 840, 599-607.

Sheline, Y. I., Wang, P. W., Gado, M. H., Csernansky, J. G., and Vannier, M. W. (1996). Hippocampal atrophy in recurrent major depression. Proc Natl Acad Sci U S A 93, 3908-3913.

Shibahara, S., Morimoto, Y., Furutani, Y., Notake, M., Takahashi, H., Shimizu, S., Horikawa, S., and Numa, S. (1983). Isolation and sequence analysis of the human corticotropin-releasing factor precursor gene. Embo J 2, 775-779.

Sipos, M. L., Bauman, R. A., Widholm, J. J., and Kant, G. J. (2000). Behavioral effects Of 8-OH-DPAT in chronically stressed male and female rats. Pharmacol Biochem Behav 66, 403-411.

Skelton, K. H., Nemeroff, C. B., Knight, D. L., and Owens, M. J. (2000). Chronic administration of the triazolobenzodiazepine alprazolam produces opposite effects on corticotropin-releasing factor and urocortin neuronal systems. J Neurosci 20, 1240-1248.

Smagin, G. N., Heinrichs, S. C., and Dunn, A. J. (2001). The role of CRH in behavioral responses to stress. Peptides 22, 713-724.

Smith, G. W., Aubry, J. M., Dellu, F., Contarino, A., Bilezikjian, L. M., Gold, L. H., Chen, R., Marchuk, Y., Hauser, C., Bentley, C. A., et al. (1998). Corticotropin releasing factor receptor 1-deficient mice display decreased anxiety, impaired stress response, and aberrant neuroendocrine development. Neuron 20, 1093-1102.

Smith, M. A., Weiss, S. R., Berry, R. L., Zhang, L. X., Clark, M., Massenburg, G., and Post, R. M. (1997). Amygdala-kindled seizures increase the expression of corticotropinreleasing factor (CRF) and CRF-binding protein in GABAergic interneurons of the dentate hilus. Brain Res 745, 248-256.

Soriano, P. (1999). Generalized lacZ expression with the ROSA26 Cre reporter strain. Nat Genet 21,70-71. 
Spina, M., Merlo-Pich, E., Chan, R. K., Basso, A. M., Rivier, J., Vale, W., and Koob, G. F. (1996). Appetite-suppressing effects of urocortin, a CRF-related neuropeptide. Science 273, 1561-1564.

Starkman, M. N., Gebarski, S. S., Berent, S., and Schteingart, D. E. (1992). Hippocampal formation volume, memory dysfunction, and cortisol levels in patients with Cushing's syndrome. Biol Psychiatry 32, 756-765.

Steckler, T., and Holsboer, F. (1999). Corticotropin-releasing hormone receptor subtypes and emotion. Biol Psychiatry 46, 1480-1508.

Stenzel, P., Kesterson, R., Yeung, W., Cone, R. D., Rittenberg, M. B., and Stenzel-Poore, M. P. (1995). Identification of a novel murine receptor for corticotropin-releasing hormone expressed in the heart. Mol Endocrinol 9, 637-645.

Stenzel-Poore, M. P., Cameron, V. A., Vaughan, J., Sawchenko, P. E., and Vale, W. (1992). Development of Cushing's syndrome in corticotropin-releasing factor transgenic mice. Endocrinology 130, 3378-3386.

Stenzel-Poore, M. P., Heinrichs, S. C., Rivest, S., Koob, G. F., and Vale, W. W. (1994). Overproduction of corticotropin-releasing factor in transgenic mice: a genetic model of anxiogenic behavior. J Neurosci 14, 2579-2584.

Steru, L., Chermat, R., Thierry, B., Mico, J. A., Lenegre, A., Steru, M., Simon, P., and Porsolt, R. D. (1987). The automated Tail Suspension Test: a computerized device which differentiates psychotropic drugs. Prog Neuropsychopharmacol Biol Psychiatry $11,659-671$.

Steru, L., Chermat, R., Thierry, B., and Simon, P. (1985). The tail suspension test: a new method for screening antidepressants in mice. Psychopharmacology (Berl) 85, 367-370.

Suda, T., Tomori, N., Tozawa, F., Mouri, T., Demura, H., and Shizume, K. (1984). Effect of dexamethasone on immunoreactive corticotropin-releasing factor in the rat median eminence and intermediate-posterior pituitary. Endocrinology 114, 851-854.

Swerdlow, N. R., Braff, D. L., Taaid, N., and Geyer, M. A. (1994). Assessing the validity of an animal model of deficient sensorimotor gating in schizophrenic patients. Arch Gen Psychiatry 51, 139-154.

Swerdlow, N. R., Caine, S. B., and Geyer, M. A. (1992). Regionally selective effects of intracerebral dopamine infusion on sensorimotor gating of the startle reflex in rats. Psychopharmacology (Berl) 108, 189-195.

Swerdlow, N. R., and Geyer, M. A. (1998). Using an animal model of deficient sensorimotor gating to study the pathophysiology and new treatments of schizophrenia. Schizophr Bull 24, 285-301.

Swerdlow, N. R., Geyer, M. A., Vale, W. W., and Koob, G. F. (1986). Corticotropinreleasing factor potentiates acoustic startle in rats: blockade by chlordiazepoxide. Psychopharmacology (Berl) 88, 147-152.

Tang, J., Wotjak, C. T., Wagner, S., Williams, G., Schachner, M., and Dityatev, A. (2001). Potentiated amygdaloid auditory-evoked potentials and freezing behavior after fear conditioning in mice. Brain Res 919, 232-241.

Taniguchi, M., Sanbo, M., Watanabe, S., Naruse, I., Mishina, M., and Yagi, T. (1998). Efficient production of Cre-mediated site-directed recombinants through the utilization of the puromycin resistance gene, pac: a transient gene-integration marker for ES cells. Nucleic Acids Res 26, 679-680.

Thomas, K. R., and Capecchi, M. R. (1987). Site-directed mutagenesis by gene targeting in mouse embryo-derived stem cells. Cell 51, 503-512.

Thompson, R. C., Seasholtz, A. F., and Herbert, E. (1987). Rat corticotropin-releasing hormone gene: sequence and tissue-specific expression. Mol Endocrinol 1, 363-370.

Timpl, P., Spanagel, R., Sillaber, I., Kresse, A., Reul, J. M., Stalla, G. K., Blanquet, V., Steckler, T., Holsboer, F., and Wurst, W. (1998). Impaired stress response and reduced anxiety in mice lacking a functional corticotropin-releasing hormone receptor 1 . Nat Genet 19, 162-166. 
Tronche, F., Kellendonk, C., Kretz, O., Gass, P., Anlag, K., Orban, P. C., Bock, R., Klein, R., and Schutz, G. (1999). Disruption of the glucocorticoid receptor gene in the nervous system results in reduced anxiety. Nat Genet 23, 99-103.

Tronche, F., Kellendonk, C., Reichardt, H. M., and Schutz, G. (1998). Genetic dissection of glucocorticoid receptor function in mice. Curr Opin Genet Dev 8, 532-538.

Turnbull, A. V., and Rivier, C. (1996). Corticotropin-releasing factor, vasopressin, and prostaglandins mediate, and nitric oxide restrains, the hypothalamic-pituitary-adrenal response to acute local inflammation in the rat. Endocrinology 137, 455-463.

Turnbull, A. V., and Rivier, C. (1997). Corticotropin-releasing factor (CRF) and endocrine responses to stress: CRF receptors, binding protein, and related peptides. Proc Soc Exp Biol Med 215, 1-10.

Turnbull, A. V., Smith, G. W., Lee, S., Vale, W. W., Lee, K. F., and Rivier, C. (1999). CRF type I receptor-deficient mice exhibit a pronounced pituitary-adrenal response to local inflammation. Endocrinology 140, 1013-1017.

Turnbull, A. V., Vale, W., and Rivier, C. (1996). Urocortin, a corticotropin-releasing factor-related mammalian peptide, inhibits edema due to thermal injury in rats. Eur $\mathbf{J}$ Pharmacol 303, 213-216.

Valdenaire, O., Giller, T., Breu, V., Gottowik, J., and Kilpatrick, G. (1997). A new functional isoform of the human CRF2 receptor for corticotropin-releasing factor. Biochim Biophys Acta 1352, 129-132.

Valdez, G. R., Inoue, K., Koob, G. F., Rivier, J., Vale, W., and Zorrilla, E. P. (2002). Human urocortin II: mild locomotor suppressive and delayed anxiolytic-like effects of a novel corticotropin-releasing factor related peptide. Brain Res 943, 142-150.

Vale, W., Rivier, C., Brown, M. R., Spiess, J., Koob, G., Swanson, L., Bilezikjian, L., Bloom, F., and Rivier, J. (1983a). Chemical and biological characterization of corticotropin releasing factor. Recent Prog Horm Res 39, 245-270.

Vale, W., Spiess, J., Rivier, C., and Rivier, J. (1981). Characterization of a 41-residue ovine hypothalamic peptide that stimulates secretion of corticotropin and beta-endorphin. Science 213, 1394-1397.

Vale, W., Vaughan, J., Yamamoto, G., Bruhn, T., Douglas, C., Dalton, D., Rivier, C., and Rivier, J. (1983b). Assay of corticotropin releasing factor. Methods Enzymol 103, 565577.

Vamvakopoulos, N. C., Karl, M., Mayol, V., Gomez, T., Stratakis, C. A., Margioris, A., and Chrousos, G. P. (1990). Structural analysis of the regulatory region of the human corticotropin releasing hormone gene. FEBS Lett 267, 1-5.

Van den Berg, D. T., de Jong, W., and de Kloet, E. R. (1994). Mineralocorticoid antagonist inhibits stress-induced blood pressure response after repeated daily warming. Am J Physiol 267, E921-926.

van den Buuse, M., van Acker, S. A., Fluttert, M. F., and de Kloet, E. R. (2002). Involvement of corticosterone in cardiovascular responses to an open-field novelty stressor in freely moving rats. Physiol Behav 75, 207-215.

van Gaalen, M. M., Stenzel-Poore, M. P., Holsboer, F., and Steckler, T. (2002). Effects of transgenic overproduction of CRH on anxiety-like behaviour. Eur J Neurosci 15, 20072015.

Van Pett, K., Viau, V., Bittencourt, J. C., Chan, R. K., Li, H. Y., Arias, C., Prins, G. S., Perrin, M., Vale, W., and Sawchenko, P. E. (2000). Distribution of mRNAs encoding CRF receptors in brain and pituitary of rat and mouse. J Comp Neurol 428, 191-212.

van Steensel, B., van Binnendijk, E. P., Hornsby, C. D., van der Voort, H. T., Krozowski, Z. S., de Kloet, E. R., and van Driel, R. (1996). Partial colocalization of glucocorticoid and mineralocorticoid receptors in discrete compartments in nuclei of rat hippocampus neurons. J Cell Sci 109 ( Pt 4), 787-792.

Vaughan, J., Donaldson, C., Bittencourt, J., Perrin, M. H., Lewis, K., Sutton, S., Chan, R., Turnbull, A. V., Lovejoy, D., and Rivier, C. (1995). Urocortin, a mammalian neuropeptide related to fish urotensin I and to corticotropin-releasing factor. Nature 378, 287-292. 
Vedeckis, W. V., Ali, M., and Allen, H. R. (1989). Regulation of glucocorticoid receptor protein and mRNA levels. Cancer Res 49, 2295s-2302s.

Venihaki, M., and Majzoub, J. A. (1999). Animal models of CRH deficiency. Front Neuroendocrinol 20, 122-145.

Vidal, M., Morris, R., Grosveld, F., and Spanopoulou, E. (1990). Tissue-specific control elements of the Thy-1 gene. Embo J 9, 833-840.

Watts, A. G. (1992). Osmotic stimulation differentially affects cellular levels of corticotropin-releasing hormone and neurotensin/neuromedin $\mathrm{N}$ mRNAs in the lateral hypothalamic area and central nucleus of the amygdala. Brain Res 581, 208-216.

Weninger, S. C., Dunn, A. J., Muglia, L. J., Dikkes, P., Miczek, K. A., Swiergiel, A. H., Berridge, C. W., and Majzoub, J. A. (1999). Stress-induced behaviors require the corticotropin-releasing hormone $(\mathrm{CRH})$ receptor, but not $\mathrm{CRH}$. Proc Natl Acad Sci U S A 96, 8283-8288.

Wiessner, C., Allegrini, P. R., Rupalla, K., Sauer, D., Oltersdorf, T., McGregor, A. L., Bischoff, S., Bottiger, B. W., and van der Putten, H. (1999). Neuron-specific transgene expression of Bcl-XL but not Bcl-2 genes reduced lesion size after permanent middle cerebral artery occlusion in mice. Neurosci Lett 268, 119-122.

Wu, M. F., Suzuki, S. S., and Siegel, J. M. (1988). Anatomical distribution and response patterns of reticular neurons active in relation to acoustic startle. Brain Res 457, 399-406.

Xiong, Y., Xie, L. Y., and Abou-Samra, A. B. (1995). Signaling properties of mouse and human corticotropin-releasing factor (CRF) receptors: decreased coupling efficiency of human type II CRF receptor. Endocrinology 136, 1828-1834.

Yamamoto, H., Maeda, T., Fujimura, M., and Fujimiya, M. (1998). Urocortin-like immunoreactivity in the substantia nigra, ventral tegmental area and Edinger-Westphal nucleus of rat. Neurosci Lett 243, 21-24.

Yeomans, J. S., Hempel, C. M., and Chapman, C. A. (1993). Axons and synapses mediating startle-like responses evoked by electrical stimulation of the reticular formation in rats: symmetric and asymmetric collision effects. Brain Res 617, 309-319.

Zambrowicz, B. P., Imamoto, A., Fiering, S., Herzenberg, L. A., Kerr, W. G., and Soriano, P. (1997). Disruption of overlapping transcripts in the ROSA beta geo 26 gene trap strain leads to widespread expression of beta-galactosidase in mouse embryos and hematopoietic cells. Proc Natl Acad Sci U S A 94, 3789-3794.

Zobel, A. W., Nickel, T., Kunzel, H. E., Ackl, N., Sonntag, A., Ising, M., and Holsboer, F. (2000). Effects of the high-affinity corticotropin-releasing hormone receptor 1 antagonist R121919 in major depression: the first 20 patients treated. J Psychiatr Res 34, 171-181. 


\section{Acknowledgments}

Many thanks from the bottom of my heart to Dr. Jan Deussing for good supervision, professional guidance, as well as effective support, and to Prof. Wolfgang Wurst for permanent support and encouraging discussion.

I thank Prof. Kay Schneitz very much for examination of my thesis, as well as Prof. Alfons Gierl for chairing the promotion process.

Special thanks to my colleagues for all their help, support, as well as nice cooperation in work and life here in Munich.

I am very grateful to Dr. Carstern Wotjak, Michel Steiner and Dr. Vickie Risbrough for their help with behavioral tests, to Johanna Stalla for the CRH RIA, Ursula Habersetzer for help with the endocrinological measurements, Maik Engeholm for providing ROSA26 vector, Dr. Ralf Kühne, Susanne Bourier, Sawoula Michailidou for injection of clones and cell culture, Dr. Daniela. M. Vogt Weisenhorn for histochemistry, Daniela Kohl for excellent technical assistant.

Thanks a lot to my husband Guangxun, my mother, brothers and sisters, as well as my friends for understanding and support of my work. 


\section{Curriculum vitae}

$\begin{array}{ll}\text { Family name } & \text { Lu } \\ \text { First name } & \text { Ailing } \\ \text { Sex } & \text { Female } \\ \text { Date of birth } & \text { 20 Jan. 1973 } \\ \text { Place of birth } & \text { Henan, China } \\ \text { Citizenship } & \text { Chinese } \\ \text { Marital status } & \text { Married }\end{array}$

\section{Contact address}

Max-Planck-Institute of Psychiatry

Molecular Neurogenetics (AG wurst)

Kraepelinstrasse 2-10

D-80804, Munich

Germany

Tel: 00498930622 202/626

Fax: 00498930622642

Email: ailinglu@mpipsykl.mpg_de

\section{Research Experience and Education}

\section{November 2001-present:}

Max-Planck-Institute of Psychiatry, Kraepelinstrasse 2-10, D-80804, Munich, Germany.

Work as a PhD student on the topic: Site-specific overexpression of corticotrophin-releasing hormone $(\mathrm{CRH})$ in the mouse brain - modelling central $\mathrm{CRH}$ system hyperactivity

\section{September 1999-June 2001:}

Max-Planck Guest Laboratory, Shanghai Institute of Cell Biology, Chinese Academy of Sciences, Shanghai, China.

Work as a visiting postgraduate student, major in Hepatocarcinoma Related Genomics.

Project: 24164 gene - a novel gene related to hepatocarcinoma. 


\section{September 1998- July 1999:}

Bioengineering Key Laboratory of Henan Province, Henan Normal University, Xinxiang, Henan, China.

Study as a postgraduate student, major in Cell biology.

Master thesis: The effect of HSC70/HSP68, Acid- and Alkaline Phosphotase and PCNA on liver regeneration and the embryonic development of rat.

\section{September 1994-July 1998:}

Henan Normal University, Xinxiang, Henan, China.

Study as an undergraduate student for B.S. degree major in Normal Biology.

\section{References:}

1, Dr. Jan Deussing, supervisor.

Max-Planck-Institute of Psychiatry

Kraepelinstrasse 2-10

D-80804, Munich

Germany

Tel: +49 8930622639

Fax: +49 8930622642

Email: deussing@mpipsykl.mpg.de

2, Prof. Dr. Wolfgang Wurst, supervisor.

GSF-Institute genetic development

Ingolstadter Landstraße 1

D-85764, Neuherberg

Germany

Tel: +49 $893187-4110$

Fax: $+49893187-3099$

Email: wurs@ggsf.de

3, Prof. Dr. Dr. Florian Holsboer, supervisor.

Max-Planck-Institute of Psychiatry

Kraepelinstrasse 2-10

D-80804, Munich, Germany. 
Tel: +49 8930622637

Fax: +498930622493

Email: holsboer@mpipsykl.mpg.de

4, Professor Dr. Gengxi Hu, supervisor.

Max-Planck Guest Laboratory, Shanghai Institute of Cell Biology,

Chinese Academy of Sciences, Shanghai, China.

Tel: +862164378218

Fax: +862164718563

E-mail: hugengxi@health-digit.com

5, Professor Gengwu Li, supervisor.

Bioengineering Key Laboratory of Henan Province, Henan Normal University, Xinxiang, Henan, China.

Tel: +863733325054

Fax: +86373332652 